\title{
Development of a Modeling Framework for Predicting Decadal Barrier Island Evolution
}

By Rangley C. Mickey, Joseph W. Long, P. Soupy Dalyander, Robert L. Jenkins III, David M. Thompson, Davina L. Passeri, and Nathaniel G. Plant

Open-File Report 2019-1139

U.S. Department of the Interior U.S. Geological Survey 


\title{
U.S. Department of the Interior DAVID BERNHARDT, Secretary
}

\author{
U.S. Geological Survey \\ James F. Reilly II, Director
}

U.S. Geological Survey, Reston, Virginia: 2020

For more information on the USGS-the Federal source for science about the Earth, its natural and living resources, natural hazards, and the environment-visit http://www.usgs.gov/ or call 1-888-ASK-USGS (1-888-275-8747).

For an overview of USGS information products, including maps, imagery, and publications, visit http://www.usgs.gov/pubprod/.

Any use of trade, firm, or product names is for descriptive purposes only and does not imply endorsement by the U.S. Government.

Although this information product, for the most part, is in the public domain, it also may contain copyrighted materials as noted in the text. Permission to reproduce copyrighted items must be secured from the copyright owner.

Suggested citation:

Mickey, R.C., Long, J.W., Dalyander, P.S., Jenkins, R.L., III, Thompson, D.M., Passeri, D.L., and Plant, N.G., 2020, Development of a modeling framework for predicting decadal barrier island evolution: U.S. Geological Survey Open-File Report 2019-1139, 46 p., https://doi.org/10.3133/ofr20191139.

Associated data for this publication:

Mickey, R.C., Jenkins, R.L., Dalyander, P.S., Thompson, D.M., Plant, N.G., and Long, J.W., 2019, Dauphin Island decadal hindcast model inputs and results: U.S. Geological Survey data release, https://doi.org/10.5066/P91ALL6C.

ISSN 2331-1258 (online) 


\section{Acknowledgments}

This work was supported by the National Fish and Wildlife Foundation (NFWF) Gulf Environmental Benefits Fund (GEBF) under the Alabama Barrier Island Restoration Assessment project. The authors would like to thank Justin Birchler (USGS) and Legna Torrres-Garcia (Cherokee Nation Technologies) for their thoughtful reviews, which helped to improve the report. 


\section{Contents}

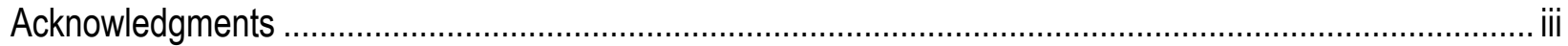

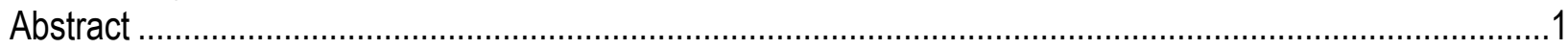

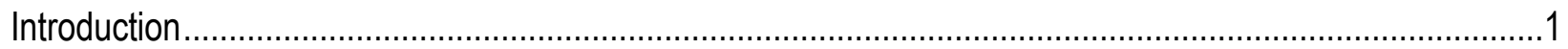

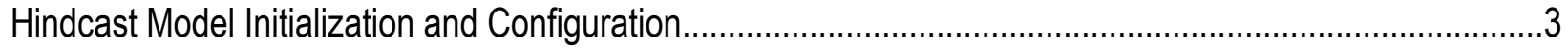

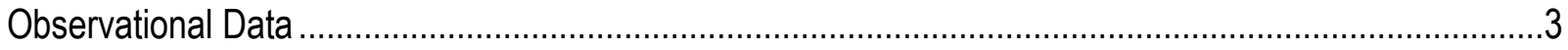

Delft3D Model Operation …………………………………………………………………….

Empirical Dune Growth Model Operation ……………………….............................................

XBeach Model Operation.........................................................................................................

Model Forcing with Synthetic Storms .....................................................................................

Model Boundary Wave Forcing Configuration...............................................................................

Hindcast Coupled Model Framework........................................................................................11

Model Results and Comparison to Observed Island Evolution ..............................................................13

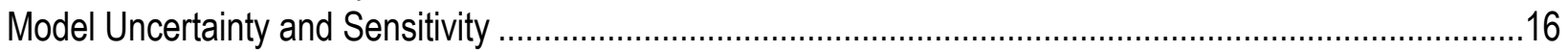

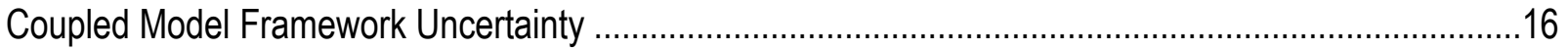

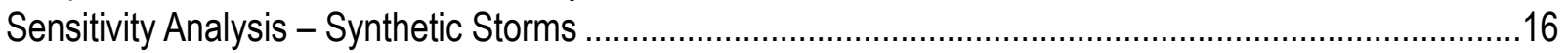

Synthetic Storm Time-Series Extension ....................................................................................17

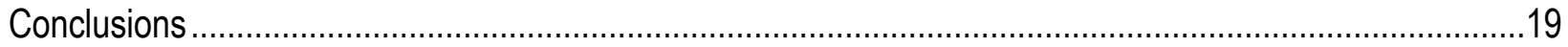

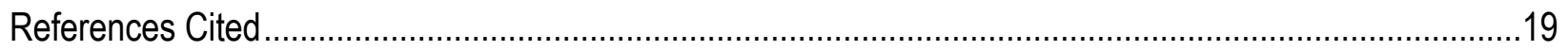

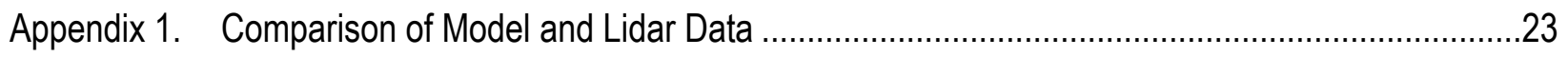

Appendix 2. Development and Use of an Empirical Dune Growth Model..............................................36

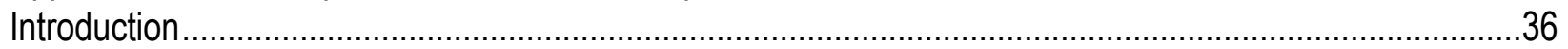

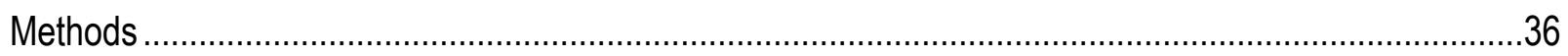

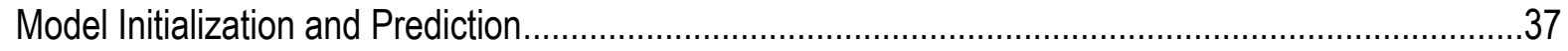

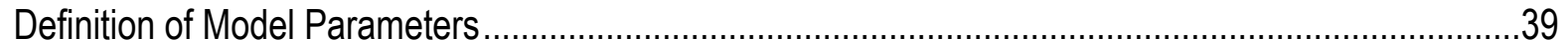

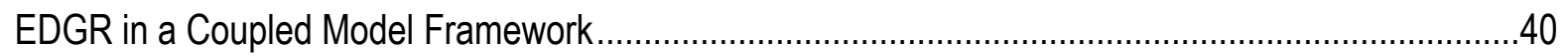

Study Site and Observational Data .......................................................................................42

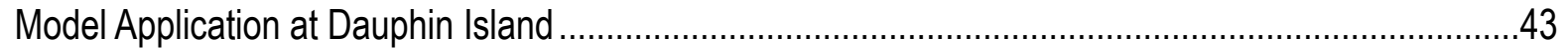

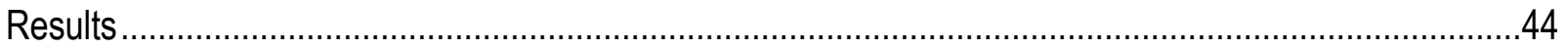

\section{Figures}

1. A, Location of Dauphin Island, Ala., with tide gauge locations 8735180 and 8729840 indicated by green dots within the northern Gulf of Mexico; $B$, Dauphin Island, Ala., with locations of Katrina Cut, EDGR growth area, tide gauge station 8735180, and Pelican Island .......................................... 2

2. D3DMM model domain for the decadal hindcast simulation ...................................................... 4

3. $\quad$ Model domain for all XBeach simulations ………………................................................. 6

4. A, DEM of Dauphin Island pre-Hurricane Ivan labeled map; $B, X$ Beach model domain and DEM of Dauphin Island pre-Hurricane Katrina labeled map ................................................................ 9

5. Model comparison of final 2015 DEM with February 2015 lidar survey ...................................... 14

6. A, Significant wave height for SS 189 with the extended time series extracted from the single offshore point; $B$, Significant wave height time series for SS 115 extracted at the same point as SS 189

7. A, Difference between morphological change along Dauphin Island from extending the time series of SS 189 compared to not extending the time series; $B$, Difference between morphological change along

Dauphin Island for SS 115 at timestep 63 hours and the initial morphology at timestep 0 hours 


\section{Tables}

1. Observed tropical cyclones and corresponding best match synthetic storm from the approximate 10-year period.

2. Boundary setup description, indicator, and model accuracy for XBeach simulations run on the respective pre-storm DEMs for Hurricane Ivan and Hurricane Katrina ......................................... 10

3. Hindcast coupled model framework sequence..................................................................... 12

4. Statistics quantifying the changes to Gulf and Sound shoreline location, and dune elevation and

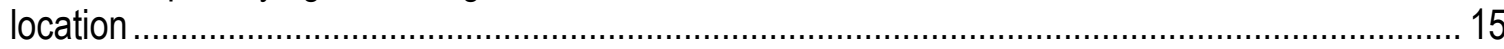

\section{Appendix 1}

\section{Figures}

1-1. Comparison of initial September 2004 DEM with September 2004 lidar survey .............................. 23

1-2. Comparison of September 2005 model DEM with September 2005 lidar survey ............................ 24

1-3. Comparison of March 2006 DEM with March 2006 lidar survey ................................................... 25

1-4. Comparison of September 2006 model DEM with September 2006 lidar survey ............................ 26

1-5. Comparison of June 2007 model DEM with June 2007 lidar survey ........................................... 27

1-6. Comparison of June 2008 model DEM with June 2008 lidar survey ............................................ 28

1-7. Comparison of September 2008 model DEM with September 2008 lidar survey .......................... 29

1-8. Comparison of January 2010 model DEM with January 2010 post-Hurricane Ida lidar survey ...... 30

1-9. Comparison of July 2010 model DEM with July 2010 lidar survey................................................. 31

1-10. Comparison of June 2011 model DEM with June 2011 lidar survey ....................................... 32

1-11. Comparison of September 2012 model DEM with September 2012 lidar survey, post-Hurricane

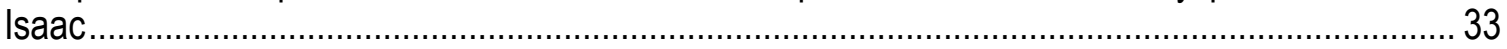

1-12. Comparison of July 2013 model DEM with July 2013 lidar survey............................................ 34

1-13. Comparison of January 2014 model DEM with January 2014 lidar survey .................................. 35

\section{Appendix 2}

\section{Figures}

2-1. Example of EDGR prediction of foredune growth after a storm ................................................ 39

2-2. EDGR workflow for each time step when coupled with an external model to predict dune erosion.

2-3. A, Dates of lidar surveys used in EDGR model calibration and assessment; $B$, Percentage of cross-shore profiles within each analysis region with $D_{\text {high }}$ elevation loss exceeding 0.25 meters compared to the previous survey

2-4. A, Dauphin Island topography in September, 2005; and B, in January, 2015. Also shown in $C$ and $D$ are post-Katrina lidar observations of $D_{\text {high }}$ for transects T1-T4 along with results of the Houser2015 model for dune growth using $C$, a fitted growth rate and terminal height; and using $D$, a fixed value of $0.53 \mathrm{~m} / \mathrm{yr}$ and the 2015 elevation as $D_{\text {high, } F}$

\section{Tables}

2-1. Longshore mean and standard deviation of maximum elevation for cross-shore transects within each of the analysis regions R1-R4 for the 2005 and 2015 lidar survey 


\section{Conversion Factors}

International System of Units to U.S. customary units

\begin{tabular}{llll}
\hline & Multiply & By & \multicolumn{1}{c}{ To obtain } \\
\hline & Length & \\
meter $(\mathrm{m})$ & 3.281 & foot $(\mathrm{ft})$ & \\
meter $(\mathrm{m})$ & 1.094 & yard $(\mathrm{yd})$ \\
kilometer $(\mathrm{km})$ & 0.6214 & mile (mi) \\
kilometer $(\mathrm{km})$ & 0.5400 & mile, nautical (nmi) \\
\hline
\end{tabular}

Temperature in degrees Celsius $\left({ }^{\circ} \mathrm{C}\right)$ may be converted to degrees Fahrenheit $\left({ }^{\circ} \mathrm{F}\right)$ as ${ }^{\circ} \mathrm{F}=\left(1.8 \times{ }^{\circ} \mathrm{C}\right)+32$. Temperature in degrees Fahrenheit $\left({ }^{\circ} \mathrm{F}\right)$ may be converted to degrees Celsius $\left({ }^{\circ} \mathrm{C}\right)$ as ${ }^{\circ} \mathrm{C}=\left({ }^{\circ} \mathrm{F}-32\right) / 1.8$.

\section{Datum}

Vertical coordinate information is referenced to the North American Vertical Datum of 1988 (NAVD 88). Horizontal coordinate information is referenced to the North American Datum of 1983 (NAD 83).

\section{Abbreviations}

$\begin{array}{ll}\text { 2DH } & \text { 2D horizontal plane } \\ \text { D3D } & \text { Delft3D } \\ \text { D3DMM } & \text { Delft3D mormerge } \\ \text { DEM } & \text { digital elevation model } \\ D_{\text {hi }} & \text { maximum dune crest elevation } \\ \text { EDGR } & \text { empirical dune growth model } \\ \text { ECMWF } & \text { European Centre for Medium-Range Weather Forecasts } \\ \text { ERA } & \text { ECMWF reanalysis model } \\ \text { FEMA } & \text { Federal Emergency Management Agency } \\ \text { GEBF } & \text { Gulf Environmental Benefits Fund } \\ \text { HURDAT } & \text { National Hurricane Center's hurricane database } \\ \text { H } & \text { significant wave height } \\ \text { JPM-OS } & \text { joint probability method-optimal sampling } \\ \text { km } & \text { kilometer } \\ \text { lidar } & \text { light detection and ranging } \\ \text { m } & \text { meter } \\ \text { MsCIP } & \text { Mississippi Coastal Improvements Program } \\ \text { MSL } & \text { mean sea level } \\ \text { NAD83 } & \text { North American Datum of 1983 } \\ \text { NAVD88 } & \text { North American Vertical Datum of 1988 } \\ \text { NOAA } & \text { National Oceanic and Atmospheric Administration } \\ \text { NGOM } & \text { Northern Gulf of Mexico } \\ \text { NFWF } & \text { National Fish and Wildlife Foundation } \\ \text { RMSE } & \text { root mean square error } \\ \text { R } & \text { coefficient of determination } \\ T_{p} & \text { dominant (peak) wave period } \\ \text { TWL } & \text { total water level } \\ \text { USGS } & \text { U.S. Geological Survey } \\ & \end{array}$




\title{
Development of a Modeling Framework for Predicting Decadal Barrier Island Evolution
}

By Rangley C. Mickey, ${ }^{1}$ Joseph W. Long, ${ }^{2}$ P. Soupy Dalyander, ${ }^{3}$ Robert L. Jenkins III, ${ }^{1}$ David M. Thompson, ${ }^{1}$ Davina L. Passeri, ${ }^{1}$ and Nathaniel G. Plant ${ }^{1}$

\begin{abstract}
Predicting the decadal evolution of barrier island systems is important for coastal managers who propose restoration or preservation alternatives aimed at increasing the resiliency of the island and its associated habitats or communities. Existing numerical models for simulating morphologic changes typically include either long-term (for example, longshore transport under quiescent conditions) or short-term (for example, storm-driven waves) processes, with limited capacity to predict the decadal time-scale that is often most relevant in coastal planning. As part of the Alabama Barrier Island Restoration Assessment (https://www.usgs.gov/centers/spcmsc/ science/alabama-barrier-island-restoration-study), a methodology was developed to predict barrier island evolution on decadal time scales. The developed modeling scheme uses multiple models including (1) Delft3D (Deltares, 2019); (2) the empirical dune growth model (EDGR; appendix 2); and (3) XBeach (Roelvink and others, 2009) that run sequentially to simulate evolution of barrier island geomorphology. The model framework was developed and applied to hindcast the evolution of Dauphin Island, Alabama, between 2004 and 2015, and was assessed using lidar data over the same period.
\end{abstract}

\section{Introduction}

Dauphin Island (fig. 1), located off the southern coast of Alabama, provides multiple ecosystem benefits (for example, attenuation of wave energy prior to reaching the mainland coast and providing the foundation for habitat types including beach, dune, and marsh) in addition to providing a popular vacation area and home to the community of Dauphin Island. The barrier island has continuously evolved in response to major storms, longer-term natural processes, and anthropogenic action (Douglass, 1994; Passeri and others, 2018; appendix 2). Some of the largest-scale changes to the island in recent history occurred following the passages of Hurricanes Ivan and Katrina in September 2004 and August 2005, respectively, when an approximately 2-kilometer (km)-wide breach formed (Froede, 2008; Martinez and others, 2011) and was subsequently closed in 2010 with a rubble rock mound. The 2-km-wide breach is referred to as "Katrina Cut" (fig. $1 B$ ). The area east of Katrina Cut is inhabited and consists of a narrow barrier island (just east of Katrina Cut) and it broadens to a wide, high-elevation region at the eastern terminus of the island (Douglass, 1994).

\footnotetext{
${ }^{1}$ U.S. Geological Survey.

${ }^{2}$ University of North Carolina at Wilmington.

${ }^{3}$ U.S. Army Corp of Engineers.
} 
The area just west of Katrina Cut is lower and narrower than other portions of the island, and broadens out to a wider platform at the western terminus of the island (Douglass, 1994). The area west of Katrina Cut is uninhabited and has evolved in response to natural processes over time, whereas the inhabited area to the east has been the location of beach nourishment and dune restoration actions to protect homes and infrastructure (Froede, 2010).
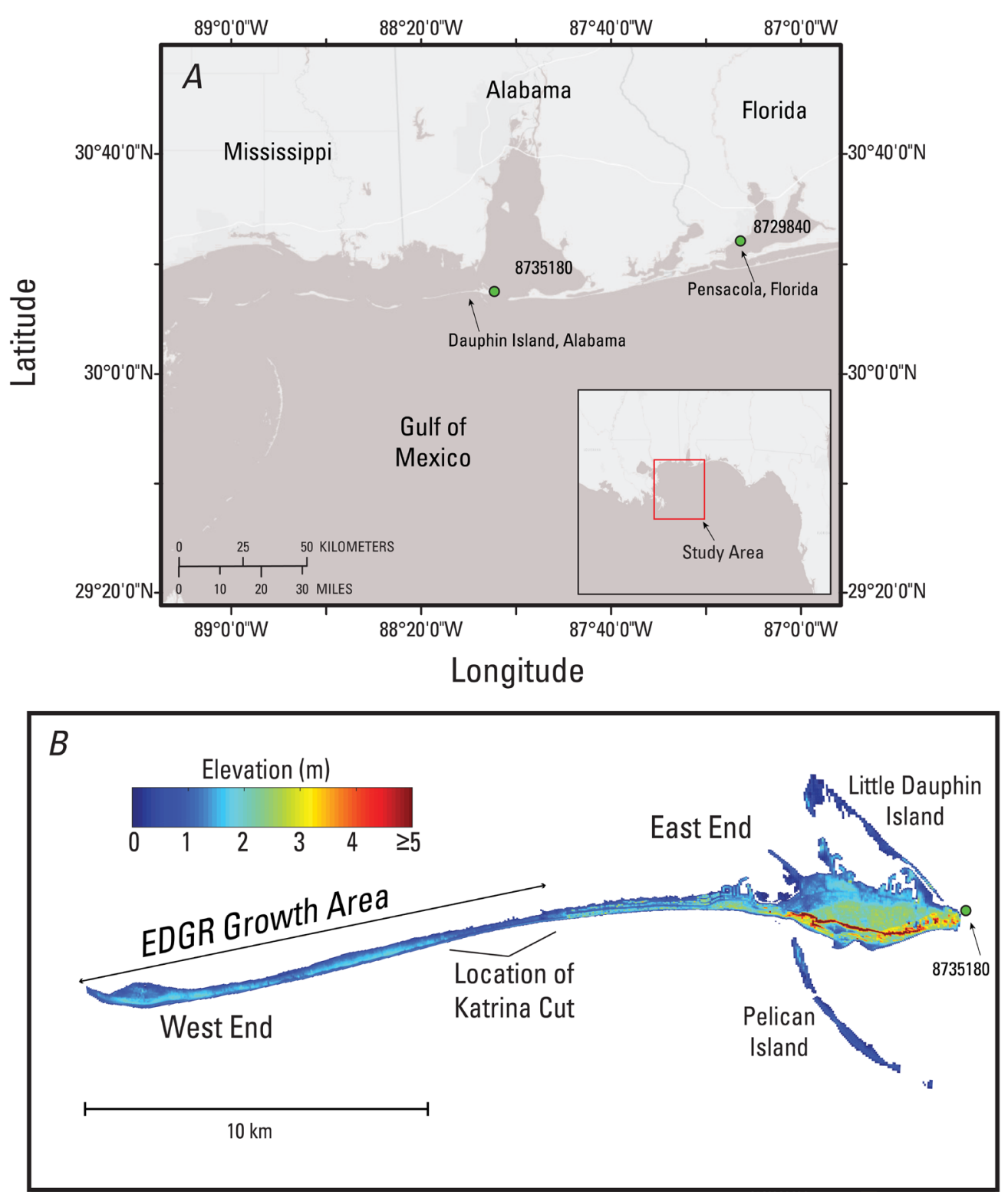

Figure 1. A, Location of Dauphin Island, Alabama, with tide gauge locations (NOAA tide stations 8735180 and 8729840) indicated by green dots within the northern Gulf of Mexico. B, Dauphin Island, Alabama, with locations of Katrina Cut, EDGR growth area, tide gauge (NOAA tide station 8735180), and Pelican Island. Abbreviations: EDGR, empirical dune growth model; km, kilometers; $m$, meters. 
To hindcast the evolution of Dauphin Island over decadal scales, a model framework was developed consisting of three individual models for capturing longshore transport with associated shoreline changes, foredune growth, and storm impacts to the beach and dunes. Longshore transport was modeled with the numerical model Delft3D (D3D; Deltares, 2019), which simulates waves, water levels, and morphologic changes to the entire island during more quiescent periods. Foredune growth for the uninhabited western half of Dauphin Island was modeled with an empirical dune growth model (EDGR), which increases the height and width of the foredune through time based on historical growth rates. Combined, these two models simulated island shoreline change, spit growth, and increase in island height through dune growth on monthly to yearly time scales. The impacts of tropical storm conditions were simulated with the numerical model XBeach (Roelvink and others, 2009). XBeach simulates storm waves, storm surge, and morphological erosion processes on hourly to daily time scales. A description of the coupled model framework and application to Dauphin Island is provided below. Also provided is an assessment of model framework performance based on a comparison to observational data over the same time period, and a description of model analysis conducted to evaluate the sensitivity of the results to known uncertainties in model parameters and boundary conditions.

\section{Hindcast Model Initialization and Configuration}

The model framework was developed and applied to hindcast the evolution of Dauphin Island, Ala., from 2004 to 2015. In the coupled model framework D3D and EDGR operate over concurrent monthly to yearly time periods corresponding to intervals in the hindcast period when no tropical storms were impacting the island. XBeach is used to model each tropical storm that impacted the island during the hindcast period. The details of each individual model configuration and an overview of the data sets used to parameterize and initialize each component are provided in the following sections, concluding with a description of the model coupling.

\section{Observational Data}

The model domain was initialized and assessed against 14 aerial light detection and ranging (lidar) surveys acquired between late 2004 and 2015. Elevation offsets identified in these surveys were corrected following the methodology described in Thompson and others (2017). The initial configuration of the island, nearshore areas, and offshore bathymetry for the hindcast simulation consisted of topography and bathymetry measurements from the United States Geological Survey's (USGS) Coastal National Elevation Database and the National Oceanic and Atmospheric Administration (NOAA) National Geophysical Data Center, along with lidar-derived elevations from September 2004 following Hurricane Ivan; the September 2004 survey provided elevation data where available, with the closer dated survey data filling spatial gaps in this post storm survey (Jenkins and others, 2020). Coincident nearshore bathymetry was not available at this time; therefore, the additional bathymetry data was taken from the final bathymetry from validated XBeach simulations of Hurricane Ivan and Hurricane Katrina at Dauphin Island by Passeri and others (2018), which provides more up-to-date nearshore bathymetry for this area (Jenkins and others, 2020). A description of the methods and data sources used to merge lidar topographies and bathymetric surveys can be found in Jenkins and others (2020). 


\section{Delft3D Model Operation}

Delft3D (D3D) is a numerical modeling system that incorporates waves, water levels, and sediment transport (Deltares, 2019) that was used to simulate hydrodynamic and morphologic changes on monthly to yearly time scales for the entirety of Dauphin Island and surrounding areas (fig. 2). Information on grid configuration as well as testing and validation of the D3D configuration using deterministic runs over multiple time periods is provided in Jenkins and others (2020). For model simulations in the coupled model framework to be computationally feasible on monthly to yearly time scales, D3D used the mormerge configuration (D3DMM), which simultaneously simulates waves, flow, and sediment transport associated with a wave climatology (Benedet, 2016; Deltares, 2019). The wave climatology for the D3DMM configuration was derived from data produced by the European Centre for Medium-Range Weather Forecasts (ECMWF) ReAnalysis-Interim (ERA) model, while the morphological tide was derived from water-level data at the Dauphin Island tide gauge (fig. 1) and processed following Lesser (2009). More detailed descriptions of the methods and results from the sensitivity and validation analysis for the D3D model, the D3DMM climatology setup, and the morphologic tide generation can be found in Jenkins and others (2020).

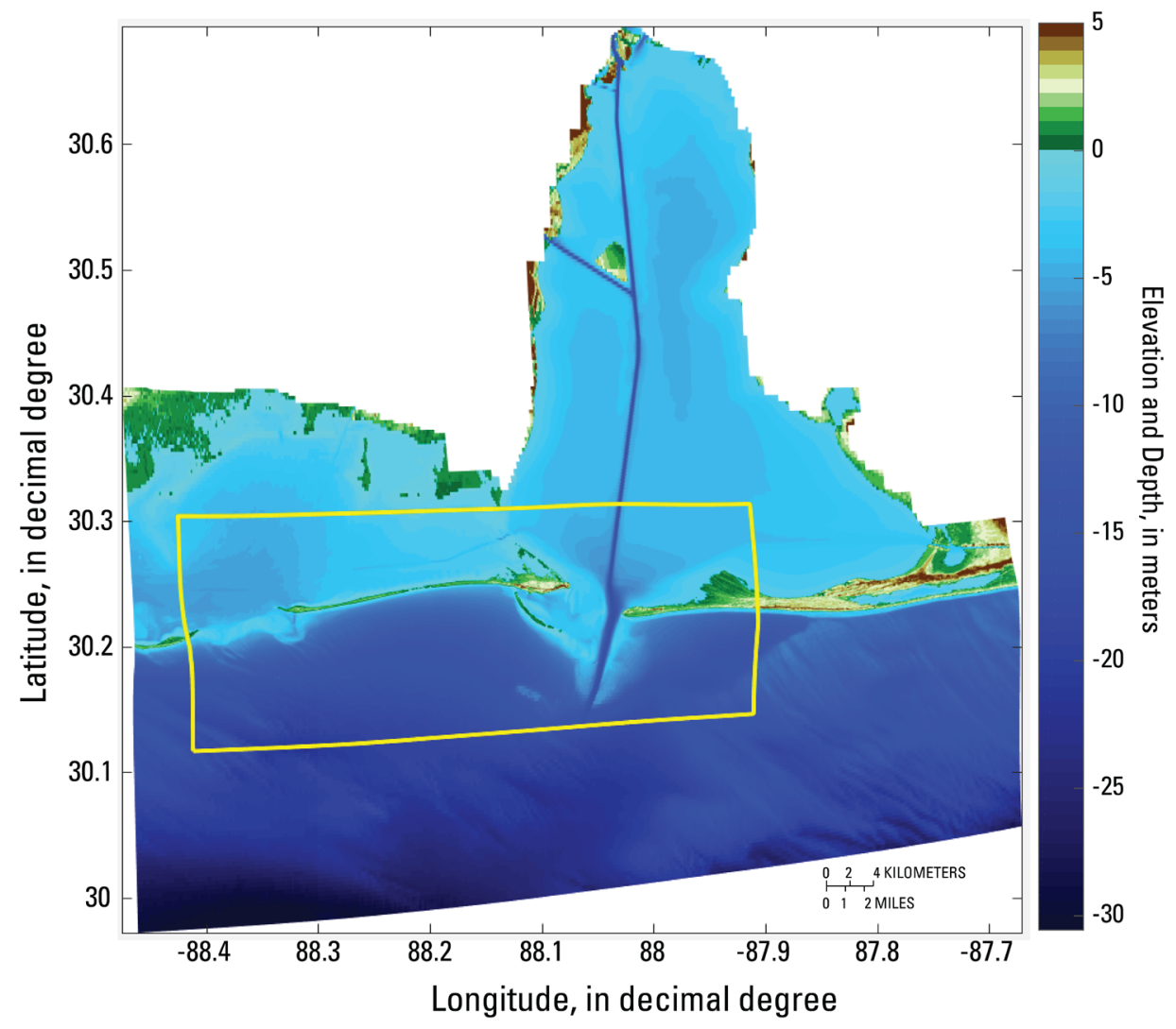

Figure 2. D3DMM model domain for the decadal hindcast simulation. The figure shows the full D3DMM model domain that illustrates the flow grid and coarse-wave grid; the fine-wave grid extent is shown within the yellow box. The coarse-grid resolution was variable, ranging from $15 \mathrm{~m}$ (closer to Dauphin Island and Mobile Bay) to $300 \mathrm{~m}$ (offshore) in the cross-shore, and 250 to $325 \mathrm{~m}$ alongshore. The fine-grid cross-shore resolutions ranged from $5 \mathrm{~m}$ (close to Dauphin Island) to over $250 \mathrm{~m}$ (to the north and south) and 40 to $100 \mathrm{~m}$ alongshore (Jenkins and others, 2020). Abbreviations: D3DMM, Deflt3D mormerge; m, meters. 


\section{Empirical Dune Growth Model Operation}

EDGR modeled barrier island cross-shore profiles as a sum of Gaussian function curves that represent the subaerial island platform, dunes, and berms. The model process evolved the foredune of each island profile based on empirical growth curves parameterized with terminal dune height and location data (appendix 2). Growth rates for the dune height were based on the sigmoid growth curves of Houser and others (2015) that are derived from foredune changes observed in the lidar elevations over the decadal timespan of the surveys, specifically September 2004 to the beginning of 2015. Growth rates for the foredune width were based on the linear relationship between dune height and width obtained from the Gaussian fits of observed foredune morphologies (appendix 2). EDGR was used to evolve the foredune for each model grid crossshore profile along Dauphin Island from the western spit to the eastern side of the Katrina Cut and along the length of Pelican Island (fig. 1B). Dune evolution in the inhabited portion of the island has historically been dominated by anthropogenic processes outside the scope of EDGR, so natural dune growth in this region was not modelled in the framework. Due to the orientation and relatively coarse cross-shore resolution of Pelican Island in the D3D/EDGR grid, cross-shore profiles for this location were interpolated to 5-m resolution prior to running EDGR, then interpolated back into the D3D/EDGR model grid after applying dune growth.

For the hindcast simulation, EDGR was setup using the same growth rate $(0.53$ meters per year) and dune growth reset thresholds $(0.25$ meters $[\mathrm{m}])$ as described in appendix 2 . Conversely, the linear-fit slope of dune heights versus dune widths, and the y-intercept for the Dauphin Island portion of the grid ( $m_{d W d H}$ and $b_{d W d H}$ in appendix 2 ) were calculated from the 14 lidar surveys to be $4.2 \mathrm{~m}$ and $13.5 \mathrm{~m}$, respectively; for Pelican Island the values were calculated to be $27.56 \mathrm{~m}$ and $2.95 \mathrm{~m}$, respectively. These linear-fit values were calibrated for the growth only unlike the case in appendix 2 that calibrated using growth and erosion. The terminal dune heights and distance from shore were selected from the 2015 lidar survey (Thompson and others, 2017).

\section{XBeach Model Operation}

XBeach is a coupled 2DH (two dimensional in the horizontal plane) model that was developed to simulate nearshore, dune and barrier island response to storm events. The model concurrently solves wave-group scale equations for roller energy, time-dependent short-wave action balance, nonlinear shallow water mass and momentum, and sediment transport (Roelvink and others, 2009). XBeach has been validated in previous studies that were aimed at determining erosional responses of barrier islands to major storm events in the northern Gulf of Mexico (Lindemer and others, 2010; McCall and others, 2010; Sherwood and others, 2014). The model grid varied in cross-shore resolution with a minimum of $3 \mathrm{~m}$ across the subaerial island and a maximum of $12.5 \mathrm{~m}$ offshore, with uniform alongshore resolution of $25 \mathrm{~m}$ for the entire domain, with spatially varying bottom friction coefficients. The grid formulation and derivation of bottom friction values are described in Passeri and others (2018).

\section{Model Forcing with Synthetic Storms}

To allow the model framework being developed to also be used to forecast future scenarios, boundary conditions for storm events were not taken from the historical record. Instead, a suite of synthetic storms provided by the U.S. Army Corps of Engineers and derived using the Joint Probability Method-Optimal Sampling (JPM-OS) approach were used as boundary 
conditions for XBeach. The JPM-OS set of 295 synthetic storms was originally developed to simulate the flooding impact of tropical storms that made landfall within $200 \mathrm{~km}$ of Alabama's barrier islands and mainland coast (FEMA, 2014). More information on the JPM and JPM-OS approaches for storm climatology and how the storm conditions were modeled for flood risk can be found in Slinn (2008), Niedoroda and others (2010), Toro and others (2010), and Nadal-Caraballo and others (2015).

Pre-H. Ivan: September 2004

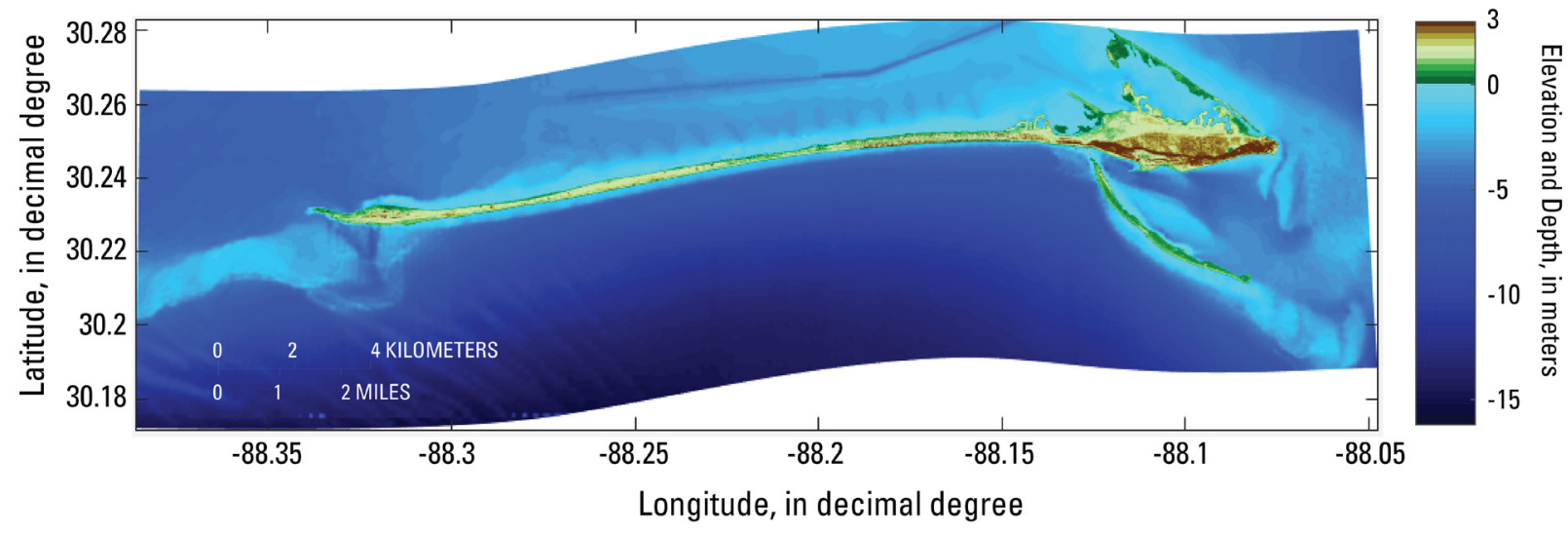

Figure 3. Model domain for all XBeach simulations. The DEM here is the pre-Hurricane Ivan (September, 2004) Dauphin Island elevations generated by Passeri and others (2018). Abbreviations: DEM, digital elevation model.

For each of the seven tropical storms that made landfall within $200 \mathrm{~km}$ of Dauphin Island during the years of 2004 to 2015, the timespan of our decadal hindcast (table 1), a synthetic storm was selected as a best-match to the historic event and used to provide boundary conditions to XBeach for simulation on the model domain shown in figure 3. The total water level (TWL), defined as the combination of storm surge, tide, and wave induced water levels (wave setup and swash excursion, collectively called run-up), was chosen as the best-match comparison parameter because of the established relationship between TWL and barrier island response during storms (Sallenger, 2000). Wave run-up for the historic storms was calculated following Stockdon and others (2006) from ERA wave data using significant wave height $\left(\mathrm{H}_{\mathrm{s}}\right)$ and dominant (peak) wave period $\left(\mathrm{T}_{\mathrm{p}}\right.$ ) that were extracted from a point offshore of Dauphin Island (fig. $4 B$ red circle with asterisk; water depth of $\sim 15 \mathrm{~m}$ ) and an island-wide mean foreshore beach slope of 0.04 (data from Doran and others [2017]; averaging method from Doran and others [2015]). The still water level, taken from a merged tide/surge record using input from the Dauphin Island, Ala., tide gauge (fig. 1; NOAA tide station 8735180) and the Pensacola, Fla., tide gauge (fig. 1; NOAA tide station 8729840) (merging details in Mickey and others [2017]; datum corrected from MSL to NAVD88) was added to the estimated wave run-up. Since the synthetic storms in the database do not include tides, the predicted astronomical tide was removed from the observed TWL timeseries for each storm event. Storm events were isolated in the TWL timeseries based on the landfall date provided from the National Hurricane Center's hurricane database (National Oceanic and Atmospheric Administration, Hurricane Research Division, 2018), with each event including 4 days prior to and 2 days after the landfall date. The TWL for each synthetic storm was also calculated following Stockdon and others (2006), using the same beach slope, wave 
data, and still water-level information from the same location as for the historic storms. Out of the 295 synthetic storms provided, four synthetic storms were removed due to data gaps in the time series.

The method for determining which synthetic storm best represented the observed storm events required a two-fold analysis of time series comparisons. First, the best alignment in time of each synthetic storm to a given observed storm was identified by translating the 4-day time series of TWL for each synthetic storm along the 6-day time series of TWL for each observed event until the maximum difference (over all times) between the two time-series was minimized (equation 1):

$$
\eta_{\text {diff }}=\min \left[\max \left[\mid\left(\eta_{s}-\eta_{o}\left(t_{0 \rightarrow t_{\eta_{s}}}+\tau\right) \mid\right]\right]\right.
$$

where $\quad \eta_{s} \quad$ is the full 4-day synthetic storm TWL;

$\eta_{o} \quad$ is the full 6-day observed TWL;

$t \quad$ is the time step starting at 0 and increasing to $\left[t_{\text {max obs }}-\right.$ length of $\left.\eta_{s}\right]$;

$\tau \quad$ is the difference in time $t_{0}$ to $t_{\eta \mathrm{s}}$; and

$\eta_{\text {diff }} \quad$ is the lowest absolute maximum difference between $\eta_{s}$ and $\eta_{o}$ with best alignment in time $\left(t_{0}=\tau\right)$.

The synthetic storm time series moves along the time axis of the observed event time series one step $(t)$ at a time and the maximum difference for the time series of each step is recorded. After the last functional time-step for matching is reached, the maximum absolute difference of all sections is analyzed to find the minimum value $\left(\eta_{\text {diff }}\right)$ for the synthetic storm time series.

After each synthetic storm has been aligned in time to the observed time-series, the second step of the matching process calculates the weighted sum of difference (WSD) (equation 2):

$$
W S D=\frac{\sum\left(\left|T W L_{O b s}-T W L_{S S}\right| * T W L_{O b S}\right)}{\sum T W L_{O b s}},
$$

where $T W L_{O b s} \quad$ is the 4-day window of the observed TWL extracted from step 1;

$T W L_{S S} \quad$ is the synthetic storm TWL; and

$W S D \quad$ is the sum of differences between the entire TWL time series of the synthetic storm and observed events.

The synthetic storm that has the lowest WSD for the observed event is designated the best representative storm for the observed event. This process was repeated for each of the seven storms identified during the hindcast period (table 1). 
Table 1. Observed tropical cyclones and corresponding best match synthetic storm from the approximate 10-year period.

\begin{tabular}{|c|c|c|}
\hline $\begin{array}{c}\text { Tropical cyclone } \\
\text { name }\end{array}$ & Landfall date & Best match SS \\
\hline TS Arlene & June 11, 2005 & 119 \\
\hline TS Cindy & July 6, 2005 & 141 \\
\hline TS Dennis & July 10, 2005 & 120 \\
\hline Hurricane Katrina & Aug. 29, 2005 & 262 \\
\hline TS Claudette & Aug. 17, 2009 & 126 \\
\hline Hurricane Ida & Nov. 10, 2009 & 189 \\
\hline Hurricane Isaac & Aug. 29, 2012 & 164 \\
\hline
\end{tabular}

Since the synthetic storms do not include tides, the water level contribution from tidal variability needed to be added. To enable the methodology to be used in future applications (such as forecasts) where observed tides are unavailable, the morphologic tide derived for D3D was aligned in time to the observed time for each event and added to the boundary condition water levels for each synthetic storm. The morphological tide consists of 9915 -minute timesteps that represent 99 possible starting water elevations. For each possible start index into the morphological tide, the sum of the absolute difference between the 4-day observed astronomical tide and a 4-day instance of the morphologic tide sequence was calculated. The timestep within the 99 timestep sequence with the smallest sum of absolute difference was considered the best starting point. For each synthetic storm, water level forcing was applied uniformly to the offshore and bayside boundary.

\section{Model Boundary Wave Forcing Configuration}

A suite of deterministic runs for Hurricanes Ivan and Katrina were simulated using boundary conditions extracted from an alternate parent grid with more complete spatial coverage that was developed under the Mississippi Coastal Improvements Program (MsCIP; Walstra and others, 2012). This sensitivity testing used the respective pre-storm DEMs (fig. 4) and the friction coefficient of Passeri and others (2018). For the sensitivity analysis, simulations were conducted using wave conditions extracted along the full XBeach boundary, representing the best possible prediction with the given inputs. Alternate boundary condition configurations were then extracted from the MsCIP output corresponding to configurations that could be created using the more limited synthetic storm boundary conditions (table 2). Tides and water levels for these deterministic simulations were applied at the four corners of the XBeach model domain and derived from the northern Gulf of Mexico (NGOM3) model (Luettich and others 1992; Dietrich and others, 2011; Bilskie and others, 2016; described in Passeri and others, 2018). Potential model boundary configurations were evaluated based on the comparison of simulated topographic changes to observed changes derived from lidar surveys for the western half of the island (west of Katrina Cut; west of longitude $-88.225^{\circ}$ ). The model bias, root mean square error (RMSE), and coefficients of determination $\left(\mathrm{R}^{2}\right)$ were calculated and are presented in table 2 for each boundary setup simulation. The calculated model bias, RMSE, and $\mathrm{R}^{2}$ for all the model boundary sensitivity simulations were within a range of less than $0.1 \mathrm{~m}$ of each other (table 2). For the full hindcast simulation, setup ID 6 (table 2) was chosen to be used for the XBeach model; synthetic storm domain-point 
data were interpolated to the XBeach offshore boundary over the region for which data points were available, then the western-most point was extrapolated to the western edge of the offshore boundary.

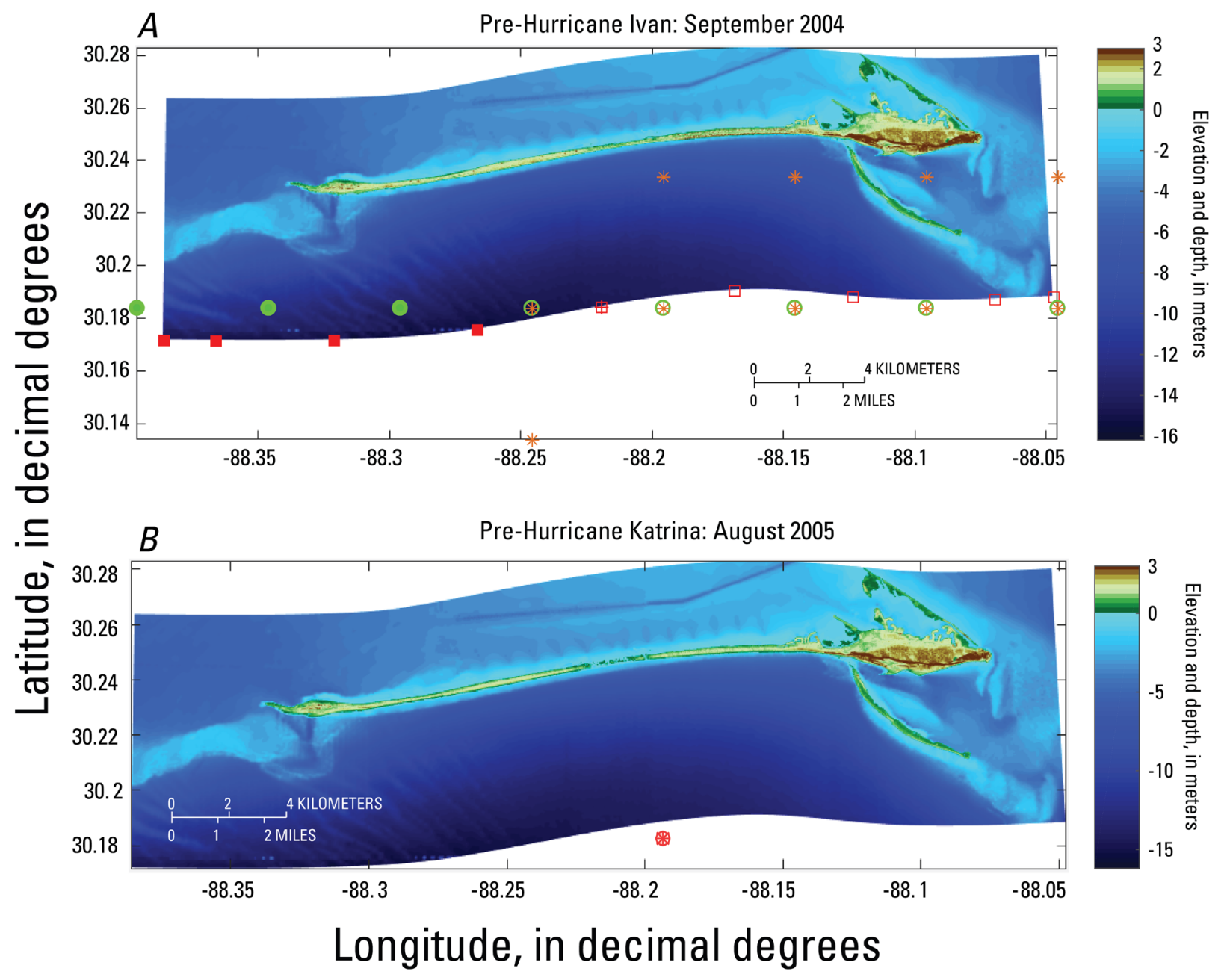

Figure 4. A, DEM of Dauphin Island pre-Hurricane Ivan (September, 2004) with point symbols indicating the boundary condition configuration described in table 2; filled and open red squares correspond to setup ID 2; filled and open green circles (with orange asterisks) correspond to setup ID 3; open red squares and open green circles (with orange asterisks) correspond the setup IDs 4 and 5 respectively, and orange asterisks correspond to setup ID 6. B, XBeach model domain and DEM of Dauphin Island pre-Hurricane Katrina (August, 2005) with a red circled asterisk corresponding to setup ID 1. Abbreviations: DEM, digital elevation model. 
Table 2. Boundary setup description, indicator, and model accuracy for XBeach simulations run on the respective pre-storm DEMs for Hurricane Ivan and Hurricane Katrina.

[Wave data was extracted from indicator points and applied to the XBeach offshore boundary. Abbreviations: ID, identification; JPM-OS, joint probability method-optimal sampling; km, kilometer; RMSE, root mean square error; $\mathrm{R}^{2}$, coefficient of determination]

\begin{tabular}{|c|c|c|c|c|c|c|c|c|c|c|}
\hline $\begin{array}{l}\text { Setup } \\
\text { ID }\end{array}$ & $\begin{array}{l}\text { Boundary } \\
\text { setup }\end{array}$ & Description of data extracted & Description of data applied & $\begin{array}{l}\text { Point indicator } \\
\text { (fig. } 4 A)\end{array}$ & \multicolumn{3}{|c|}{ Hurricane Ivan } & \multicolumn{3}{|c|}{ Hurricane Katrina } \\
\hline \multicolumn{5}{|c|}{ Wave data extracted from the JPM-OS derived synthetic storm data } & $\mathbf{R}^{2}$ & RMSE & $\begin{array}{l}\text { Bias of } \Delta \\
\text { Elevation }\end{array}$ & $\mathbf{R}^{2}$ & RMSE & $\begin{array}{l}\text { Bias of } \Delta \\
\text { Elevation }\end{array}$ \\
\hline 1 & $\begin{array}{l}\text { Single bound- } \\
\text { ary point }\end{array}$ & $\begin{array}{l}\text { Waves extracted at a single point } \\
\text { nearest to the middle of the } \\
\text { XBeach offshore boundary }\end{array}$ & $\begin{array}{l}\text { Uniform waves applied along the } \\
\text { offshore boundary }\end{array}$ & $\begin{array}{l}\text { Red circle } \\
\text { with asterisk } \\
\text { (fig. } 4 B \text { ) }\end{array}$ & 0.26 & 0.67 & 0.13 & 0.18 & 0.84 & 0.61 \\
\hline 2 & $\begin{array}{l}\text { Spatially } \\
\text { varying } \\
\text { boundary } \\
\text { point }\end{array}$ & $\begin{array}{l}\text { Spatially variable waves extracted } \\
\text { at points along the offshore } \\
\text { boundary ( } \sim 2 \text { to } 5 \mathrm{~km} \text { apart })\end{array}$ & $\begin{array}{l}\text { Spatially variable waves applied } \\
\text { at the same offshore boundary } \\
\text { points ( } \sim 2 \text { to } 5 \mathrm{~km} \text { apart) }\end{array}$ & $\begin{array}{l}\text { Filled and open } \\
\text { red squares }\end{array}$ & 0.27 & 0.69 & 0.17 & 0.18 & 0.79 & 0.56 \\
\hline 3 & $\begin{array}{l}\text { Spatially } \\
\text { varying } \\
\text { JPM-OS } \\
\text { point }\end{array}$ & $\begin{array}{l}\text { Spatially variable waves extracted } \\
\text { nearest to boundary JPM-OS } \\
\text { points ( } 4.8 \mathrm{~km} \text { apart), western } \\
\text { point extracted every } 4.8 \mathrm{~km} \\
\text { at alongshore locations from } \\
\text { farthest west point to western } \\
\text { boundary }\end{array}$ & $\begin{array}{l}\text { Spatially variable waves applied } \\
\text { at the nearest boundary points } \\
\text { (like the points mentioned } \\
\text { above) }\end{array}$ & $\begin{array}{l}\text { Filled and open } \\
\text { green circles } \\
\text { (with orange } \\
\text { asterisk) }\end{array}$ & 0.25 & 0.68 & 0.15 & 0.18 & 0.83 & 0.61 \\
\hline 4 & $\begin{array}{l}\text { Spatially } \\
\text { varying east } \\
\text { boundary } \\
\text { point }\end{array}$ & $\begin{array}{l}\text { Same partial data as ID } 2 \text { "Spa- } \\
\text { tially varying boundary point" }\end{array}$ & $\begin{array}{l}\text { Spatially variable waves applied } \\
\text { at the boundary, where the } \\
\text { boundary point that was closest } \\
\text { to the farthest west JPM-OS } \\
\text { point was applied uniformly } \\
\text { from there to the western } \\
\text { boundary }\end{array}$ & Open red squares & 0.28 & 0.68 & 0.17 & 0.19 & 0.78 & 0.57 \\
\hline 5 & $\begin{array}{l}\text { Spatially } \\
\text { varying east } \\
\text { JPM-OS } \\
\text { point }\end{array}$ & $\begin{array}{l}\text { Same partial data as ID } 3 \text { "Spa- } \\
\text { tially varying JPM-OS point" }\end{array}$ & $\begin{array}{l}\text { Spatially variable waves applied } \\
\text { to the nearest boundary points } \\
\text { ( } 4.8 \mathrm{~km} \text { apart alongshore), uni- } \\
\text { form conditions were applied } \\
\text { from the farthest west point to } \\
\text { the western boundary }\end{array}$ & $\begin{array}{l}\text { Open green } \\
\text { circles (with } \\
\text { orange asterisk) }\end{array}$ & 0.26 & 0.67 & 0.12 & 0.16 & 0.86 & 0.62 \\
\hline 6 & $\begin{array}{l}\text { Spatially } \\
\text { varying east } \\
\text { JPM-OS } \\
\text { interpolated } \\
\text { point }\end{array}$ & $\begin{array}{l}\text { Spatially variable waves extracted } \\
\text { at JPM-OS points inshore and } \\
\text { offshore nearest to XBeach } \\
\text { boundary ( } 4.8 \mathrm{~km} \text { apart } \\
\text { alongshore; } 5.5 \mathrm{~km} \text { apart cross- } \\
\text { shore), then interpolated to } \\
\text { nearest XBeach boundary point }\end{array}$ & $\begin{array}{l}\text { Spatially variable waves applied } \\
\text { to the nearest boundary points } \\
\text { ( } 4.8 \mathrm{~km} \text { apart alongshore), uni- } \\
\text { form conditions were applied } \\
\text { from the farthest JPM-OS west } \\
\text { point to the XBeach western } \\
\text { boundary }\end{array}$ & Orange asterisks & 0.26 & 0.68 & 0.14 & 0.18 & 0.80 & 0.58 \\
\hline
\end{tabular}




\section{Hindcast Coupled Model Framework}

In the hindcast coupled model framework, the first phase was for D3DMM to simulate the background littoral transport and resultant morphologic change over the time period prior to the first storm (table 3). Dune growth over the concurrent period was then modeled with EDGR using the final DEM from D3DMM as the initial condition, such that the dune growth was in addition to the nearshore changes predicted with D3DMM. After foredunes were increased with EDGR, the D3DMM DEM was interpolated to the XBeach domain and the representative synthetic storm that best-matched the observed storm was simulated. Once the synthetic storm simulation was complete, the final XBeach DEM was interpolated back to the D3DMM domain. In addition, the post-storm EDGR analysis was conducted to identify which, if any, of the crossshore transects had become sub-aerial due to island overwash or if enough erosion of dunes had occurred to reset dune growth (see appendix 2). After the post-storm EDGR analysis, the subsequent quiescent period was simulated with D3DMM and EDGR, with the process continuing until the end of the decadal simulation. In cases where multiple storm events occurred in less than a one-year period, they were modeled consecutively with XBeach, with the EDGR post-storm analysis performed after each individual storm. In October 2007, a berm was built on the east side of Katrina Cut in front of houses along the beach (Froede, 2010). This feature was added to the D3DMM and XBeach model domains at that time in the simulation. Additionally, in May 2011, the rubble mound feature that closed Katrina Cut (Martinez, 2011) was added to both the D3DMM and XBeach model domains as a non-erodible structure and persisted as such throughout the rest of the decadal simulation. 
Table 3. Hindcast coupled model framework sequence.

[Abbreviations: DEM, digital elevation model; D3DMM, Delft3D mormerge; EDGR, empirical dune growth model; SS, synthetic storm; TS, tropical storm]

\begin{tabular}{|c|c|c|}
\hline Time sequence & Model & Lidar comparison \\
\hline Initialize & EDGR & \\
\hline $09 / 17 / 2004$ to $06 / 08 / 2005$ & D3DMM & 09/2004 Survey \\
\hline Dune growth & EDGR & \\
\hline TS Arlene, SS 119 & XBeach & \\
\hline Post-storm dune analysis & EDGR & \\
\hline TS Cindy, SS 141 & XBeach & \\
\hline Post-storm dune analysis & EDGR & \\
\hline Hurricane Dennis, SS 120 & XBeach & \\
\hline Post-storm dune analysis & EDGR & \\
\hline $07 / 12 / 2005$ to $08 / 26 / 2005$ & D3DMM & \\
\hline Dune growth & EDGR & \\
\hline Hurricane Katrina, SS 262 & XBeach & \\
\hline Post-storm dune analysis & EDGR & \\
\hline $08 / 31 / 2005$ to $10 / 08 / 2007^{*}$ & D3DMM & $\begin{array}{l}\text { 09/2005 Survey } \\
\text { 03/2006 Survey } \\
\text { 09/2006 Survey } \\
\text { 06/2007 Survey }\end{array}$ \\
\hline Dune growth & EDGR & \\
\hline $10 / 08 / 2007$ to $08 / 14 / 2009$ & D3DMM & $\begin{array}{l}\text { 06/2008 Survey } \\
\text { 09/2008 Survey }\end{array}$ \\
\hline Dune growth & EDGR & \\
\hline TS Claudette, SS 126 & XBeach & \\
\hline Post-storm dune analysis & EDGR & \\
\hline $08 / 18 / 2009$ to $11 / 06 / 2009$ & D3DMM & \\
\hline Dune growth & EDGR & \\
\hline TS Ida, SS 189 & XBeach & \\
\hline Post-storm dune analysis & EDGR & \\
\hline $11 / 11 / 2009$ to $05 / 01 / 2011^{*}$ & D3DMM & $\begin{array}{l}\text { 01/2010 Survey } \\
07 / 2010 \text { Survey }\end{array}$ \\
\hline Dune growth & EDGR & \\
\hline $05 / 01 / 2011$ to $08 / 29 / 2012$ & D3DMM & 06/2011 Survey \\
\hline Dune growth & EDGR & \\
\hline Hurricane Isaac, SS 164 & XBeach & \\
\hline Post-storm dune analysis & EDGR & \\
\hline $08 / 30 / 2012$ to $01 / 01 / 2015$ & D3DMM & $\begin{array}{l}\text { 09/2012 Survey } \\
\text { 07/2013 Survey } \\
\text { 01/2014 Survey }\end{array}$ \\
\hline $\begin{array}{l}\text { Dune growth } \\
{ }^{*} 10 / 08 / 2007: \text { eastern Dauphi }\end{array}$ & $\frac{\text { EDGR }}{\text { nd berm added }}$ & 02/2015 Survey \\
\hline
\end{tabular}




\section{Model Results and Comparison to Observed Island Evolution}

The decadal hindcast-simulated dune heights and shoreline locations were compared quantitatively to those derived from 14 lidar surveys (Thompson and others, 2017) at the time within the simulation when lidar surveys were taken (table 3). The comparison's statistical analyses were limited to the approximately $7 \mathrm{~km}$ section of the island directly west of Katrina Cut (alongshore distance from 4.5 to $12 \mathrm{~km}$; fig. 5), but did not include the spit to exclude uncertainty related to (1) anthropogenic influence that is prevalent on the eastern portion of the barrier island and (2) the extremely dynamic western spit. Shorelines were defined as the location of the mean high-water line at the $0.23 \mathrm{~m}$ (NAVD88) contour around the island (Weber and others, 2005). Lidar-derived shorelines and dune locations were interpolated to the D3DMM Dauphin Island grid for comparison. These lidar features were previously extracted as part of the research mission of the National Assessment of Coastal Change Hazards (Doran and others, 2017). If there was a lidar-derived feature (shoreline or dune crest) within $20 \mathrm{~m}$ alongshore of any of the model's cross-shore grid lines, the intersection of the alongshore feature line (20 m buffer) and the cross-shore model grid line was taken as the interpolated location. Model-derived shorelines

were taken directly from model DEMs as the $0.23 \mathrm{~m}$ (NAVD88) contour and model-derived dune crest elevations $\left(\mathrm{D}_{\text {hi }}\right)$ were extracted at locations identified as the highest elevation point for each cross-shore profile. As an example, figure 5 shows the difference in the Gulf shoreline location (fig. $5 \mathrm{~A}$ ); the difference in cross-shore location and elevation of $\mathrm{D}_{\mathrm{hi}}$ (fig. $5 B$ ); and the location of shoreline and $\mathrm{D}_{\text {hi }}$ on the western (fig. $5 C$ ) and eastern (fig. $5 D$ ) portion of Dauphin Island for the lidar and model at the end of the decadal simulation. Similar figures (figs. 1-1 to 1-13) that were generated for each of the other 13 lidar surveys to model DEM comparisons can be found in appendix 1. For brevity, the number of data points along with the root mean square error (RMSE) and standard deviation (STD) have been placed in table 4 for each of the comparisons for the area in the lightly shaded region (alongshore distance, from 4.5 to $12 \mathrm{~km}$ ) of figures $5 A$ and $5 B$. 

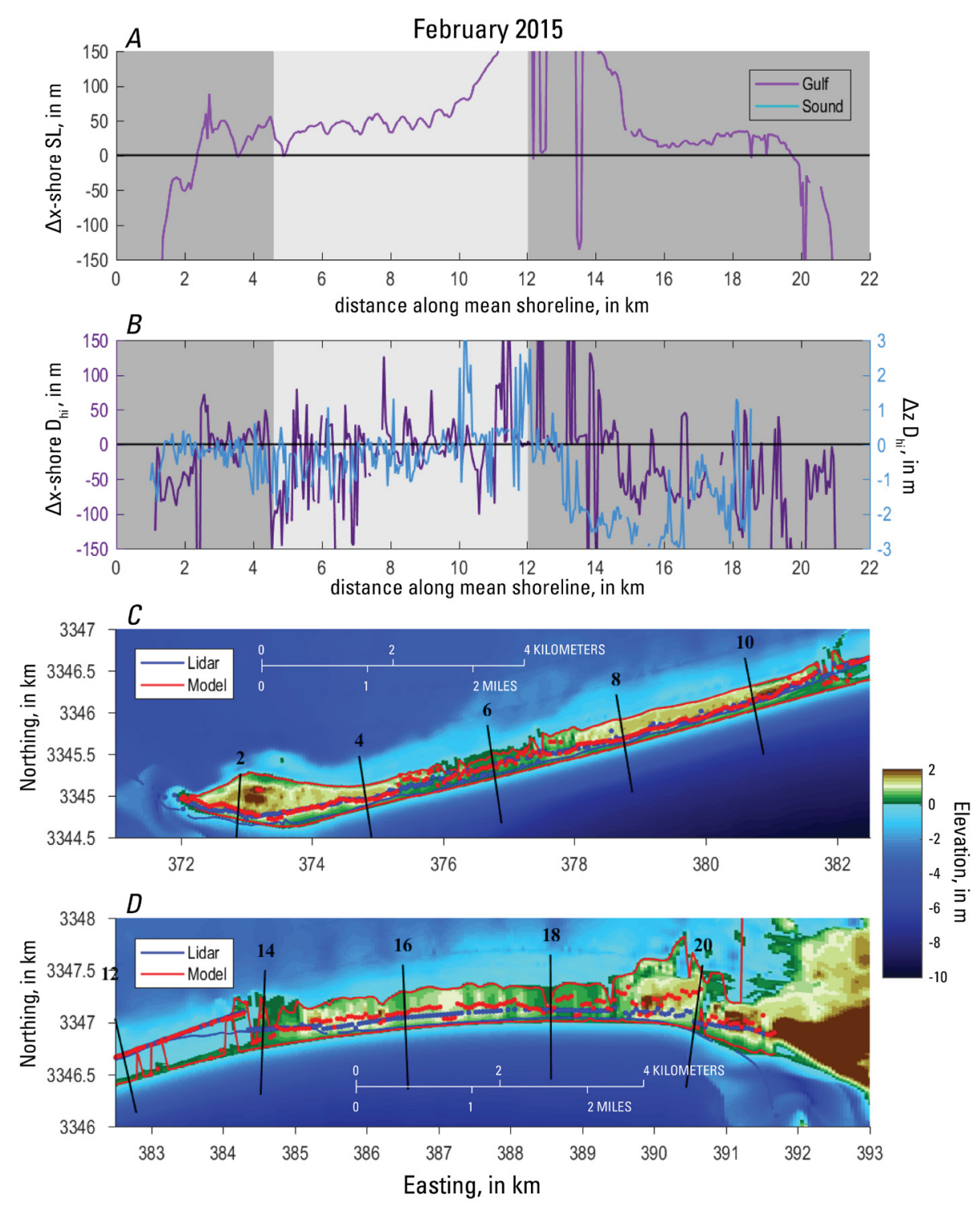

Figure 5. Model comparison of final 2015 DEM with February 2015 lidar survey. Note that the coordinates are in Easting and Northing for calculation purposes. A, Difference between model and lidar shoreline (SL) cross-shore location (Gulf shoreline: purple line). Lightly shaded area indicates alongshore location area where shoreline and dune statistics were calculated. Note that the "Sound shoreline" data were unavailable for this lidar survey, so a comparison could not be made to the Sound-side shoreline from the hindcast. $B$, Difference between model and lidar cross-shore $D_{\text {hi }}$ location $\left(\Delta x\right.$-shore $D_{h i l}$ purple line) and difference between model and lidar cross-shore $D_{h i}$ elevation $\left(\Delta z D_{h i}\right.$, blue line). $C$, Western portion of Dauphin Island with location of model shoreline and $\mathrm{D}_{\mathrm{hi}}$ locations (red line and red dot, respectively); and location of lidar shoreline and $D_{\text {hi }}$ locations (blue line and blue dot, respectively); black transect lines indicate distance (in kilometers) alongshore with respect to the $\mathrm{x}$-axis in $A$ and $B . D$, Eastern portion of Dauphin Island with location of model shoreline and $\mathrm{D}_{\mathrm{hi}}$ locations (red line and red dot, respectively); and location of lidar shoreline and $D_{h i}$ locations (blue line and blue dot, respectively); black transect lines indicate distance (in kilometers) alongshore with respect to the $x$-axis in $A$ and $B$. Abbreviations: DEM, digital elevation model; $\mathrm{km}$, kilometers; lidar, light detection and ranging; $\mathrm{m}$, meters; SL, shoreline. 
Table 4. Statistics quantifying the changes to Gulf and Sound shoreline location, and dune elevation and location.

[Abbreviations: bias, difference of observed and model; $\Delta \mathrm{x} \_\mathrm{g}$, difference in Gulf shoreline cross-shore location; $\Delta \mathrm{x} \_$s, difference in Sound shoreline cross-shore location; $\Delta \mathrm{x} \mathrm{D}_{\mathrm{hi}}$, difference in cross-shore location; $\Delta \mathrm{z} \mathrm{D}_{\mathrm{hi}}$, difference in dune crest elevation; $\mathrm{N}$, number of values; RMSE, root mean square error; $\mathrm{STD}$, standard deviation; --, data unavailable for comparison]

\begin{tabular}{|c|c|c|c|c|c|c|c|c|c|c|c|c|c|c|c|}
\hline \multirow[b]{2}{*}{$\begin{array}{c}\text { Date } \\
\text { (month/ } \\
\text { year) }\end{array}$} & \multicolumn{4}{|c|}{$\Delta x \_g$ Gulf shoreline } & \multicolumn{4}{|c|}{$\Delta x \_s$ Sound shoreline } & \multicolumn{4}{|c|}{$\Delta \times D_{h i}$} & \multicolumn{3}{|c|}{$\Delta z \mathrm{D}_{\mathrm{hi}}$} \\
\hline & $\mathrm{N}$ & $\begin{array}{l}\text { Bias } \\
\text { (m) }\end{array}$ & $\begin{array}{l}\text { RMSE } \\
(\mathrm{m})\end{array}$ & $\begin{array}{l}\text { STD } \\
(\mathrm{m})\end{array}$ & $\mathbf{N}$ & $\begin{array}{l}\text { Bias } \\
(\mathrm{m})\end{array}$ & $\begin{array}{c}\text { RMSE } \\
\text { (m) }\end{array}$ & $\begin{array}{l}\text { STD } \\
\text { (m) }\end{array}$ & $\mathbf{N}$ & $\begin{array}{l}\text { Bias } \\
(\mathrm{m})\end{array}$ & $\begin{array}{c}\text { RMSE } \\
\text { (m) }\end{array}$ & $\begin{array}{l}\text { STD } \\
(\mathrm{m})\end{array}$ & $\begin{array}{l}\text { Bias } \\
(\mathrm{m})\end{array}$ & $\begin{array}{c}\text { RMSE } \\
(\mathrm{m})\end{array}$ & $\begin{array}{l}\text { STD } \\
\text { (m) }\end{array}$ \\
\hline $09 / 2004$ & 150 & 17.9 & 21.0 & 11.0 & 150 & -5.4 & 10.5 & 9.1 & 147 & -12.5 & 21.4 & 17.4 & -0.1 & 0.1 & 0.1 \\
\hline 09/2005 & 99 & 7.4 & 40.6 & 40.2 & 99 & -15.0 & 26.1 & 21.4 & 94 & -121.5 & 124.7 & 28.2 & -0.4 & 0.5 & 0.3 \\
\hline $03 / 2006$ & 101 & -8.5 & 46.2 & 45.7 & -- & -- & -- & -- & 104 & -121.9 & 127.4 & 37.0 & -0.6 & 0.7 & 0.3 \\
\hline 09/2006 & 108 & 40.0 & 53.4 & 35.6 & 107 & 0.4 & 47.4 & 47.6 & 104 & -56.9 & 80.6 & 57.3 & -1.0 & 1.0 & 0.3 \\
\hline 06/2007 & 122 & 42.4 & 56.4 & 37.4 & 122 & 18.4 & 82.5 & 80.7 & 115 & -38.1 & 77.2 & 67.5 & -0.6 & 0.7 & 0.4 \\
\hline $06 / 2008$ & 140 & 43.3 & 69.2 & 54.2 & 140 & 47.3 & 125.0 & 116.2 & 128 & -15.7 & 84.5 & 83.3 & -0.7 & 0.8 & 0.5 \\
\hline 09/2008 & 134 & 55.6 & 71.5 & 45.1 & 133 & 40.7 & 121.0 & 114.4 & 122 & -16.3 & 79.5 & 78.1 & -0.8 & 1.0 & 0.5 \\
\hline $01 / 2010$ & 133 & 55.2 & 64.8 & 34.1 & 138 & 33.5 & 102.6 & 97.3 & 131 & 5.8 & 78.7 & 78.8 & -0.7 & 0.8 & 0.5 \\
\hline $07 / 2010$ & -- & -- & -- & -- & -- & -- & -- & -- & -- & -- & -- & -- & -- & -- & -- \\
\hline $06 / 2011$ & 53 & 49.1 & 56.0 & 27.2 & -- & -- & -- & -- & 99 & -16.0 & 60.3 & 58.4 & -0.2 & 0.5 & 0.5 \\
\hline 09/2012 & 138 & 49.9 & 74.2 & 55.1 & 148 & -0.02 & 73.4 & 73.7 & 149 & -22.6 & 72.6 & 69.2 & -0.8 & 1.0 & 0.6 \\
\hline $07 / 2013$ & 124 & 67.0 & 88.1 & 57.5 & -- & -- & -- & -- & 141 & -25.1 & 64.0 & 59.1 & -0.7 & 1.0 & 0.7 \\
\hline $01 / 2014$ & 37 & 27.1 & 33.2 & 19.5 & 15 & -8.3 & 42.7 & 43.3 & 134 & -18.9 & 63.9 & 61.3 & -0.4 & 0.9 & 0.8 \\
\hline $02 / 2015$ & 151 & 71.8 & 90.9 & 56.0 & -- & -- & -- & -- & 144 & -8.8 & 56.7 & 56.2 & -0.3 & 0.8 & 0.8 \\
\hline
\end{tabular}

Summarizing table 4, the model to lidar comparison shows that over the decadal hindcast period, the differences in the Gulf shoreline locations were variable with better agreement in some years (for example, 2005 and 2014) and poorer agreement in others (for example, 2013 and 2015). The average RMSE for Gulf shoreline locations over all surveys was approximately $59 \mathrm{~m}$. The difference in Sound shoreline locations was more variable over the decadal period and 5 of the 14 surveys did not include the back portion of the island; thus, no comparison could be made. The average RMSE for Sound shoreline locations over the decadal period was approximately 70 m. The differences in dune crest locations were also highly variable and the average RMSE was $76 \mathrm{~m}$. The extreme differences in dune crest locations for the model comparison to the second and third lidar surveys, immediately post-Hurricane Katrina (landfall 08/2005 with survey dates 09/2005 and 03/2006), were likely because the highest elevation point in the model DEM was a feature from a remnant dune ridge/ swale system illustrated by the model $\mathrm{D}_{\mathrm{hi}}$ locations positioned close to the northern side of the island (figs. 1-2 and 1-3 in appendix 1). This also would account for the decreasing RMSEs as survey comparisons progress through the decadal simulation; EDGR only builds up the foredune, while the ridge/swale features do not accrete new sediment, thus the foredune becomes the highest elevation point of each 
cross-shore profile so that the model and lidar $\mathrm{D}_{\mathrm{hi}}$ values are both identifying the same feature (table 4). Comparison of dune crest elevations was the least variable over the decadal period with a range of RMSEs between $0.5 \mathrm{~m}$ and $1 \mathrm{~m}$, with an average of $0.75 \mathrm{~m}$. This comparison excludes the year 2004 as the initial lidar survey was used to generate the initial model DEM.

\section{Model Uncertainty and Sensitivity}

Included below is a discussion of identified sources of model uncertainty contributing to the differences between predicted and observed island evolution. Also included are sensitivity analyses that were conducted to optimize the configuration of individual model components.

\section{Coupled Model Framework Uncertainty}

Several simplifications were made to the coupled modeling approach utilized in hindcasting Dauphin Island, primarily due to limitations in capacity of existing models and the need for computational efficiency; the most relevant to the decadal time-scale of the coupled model framework are described here. In the D3DMM application, local winds were not included; this had minimal impact on model prediction accuracy for the Gulf-facing shoreline but limited the accuracy of the model in predicting redistribution of back barrier sediments and storm induced overwash deposits (Jenkins and others, 2020). Exclusion of local winds combined with the north/ south orientation of Little Dauphin and the relatively coarse along-shore resolution of the model grid (fig. $1 B$ ) increased the error at this location, which is relatively sheltered from open-ocean waves. Within the XBeach model domain, waves were only applied to the offshore boundary, thus the north to south orientation of Little Dauphin Island and its proximity to the lateral-boundary limit model accuracy in predicting wave propagation to this area (fig. 3). Errors in XBeach model predictions are also likely to be greater in low-lying areas of Dauphin Island, such as the low area on the western side of Katrina Cut and the terminal spit at the western end of the island; as elevations approach tipping points for overwash and inundation (Sallenger, 2000), small errors in antecedent morphology or offshore forcing will result in relatively large errors in predictions of post-storm morphology. This may also account for the stark differences in lidar-model comparisons immediately following Hurricane Katrina. Within EDGR, aeolian transport processes are not linked to dune growth; therefore, changes to the island that impact the location or growth rate of dunes, such as the development of a wider beach or vegetation establishment, will not be captured. Additionally, there is no mechanism in this modeling approach for the development of dune ridges and swales on the back barrier of the island.

\section{Sensitivity Analysis - Synthetic Storms}

JPM-OS synthetic storm output was provided at a spatial resolution of approximately $4 \mathrm{~km}$ in the alongshore and approximately $5.5 \mathrm{~km}$ in the cross-shore directions over a region spanning across the northern Gulf of Mexico and Mobile Bay (from $-88.25^{\circ}$ to $-87.7^{\circ}$ longitude and $30.08^{\circ}$ to $31.1^{\circ}$ latitude). The synthetic storm output provided significant wave height $\left(\mathrm{H}_{\mathrm{s}}\right)$, peak wave period $\left(\mathrm{T}_{\mathrm{p}}\right)$, mean wave direction, and storm surge levels over the course of a 4-day period leading up to landfall. This domain does not cover the entirety of the XBeach model domain used in this study, therefore waves could not be prescribed along the full length of the offshore boundary. In addition, due to the hydrodynamic data terminating upon landfall some of the synthetic storms were found to have wave height time series that ended when waves were 
still high ( $>2 \mathrm{~m}$ ) and (or) before the peak of the storm; and some had an abrupt increase from low to high wave heights without a smooth ramp-up period. Sensitivity tests were performed to determine which grid points to extract XBeach wave boundary conditions, to evaluate procedures for applying waves at the offshore boundary, and to identify if wave time-series which lacked a ramp-up or ramp-down period in wave energy needed to be extrapolated in time to include these portions of the storm.

\section{Synthetic Storm Time-Series Extension}

The synthetic storm simulations in the northern Gulf of Mexico were available for a 4-day period leading up to storm landfall. Variation in the location of landfall led to differences in the timing of storm peak conditions over the 4-day time series that exists for each storm. Preliminary evaluation of the synthetic storm wave-characteristic time series indicated that some of the storms could potentially lead to unrealistic morphodynamic prediction results; specifically, several of the $\mathrm{H}_{\mathrm{s}}$ time series were found to end when waves had not returned to pre-storm conditions. A total of 52 storms were observed to have $\mathrm{H}_{\mathrm{s}}$ at the end of the time series between 2-3 m; 10 storms were observed to end with $\mathrm{H}_{\mathrm{s}}$ between $3-4 \mathrm{~m}$; and 9 storms were observed to end with $\mathrm{H}_{\mathrm{s}}$ over $4 \mathrm{~m}$. Of those 71 storms, three were observed to have $\mathrm{H}_{\mathrm{s}}$ ending before the peak of the storm (wave heights still increasing at the time of landfall). To test the sensitivity of model predictions to these truncated wave time series, simulations were conducted using synthetic storm 189 (SS 189) which had $\mathrm{H}_{\mathrm{s}}$ time series ending with waves greater than $3 \mathrm{~m}$ (fig. 6A). The baseline wave time series for SS 189 was extended by extrapolation using the slope of the line after the peak of the storm for $\mathrm{H}_{\mathrm{s}}, \mathrm{T}_{\mathrm{p}}$, wave direction, and water level until $\mathrm{H}_{\mathrm{s}}$ reached pre-storm levels. The original SS 189 conditions and the extended version were simulated on the pre-Hurricane Ivan DEM and compared; minimal morphodynamic change was found to have occurred during the post-storm ramp-down added to the baseline simulation (fig. $7 \mathrm{~A}$ ). Only one synthetic storm with wave heights greater than $3 \mathrm{~m}$ at the end of the time series was chosen as a best match to any of the observed storm events; SS 189 best matched to Hurricane Ida (table 1).
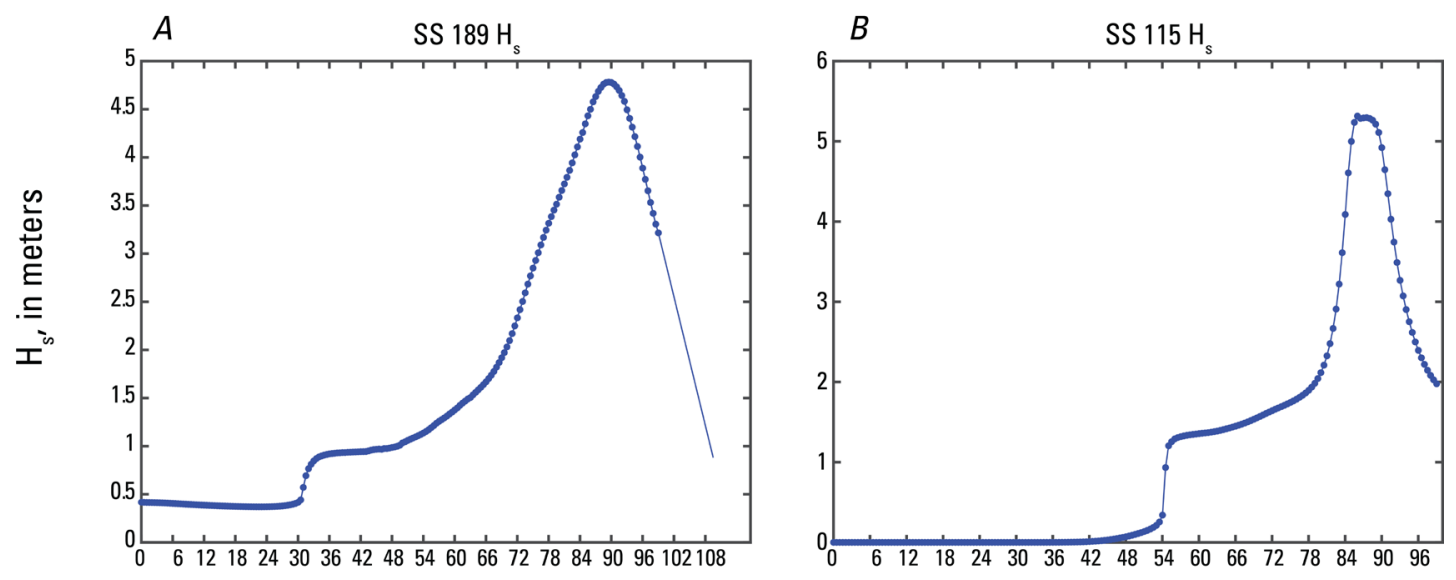

Time, in hours

Figure 6. A, Significant wave height $\left(\mathrm{H}_{\mathrm{s}}\right)$ for SS 189 (blue dots) with the extended time series represented by blue line extracted from the single offshore point (red circle with asterisk in fig. 4B). $B$, Significant wave height $\left(\mathrm{H}_{\mathrm{s}}\right)$ time series for SS 115 extracted at the same point as SS 189. 

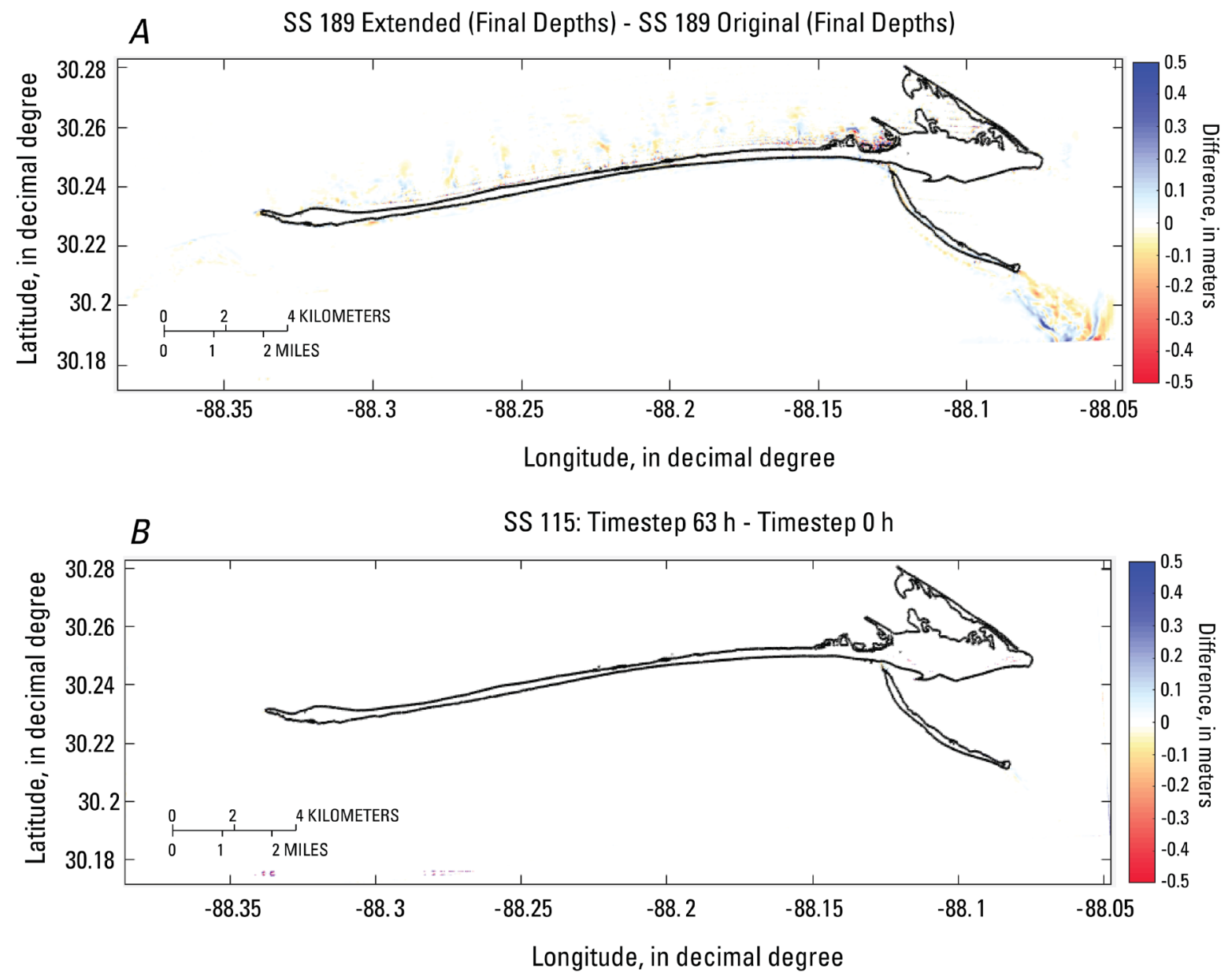

Figure 7. A, Difference between morphological change along Dauphin Island from extending the time series of SS 189 compared to not extending the time series (original). B, Difference between morphological change along Dauphin Island for SS 115 at timestep 63 hours (63 h) and the initial morphology at timestep 0 hours $(0 \mathrm{~h})$, note this panel has little differences between simulations.

Synthetic storms were also identified wherein small waves abruptly increased in wave height, sometimes increasing by roughly $1 \mathrm{~m}$ over less than 3 hours before normal storm rampup began. To examine if these abrupt changes in $\mathrm{H}_{\mathrm{s}}$ would have any effect on island morphology, synthetic storm 115 (SS 115) was simulated, which had an increase in $\mathrm{H}_{\mathrm{s}}$ of about $1 \mathrm{~m}$ over the course of 1 hour (fig. $6 B$ ) with $0 \mathrm{~m}$ waves in the first 28 hours (the first 28 hours were removed because XBeach requires some wave input greater than $0 \mathrm{~m}$ for simulation). This synthetic storm was also simulated on the pre-Hurricane Ivan DEM. The results of this simulation suggest that the abrupt increases in wave height do not have a substantial impact to predicted island morphology change (fig. $7 B$ ). 


\section{Conclusions}

To predict the decadal-scale evolution of barrier island systems, a coupled modeling framework was developed that combined individual model components for littoral alongshore transport (D3DMM), dune recovery (EDGR), and storm impacts (XBeach). The models were coupled in an "assembly line" fashion; the outputs from each model over a given time period were provided to the subsequent model as an initial condition. The model framework was calibrated and applied to hindcast the evolution of Dauphin Island, Alabama, over the period of 2004 to 2015. Simulated island evolution as represented by features such as Gulf-facing shoreline change, dune growth, and storm impacts were compared to observed data from multiple lidar surveys to evaluate model performance. Hindcast average errors (RMSE) for Gulf shoreline location, Sound shoreline location, dune location, and dune height were $59 \mathrm{~m}, 70 \mathrm{~m}, 76 \mathrm{~m}$, and $0.75 \mathrm{~m}$, respectively.

\section{References Cited}

Benedet, L., 2016, Process controlling beach nourishment performance at Delray Beach, Florida, USA: Delft, Netherlands, Ph.D. dissertation, Delft University of Technology, 189 p., accessed August 13, 2018, at https://doi.org/10.4233/uuid:aa444a96-7821-4244-ae6e-b2c28c008ef8.

Bilskie, M.V., Hagen, S.C., Medeiros, S.C., Cox, A.T., Salisbury, M., and Coggin D., 2016, Data and numerical analysis of astronomic tides, wind-waves, and hurricane storm surge along the northern Gulf of Mexico: Journal of Geophysical Research Oceans, v. 121, no. 5, p. 36253658, accessed November 2, 2018, at https://doi.org/10.1002/2015JC011400.

Brigham, E.O., 1998, The fast fourier transform and its applications: Upper Saddle River, New Jersey, Prentice-Hall, Inc., 448 p.

Deltares, 2019, Delft3D-FLOW simulation of multi-dimensional hydrodynamic flows and transport phenomena, including sediments [user manual version 3.15]: Deltares, The Netherlands, 682 p., accessed June 6, 2018, at https://content.oss.deltares.nl/delft3d/manuals/Delft3DFLOW_User_Manual.pdf.

Dietrich, J.C., Zijlema, M., Westerink, J.J., Hothuijsen, L.H., Dawson, C., Luettich, R.A., Jr., Jensen, R.E., Smith, J.M., Stelling, G.S., and Stone, G.W., 2011, Modeling hurricane waves and storm surge using integrally-coupled, scalable computations: Coastal Engineering, v. 58, no. 1, p. 45-65, accessed June 15, 2018, at https://doi.org/10.1016/j.coastaleng.2010.08.001.

Doran, K.S., Long, J.W., and Overbeck, J.R., 2015, A method for determining average beach slope and beach slope variability for U.S. sandy coastlines: U.S. Geological Survey OpenFile Report 2015-1053, 5 p., accessed May 15, 2018, available at https://doi.org/10.3133/ ofr20151053.

Doran, K.S., Long, J.W., Birchler, J.J., Brenner, O.T., Hardy, M.W., Morgan, K.L.M, Stockdon, H.F., and Torres, M.L., 2017, Lidar-derived beach morphology (dune crest, dune toe, and shoreline) for U.S. sandy coastlines: U.S. Geological Survey data release, accessed July 15, 2018, at https://doi.org/10.5066/F7GF0S0Z.

Douglas, S.L., 1994, Beach erosion and deposition on Dauphin Island, Alabama, U.S.A.: Journal of Coastal Research, v. 10, no. 2, p. 306-328, accessed April 25, 2019, at https://www.jstor.org/ stable/4298218. 
Dzwonkowski, B., and Park, K., 2010, Influence of wind stress and discharge on the mean and seasonal currents on the Alabama shelf of the northeastern Gulf of Mexico: Journal of Geophysical Research, v. 115, no. C12, p. 1-11, accessed June 10, 2017, at https://doi. org/10.1029/2010JC006449.

Enwright, N.M., Borchert, S.M., Day, R.H., Feher, L.C., Osland, M.J., Wang, L., and Wang, H., 2017, Barrier island habitat map and vegetation survey-Dauphin Island, Alabama, 2015: USGS Open-File Report 2017-1083, 17 p., accessed June 10, 2017, at https://doi.org/10.3133/ ofr20171083.

Federal Emergency Management Agency [FEMA], 2014, Comparisons of FEMA coastal model data with data from other coastal models and long-term tidal gauges: FEMA, 2 p., accessed August 18, 2018, at http://www.southeastcoastalmaps.com/PublicDocs/Fact\%20Sheet Comparisons $\% 20$ of $\% 20$ Coastal\%20Models $\% 20$ and $\% 20$ Gage $\% 20$ Analyses_Info $\% 20$ for $\% 20$ Engineers_Aug\%202014.pdf.

Froede, C.R., 2006, The impact that Hurricane Ivan (September 16, 2004) made across Dauphin Island, Alabama: Journal of Coastal Research, v. 22, no. 3, p. 561-573, accessed June 15, 2017, at https://doi.org/10.2112/05-0438.1.

Froede, C.R., 2008, Changes to Dauphin Island, Alabama, brought about by Hurricane Katrina (August 29, 2005): Journal of Coastal Research, v. 24, no. sp 3, p. 110-117, accessed August 21, 2015, at https://doi.org/10.2112/06-0782.1.

Froede, C.R., 2010, Constructed sand dunes on the developed barrier-spit portion of Dauphin Island, Alabama (U.S.A): Journal of Coastal Research, v. 264, p. 699-703, accessed August 27, 2015, at https://doi.org/10.2112/JCOASTRES-D-09-00028.1.

Gutiérrez de Velasco, G., and Winant, C.D., 1996, Seasonal patterns of wind stress and wind stress curl over the Gulf of Mexico: Journal of Geophysical Research, v. 101, no. C8, p. 18127-18140, accessed June 11, 2017, at https://doi.org/10.1029/96JC01442.

Houser, C., Wernette, P., Rentschlar, E., Jones, H., Hammond, B., and Trimble, S., 2015, Poststorm beach and dune recovery-Implications for barrier island resilience: Geomorphology, v. 234, p. 54-63, accessed June 6, 2017, at https://doi.org/10.1016/j.geomorph.2014.12.044. Hugenholtz, C.H., and Wolfe, S.A., 2005, Biogeomorphic model of dunefield activation and stabilization on the northern great plains: Geomorphology, v. 70, nos. 1-2, p. 53-70, accessed June 5, 2017, at https://doi.org/10.1016/j.geomorph.2005.03.011.

Jenkins, R.L., III, Long, J.W., Dalyander, P.S., Thompson, D.M., and Mickey, R.C., 2020, Development of a process-based littoral sediment transport model for Dauphin Island, Alabama: U.S. Geological Survey Open-File Report 2020-1011, 37 p. [Also available at https://doi. org/10.3133/ofr20201011.]

Lesser, G.R., 2009, An approach to medium-term coastal morphological modelling: Ph.D. dissertation, Delft, Netherlands, UNESCO-IHE and Delft Technical University, CRC Press/Balkema, Leiden, The Netherlands, 237 p., accessed August 13, 2018, at https://repository.tudelft.nl/ assets/uuid:62caa573-4fc0-428e-8768-0aa47ab612a9/PHD_THESIS_LESSER.pdf.

Lesser, G.R., Roelvink, J.A., van Kester, J.A.T.M., and Stelling, G.S., 2004, Development and validation of a three-dimensional morphological model: Coastal Engineering, v. 51, nos. 8-9, p. 883-915, accessed May 20, 2017, at https://doi.org/10.1016/j.coastaleng.2004.07.014. 
Lindemer, C.A., Plant, N.G., Puleo, J.A., Thompson, D.M., and Wamsley, T.V., 2010, Numerical simulation of a low-lying barrier island's morphological response to Hurricane Katrina: Coastal Engineering, v. 57, nos. 11-12, p. 985-995, accessed January 4, 2017, at https://doi. org/10.1016/j.coastaleng.2010.06.004.

Luettich, R.A., Jr., Westerink, J.J., and Scheffner, N.W., 1992, ADCIRC; An advanced three-dimensional circulation model for shelves, coasts, and estuaries; Report 1-Theory and methodology of ADCIRC-2DDI and ADCIRC-3DL: Coastal Engineering Research Center, Vicksburg, Miss., and U.S. Army Corps of Engineers, Technical Report DRP-92-6, accessed November 30, 2016, at https://apps.dtic.mil/docs/citations/ADA261608.

Martinez, M.L., Feagin, R.A., Yeager, K.M., Day, J., Costanza, R., Harris, J.A., Hobbs, R.J., Lopez-Portillo, J., Walker, I.J., Higgs, E., Moreno-Casasola, P., Sheinbaum, J., and YanezArancibia, A., 2011, Artificial modifications of the coast in response to the Deepwater Horizon oil spill-quick solutions or long-term liabilities?: Frontiers in Ecology and the Environment, v. 10, no. 1, p. 44-49, accessed April 25, 2019, at https://doi.org/10.1890/100151.

McCall, R.T., Van Thiel de Vries, J.S.M., Plant, N.G., Van Dongeren, A.R., Roelvink, J.A., Thompson, D.M., and Reniers, A.J.H.M., 2010, Two-dimensional time dependent hurricane overwash and erosion modeling at Santa Rosa Island: Coastal Engineering, v. 57, no. 7, p. 668-683, accessed September 8, 2016, at https://doi.org/10.1016/j.coastaleng.2010.02.006. Mickey, R.C., Long, J.W., Plant, N.G., Thompson, D.M., and Dalyander, P.S., 2017, A methodology for modeling barrier island storm-impact scenarios: U.S. Geological Survey Open-File Report 2017-1009, 17 p., accessed March 3, 2018, at https://doi.org/10.3133/ofr20171009.

Morton, R., Miller, T., and Moore, L., 2004, National assessment of shoreline change-Part 1; Historical shoreline changes and associated coastal land loss along the U.S. Gulf of Mexico: U.S. Geological Survey Open-File Report 2004-1043, 43 p., accessed June 20, 2017, at https:// doi.org/10.3133/ofr20041043.

Morton, R.A., 2008, Historical changes in the Mississippi-Alabama barrier-island chain and the roles of extreme storms, sea level, and human activities: Journal of Coastal Research, v. 24, no. 6, p. 1587-1600, accessed June 15, 2017, at https://doi.org/10.2112/07-0953.1.

Nadal-Caraballo, N.C., Melby, J.A., Gonzalez, V.M., and Cox, A.T., 2015, North Atlantic Coast Comprehensive Study (NACCS)-Coastal storm hazards from Virginia to Maine: U.S. Army Corps of Engineers [ERDC/CHL TR-15-5221], 221 p., accessed April 27, 2016, at https:// apps.dtic.mil/docs/citations/ADA627157.

National Oceanic and Atmospheric Administration, Hurricane Research Division, 2014, HURDAT; Re-analysis project data: National Oceanic and Atmospheric Administration, Hurricane Research Division web page, accessed January 23, 2018, at www.aoml.noaa.gov/hrd/hurdat/ Data_Storm.html.

Niedoroda, A.W., Resio, D.T., Toro, G.R., Divoky, D., Das, H.S., and Reed, C.W., 2010, Analysis of the coastal Mississippi storm surge hazard: Ocean Engineering, v. 37, no. 1, p. 82-90, accessed June 6, 2017, at https://doi.org/10.1016/j.oceaneng.2009.08.019.

Passeri, D.L., Long, J.W., Plant, N.G., Bilskie, M.V., and Hagen, S.C., 2018, The influence of bed friction variability due to land cover on storm-driven barrier island morphodynamics: Coastal Engineering, v. 132, p. 82-94, accessed July 16, 2018, at https://doi. org/10.1016/j.coastaleng.2017.11.005. 
Roelvink, D., Reniers, A., van Dongeren, A., Van Thiel de Vries, J., McCall, R., and Lescinski, J., 2009, Modelling storm impacts on beaches, dunes and barrier islands: Coastal Engineering, v. 56, nos. 11-12, p. 1133-1152, accessed December 15, 2015, at https://doi. org/10.1016/j.coastaleng.2009.08.006.

Sallenger, A.H., 2000, Storm impact scale for barrier islands: Journal of Coastal Research, v. 16, no. 3, p. 890-895, accessed September 15, 2016, at http://coastal.er.usgs.gov/hurricanes/ publications/jcr.pdf.

Sherwood, C.R., Long, J.W., Dickhudt, P.J., Dalyander, P.S., Thompson, D.M., and Plant, N.G., 2014, Inundation of a barrier island (Chandeleur Islands, Louisiana, USA) during a hurricane-Observed water-level gradients and modeled seaward sand transport: Journal of Geophysical Research Earth Surface, v. 119, no. 7, p. 1498-1515, accessed June 15, 2016, at https://doi.org/10.1002/2013JF003069.

Slinn, D., 2008, Wave setup methodology for the FEMA Mississippi Flood Study: Federal Emergency Management Agency [FEMA] report, 51 p., accessed August 17, 2017, at https://www. fema.gov/media-library/assets/documents/17503.

Stockdon, H.F., Holman, R.A., Howd, P.A., and Sallenger, A.H., 2006, Empirical parameterization of setup, swash, and runup: Coastal Engineering, v. 53, no. 7, p. 573-588, accessed January 26, 2017, at https://doi.org/10.1016/j.coastaleng.2005.12.005.

Thompson, D.M., Dalyander, P.S., Long, J.W., and Plant, N.G., 2017, Correction of elevation offsets in multiple co-located lidar datasets: U.S. Geological Survey Open-File Report 20171031, 10 p., accessed July 16, 2018, at https://doi.org/10.3133/ofr20171031.

Toro, G.R., Resio, D.T., Divoky, D., Niedoroda, A.W., and Reed, C., 2010, Efficient jointprobability methods for hurricane surge frequency analysis: Ocean Engineering, v. 37, no. 1, p. 125-134, accessed August 17, 2017, at https://doi.org/10.1016/j.oceaneng.2009.09.004. Walstra, D.J.R, deVroeg, J.H., Van Thiel de Vries, J.S.M., Swinkels, C., Luijendijk, A.P., de Boer, W.P., Hoekstra, R., Hoonhout, B., Henrotte, J., Smolders, T., Dekker, F., and Godsey, E., 2012, A comprehensive sediment budget for the Mississippi Barrier Islands, in Lynett, P., and Smith, J.M., eds., Proceedings of the 33rd International Conference on Coastal Engineering: Santander, Spain, July 1-6, 2012, International Conference on Coastal Engineering, New York, no. 33, p. 1619-1633, accessed February 28, 2017, at https://journals.tdl.org/icce/index.php/ icce/article/view/6638.

Watkins, A.D., 2011, A synthesis of Alabama beach states and nourishment histories: M.S. thesis, Tuscaloosa, Alabama, University of Alabama, 76 p., accessed June 25, 2017, at http://acumen. lib.ua.edu/u0015/0000001/0000723/u0015_0000001_0000723.pdf.

Weber, K.M., List, J.H., and Morgan, K.L.M., 2005, An operational mean high water datum for determination of shoreline position from topographic lidar data: U.S. Geological Survey OpenFile Report 2005-1027, accessed March 13, 2018, at https://pubs.usgs.gov/ofr/2005/1027/. 


\section{Appendix 1. Comparison of Model and Lidar Data}
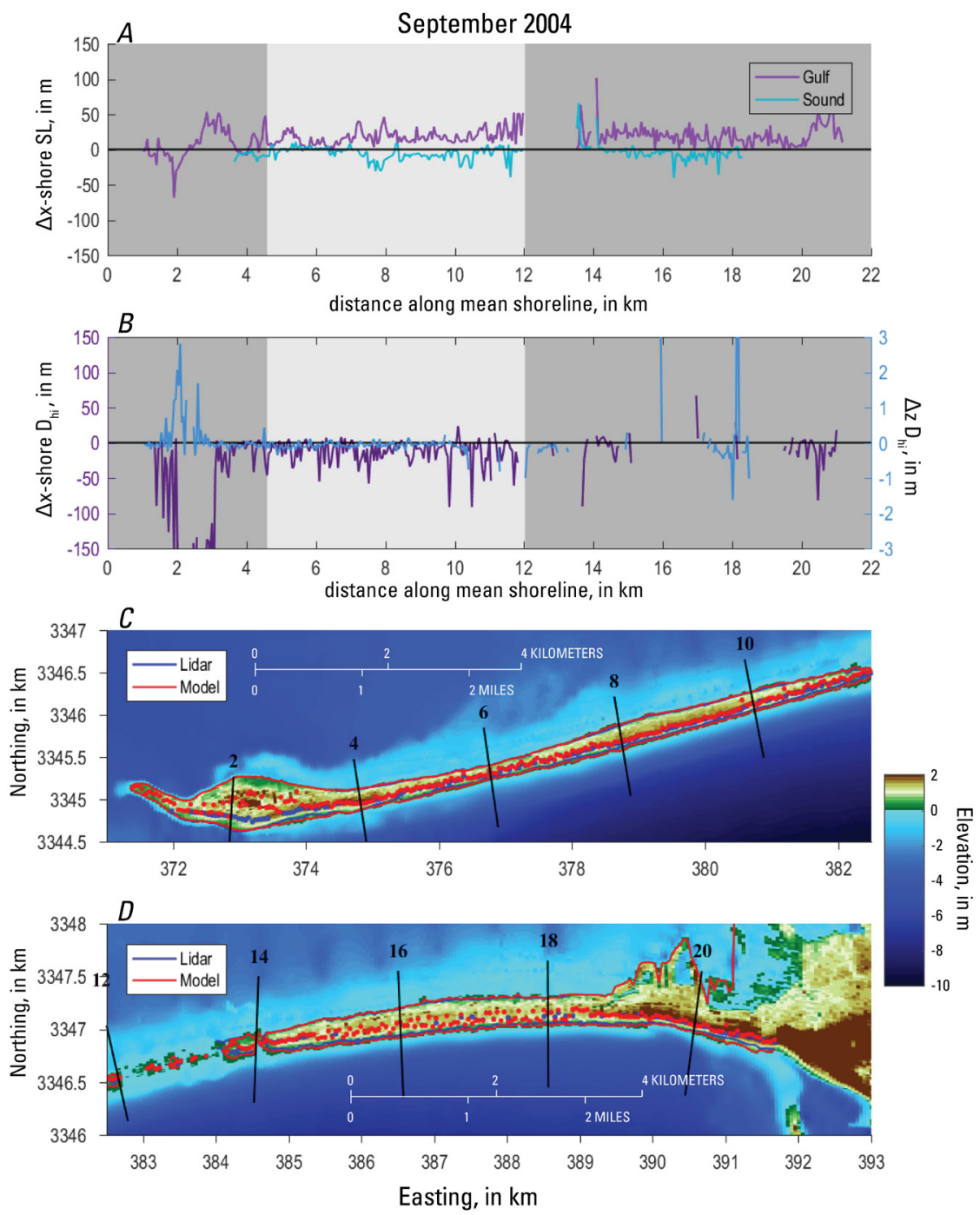

Figure 1-1. Comparison of initial September 2004 DEM with September 2004 lidar survey. A, Difference between model and lidar shoreline (SL) cross-shore location (Gulf shoreline: purple line; Sound shoreline: blue line). Lightly shaded area indicates alongshore location area where shoreline and dune statistics were calculated. $B$, Difference between model and lidar cross-shore $D_{h i}$ location ( $\Delta x$-shore $D_{\text {hi }}$ purple line) and difference between model and lidar cross-shore $D_{h i}$ elevation $\left(\Delta z D_{h i}\right.$, blue line). $C$, Western portion of Dauphin Island with location of model shoreline and $D_{h i}$ locations (red line and red dot, respectively); and location of lidar shoreline and $\mathrm{D}_{\text {hi }}$ locations (blue line and blue dot, respectively); black transect lines indicate distance (in kilometers) alongshore with respect to the x-axis in $A$ and $B$. $D$, Eastern portion of Dauphin Island with location of model shoreline and $D_{\text {hi }}$ locations (red line and red dot, respectively); and location of lidar shoreline and $D_{\text {hi }}$ locations (blue line and blue dot, respectively); black transect lines indicate distance (in kilometers) alongshore with respect to the $\mathrm{x}$-axis in $A$ and $B$. Abbreviations: DEM, digital elevation model; $\mathrm{km}$, kilometers; lidar, light detection and ranging; $m$, meters; SL, shoreline. 

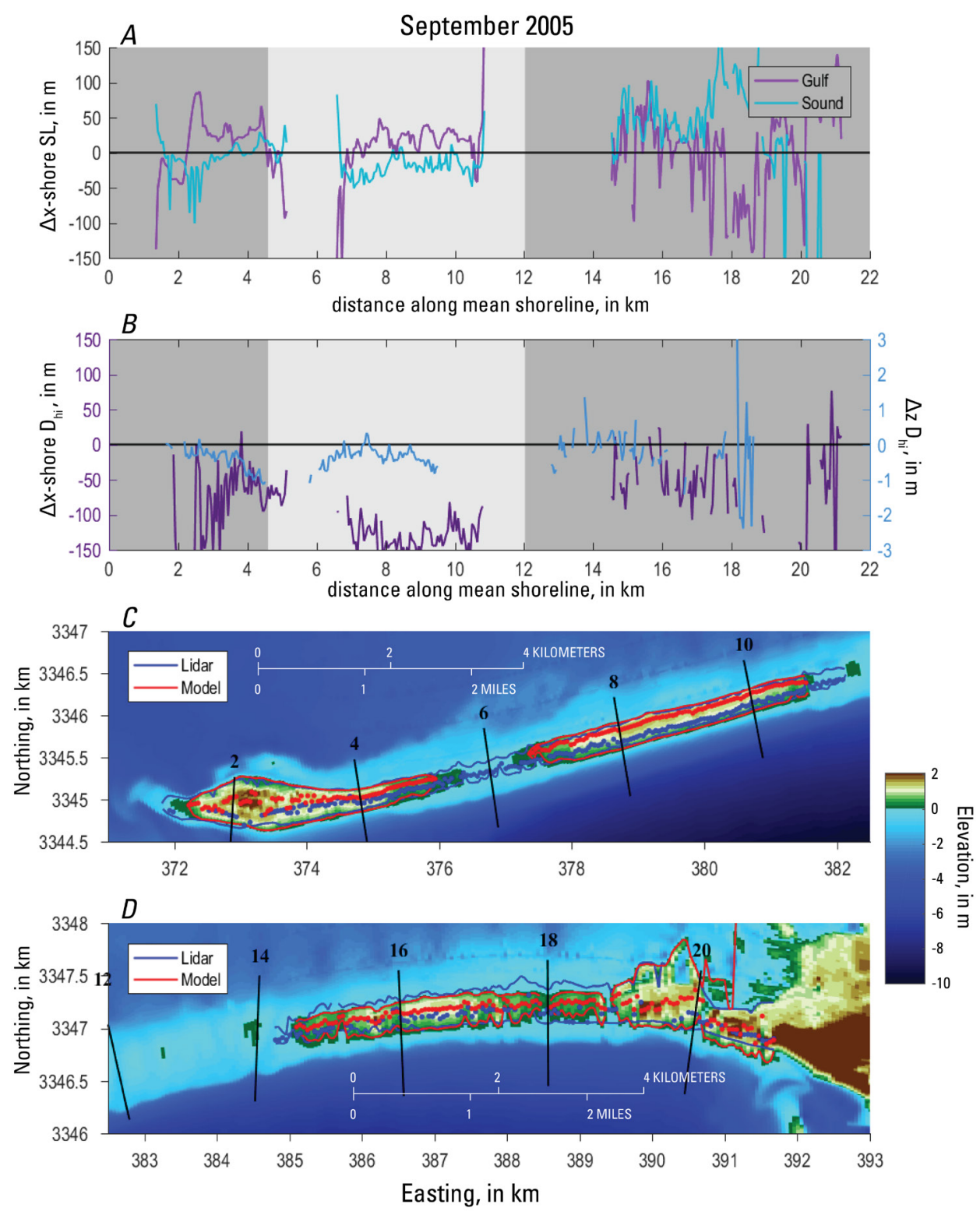

Figure 1-2. Comparison of September 2005 model DEM with September 2005 lidar survey (post-Hurricane Katrina). A, Difference between model and lidar shoreline (SL) cross-shore location (Gulf shoreline: purple line; Sound shoreline: blue line). Lightly shaded area indicates alongshore location area where shoreline and dune statistics were calculated. $B$, Difference between model and lidar cross-shore $D_{h i}$ location ( $\Delta x$-shore $D_{h i}$ purple line) and difference between model and lidar cross-shore $D_{h i}$ elevation $\left(\Delta z D_{h i}\right.$ blue line). $C$, Western portion of Dauphin Island with location of model shoreline and $D_{h i}$ locations (red line and red dot, respectively); and location of lidar shoreline and $\mathrm{D}_{\mathrm{hi}}$ locations (blue line and blue dot, respectively); black transect lines indicate distance (in kilometers) alongshore with respect to the x-axis in $A$ and B. D, Eastern portion of Dauphin Island with location of model shoreline and $D_{\mathrm{hi}}$ locations (red line and red dot, respectively); and location of lidar shoreline and $\mathrm{D}_{\mathrm{hi}}$ locations (blue line and blue dot, respectively); black transect lines indicate distance (in kilometers) alongshore with respect to the $x$-axis in $A$ and $B$. Abbreviations: DEM, digital elevation model; km, kilometers; lidar, light detection and ranging; m, meters; SL, shoreline. 

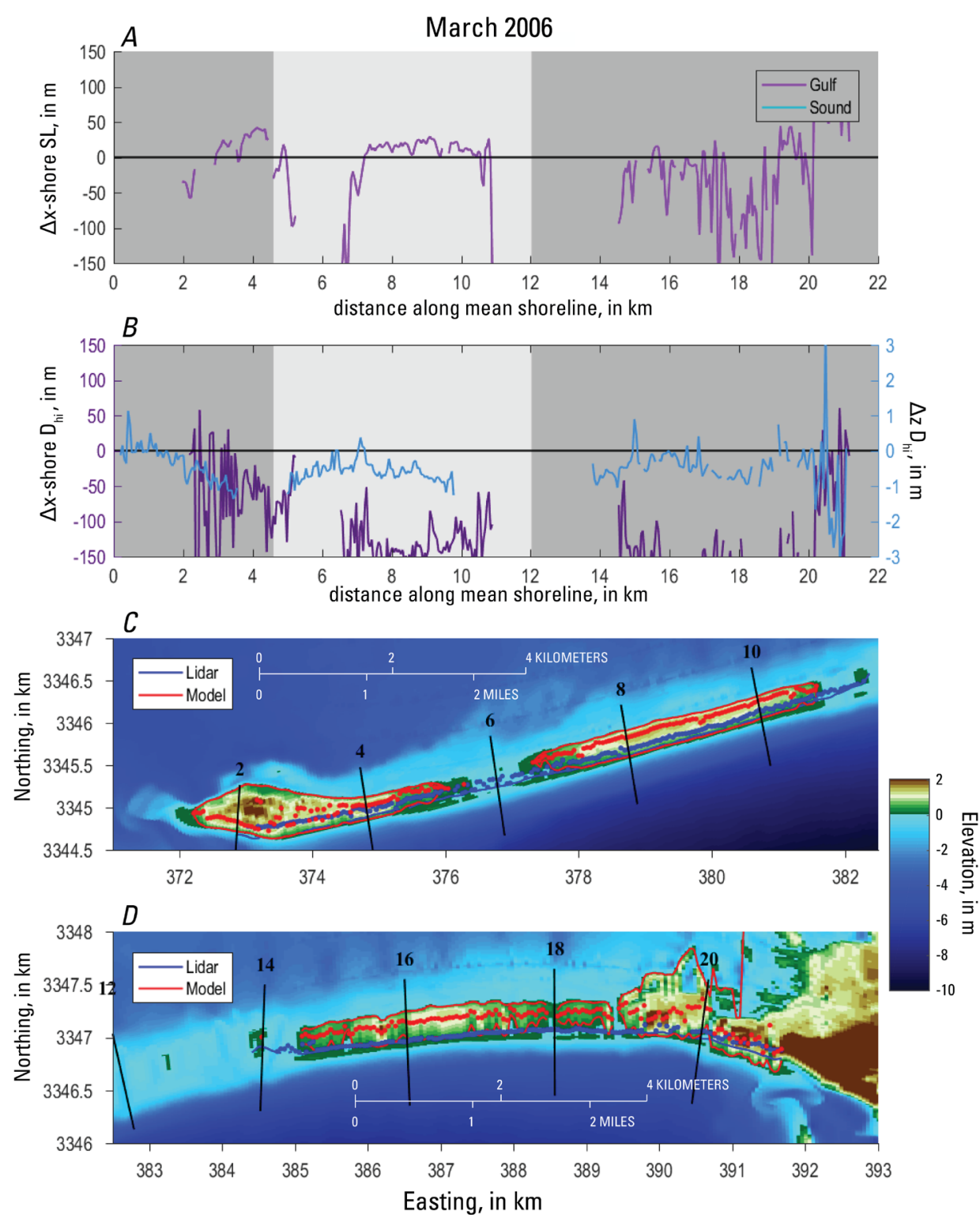

Figure 1-3. Comparison of March 2006 DEM with March 2006 lidar survey. A, Difference between model and lidar shoreline (SL) cross-shore location (Gulf shoreline: purple line). Lightly shaded area indicates alongshore location area where shoreline and dune statistics were calculated. Note that the "Sound shoreline" data were unavailable for this lidar survey, so a comparison could not be made to the Sound-side shoreline from the hindcast. $B$, Difference between model and lidar cross-shore $D_{\text {hi }}$ location $\left(\Delta x\right.$-shore $D_{\text {hi }}$ purple line) and difference between model and lidar cross-shore $D_{h i}$ elevation ( $\Delta z D_{h i}$, blue line). $C$, Western portion of Dauphin Island with location of model shoreline and $\mathrm{D}_{\mathrm{hi}}$ locations (red line and red dot, respectively); and location of lidar shoreline and $D_{\text {hi }}$ locations (blue line and blue dot, respectively); black transect lines indicate distance (in kilometers) alongshore with respect to the $\mathrm{x}$-axis in $A$ and $B$. D. Eastern portion of Dauphin Island with location of model shoreline and $\mathrm{D}_{\mathrm{hi}}$ locations (red line and red dot, respectively); and location of lidar shoreline and $D_{\text {hi }}$ locations (blue line and blue dot, respectively); black transect lines indicate distance (in kilometers) alongshore with respect to the $\mathrm{x}$-axis in $A$ and $B$. Abbreviations: DEM, digital elevation model; km, kilometers; lidar, light detection and ranging; $m$, meters; $S L$, shoreline. 

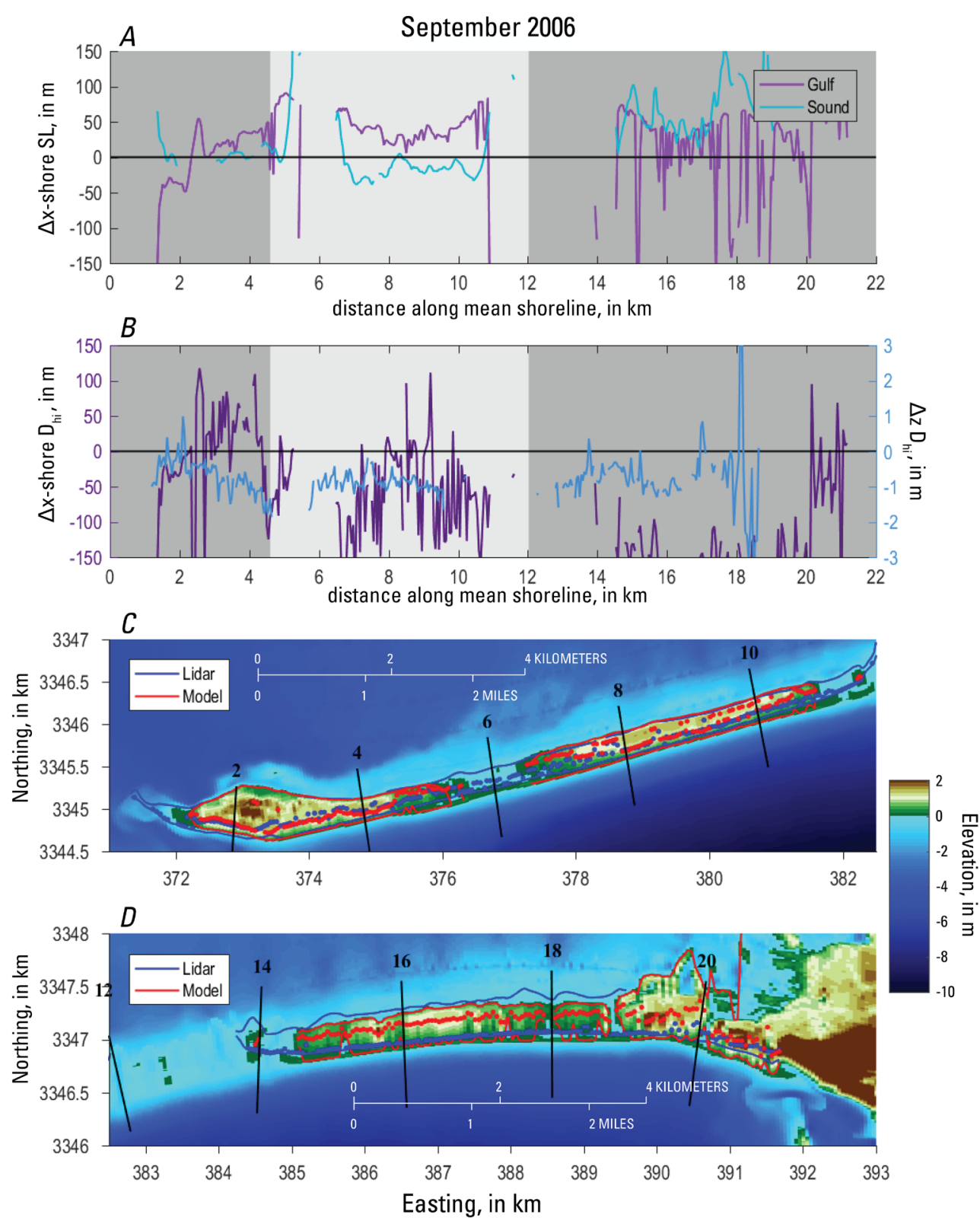

Figure 1-4. Comparison of September 2006 model DEM with September 2006 lidar survey. A, Difference between model and lidar shoreline (SL) cross-shore location (Gulf shoreline: purple line; Sound shoreline: blue line). Lightly shaded area indicates alongshore location area where shoreline and dune statistics were calculated. $B$, Difference between model and lidar cross-shore $D_{\text {hi }}$ location $\left(\Delta x\right.$-shore $D_{\text {hi }}$ purple line) and difference between model and lidar cross-shore $D_{h i}$ elevation $\left(\Delta z D_{h i,}\right.$, blue line). $C$, Western portion of Dauphin Island with location of model shoreline and $\mathrm{D}_{\mathrm{hi}}$ locations (red line and red dot, respectively); and location of lidar shoreline and $\mathrm{D}_{\mathrm{hi}}$ locations (blue line and blue dot, respectively); black transect lines indicate distance (in kilometers) alongshore with respect to the x-axis in $A$ and $B$. D, Eastern portion of Dauphin Island with location of model shoreline and $D_{\text {hi }}$ locations (red line and red dot, respectively); and location of lidar shoreline and $\mathrm{D}_{\mathrm{hi}}$ locations (blue line and blue dot, respectively); black transect lines indicate distance (in kilometers) alongshore with respect to the $\mathrm{x}$-axis in $A$ and $B$. Abbreviations: DEM, digital elevation model; $\mathrm{km}$, kilometers; lidar, light detection and ranging; $m$, meters; SL, shoreline. 

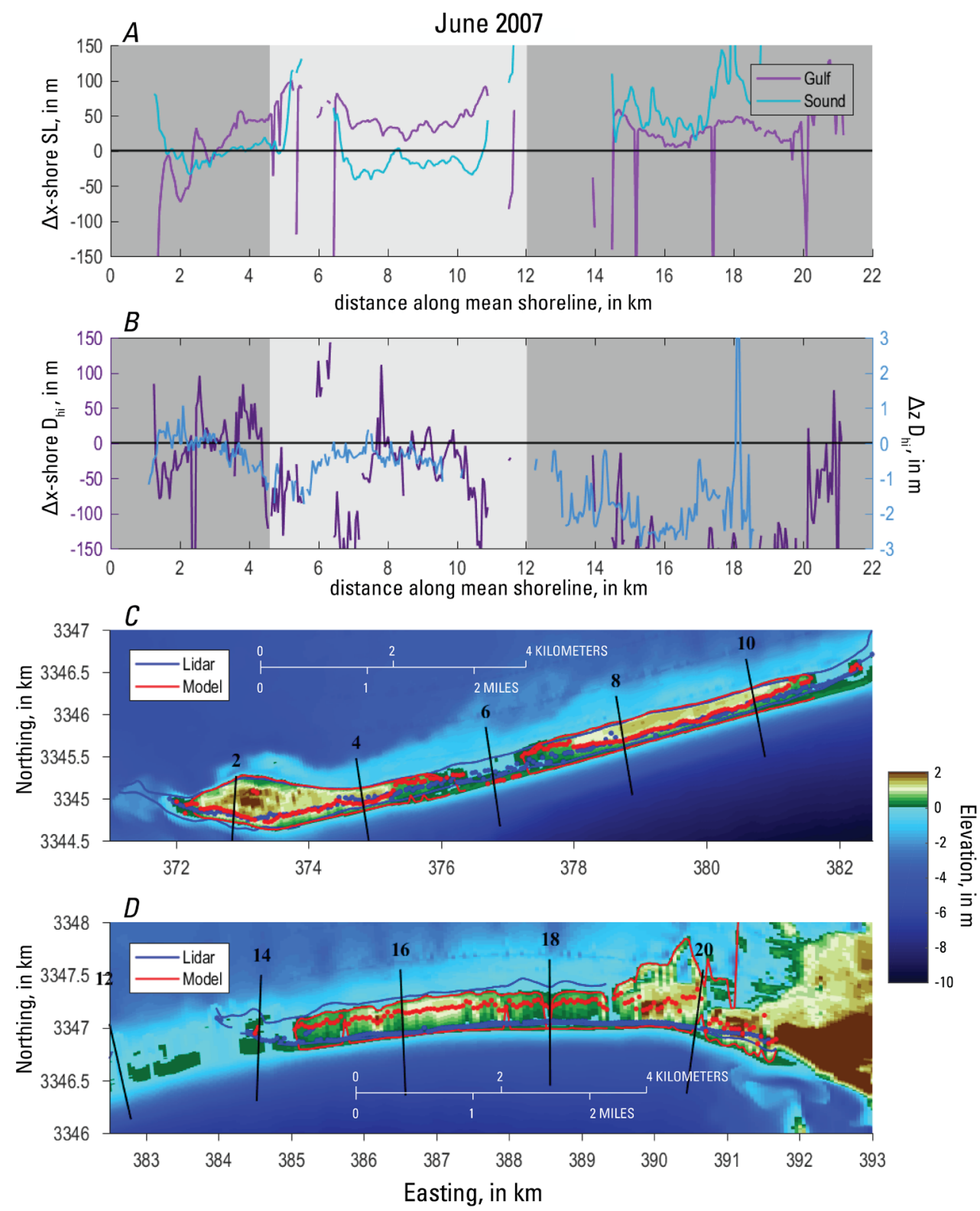

Figure 1-5. Comparison of June 2007 model DEM with June 2007 lidar survey. A, Difference between model and lidar shoreline (SL) cross-shore location (Gulf shoreline: purple line; Sound shoreline: blue line). Lightly shaded area indicates alongshore location area where shoreline and dune statistics were calculated. $B$, Difference between model and lidar cross-shore $D_{\mathrm{hi}}$ location $\left(\Delta x\right.$-shore $D_{\text {hi }}$ purple line) and difference between model and lidar cross-shore $D_{\text {hi }}$ elevation $\left(\Delta z D_{\text {hi }}\right.$ blue line). $C$, Western portion of Dauphin Island with location of model shoreline and $\mathrm{D}_{\mathrm{hi}}$ locations (red line and red dot, respectively); and location of lidar shoreline and $D_{\text {hi }}$ locations (blue line and blue dot, respectively); black transect lines indicate distance (in kilometers) alongshore with respect to the $\mathrm{x}$-axis in $A$ and $B$. D. Eastern portion of Dauphin Island with location of model shoreline and $D_{h i}$ locations (red line and red dot, respectively); and location of lidar shoreline and $D_{h i}$ locations (blue line and blue dot, respectively); black transect lines indicate distance (in kilometers) alongshore with respect to the $x$-axis in $A$ and $B$. Abbreviations: DEM, digital elevation model; $\mathrm{km}$, kilometers; lidar, light detection and ranging; $m$, meters; SL, shoreline. 

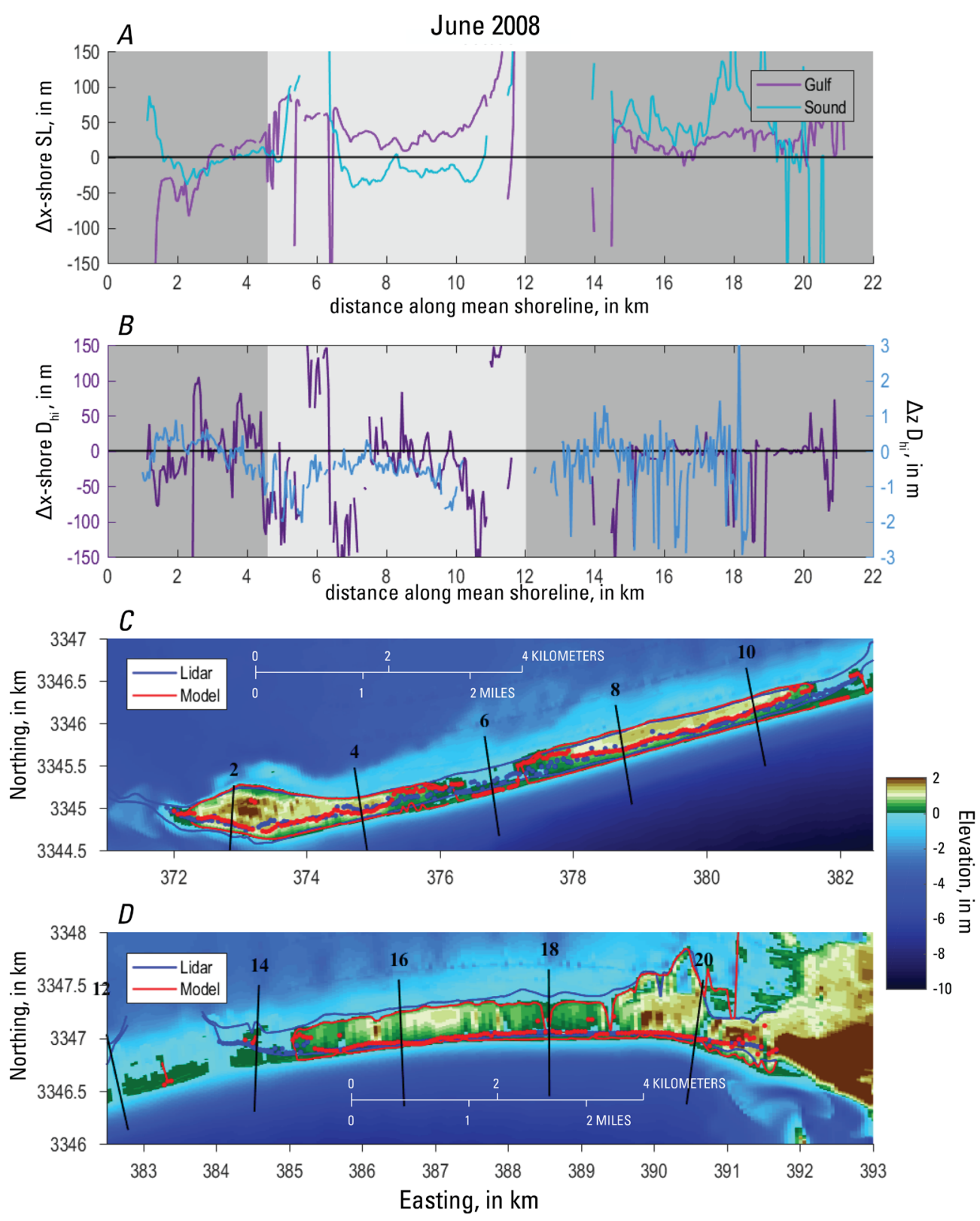

Figure 1-6. Comparison of June 2008 model DEM with June 2008 lidar survey. A, Difference between model and lidar shoreline (SL) cross-shore location (Gulf shoreline: purple line; Sound shoreline: blue line). Lightly shaded area indicates alongshore location area where shoreline and dune statistics were calculated. $B$, Difference between model and lidar cross-shore $D_{\mathrm{hi}}$ location $\left(\Delta x\right.$-shore $D_{\text {hi }}$ purple line) and difference between model and lidar cross-shore $D_{\text {hi }}$ elevation $\left(\Delta z D_{\text {hi }}\right.$ blue line). $C$, Western portion of Dauphin Island with location of model shoreline and $\mathrm{D}_{\mathrm{hi}}$ locations (red line and red dot, respectively); and location of lidar shoreline and $D_{\text {hi }}$ locations (blue line and blue dot, respectively); black transect lines indicate distance (in kilometers) alongshore with respect to the $\mathrm{x}$-axis in $A$ and $B$. D. Eastern portion of Dauphin Island with location of model shoreline and $D_{h i}$ locations (red line and red dot, respectively); and location of lidar shoreline and $D_{h i}$ locations (blue line and blue dot, respectively); black transect lines indicate distance (in kilometers) alongshore with respect to the $x$-axis in $A$ and $B$. Abbreviations: DEM, digital elevation model; km, kilometers; lidar, light detection and ranging; $m$, meters; SL, shoreline. 

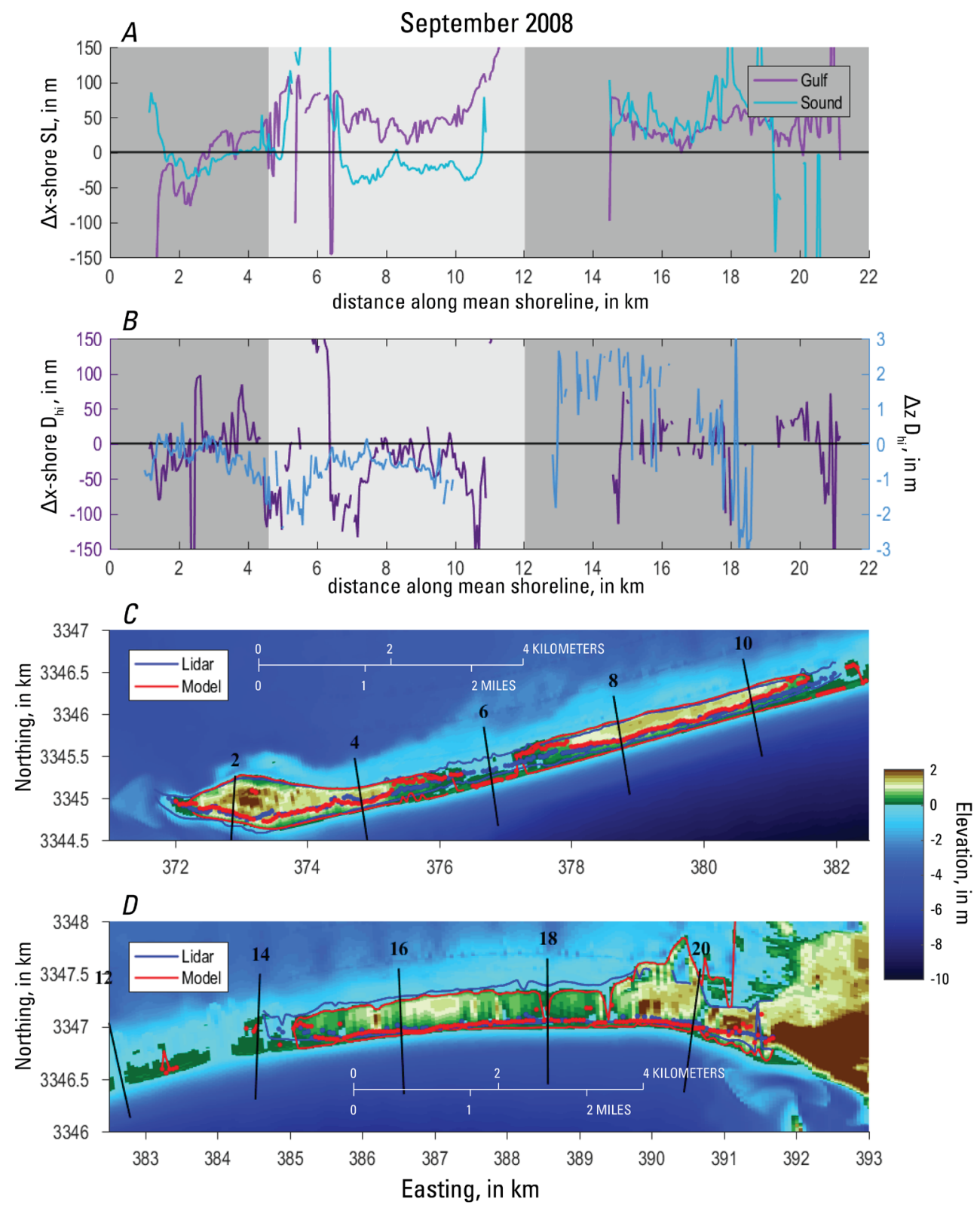

Figure 1-7. Comparison of September 2008 model DEM with September 2008 lidar survey. A, Difference between model and lidar shoreline (SL) cross-shore location (Gulf shoreline: purple line; Sound shoreline: blue line). Lightly shaded area indicates alongshore location area where shoreline and dune statistics were calculated. $B$, Difference between model and lidar cross-shore $D_{\text {hi }}$ location $\left(\Delta x\right.$-shore $D_{\text {hi }}$ purple line) and difference between model and lidar cross-shore $D_{\text {hi }}$ elevation $\left(\Delta z D_{\text {hi }}\right.$ blue line). $C$, Western portion of Dauphin Island with location of model shoreline and $\mathrm{D}_{\mathrm{hi}}$ locations (red line and red dot, respectively); and location of lidar shoreline and $\mathrm{D}_{\mathrm{hi}}$ locations (blue line and blue dot, respectively); black transect lines indicate distance (in kilometers) alongshore with respect to the $\mathrm{x}$-axis in $A$ and $B$. D, Eastern portion of Dauphin Island with location of model shoreline and $D_{\text {hi }}$ locations (red line and red dot, respectively); and location of lidar shoreline and $D_{h i}$ locations (blue line and blue dot, respectively); black transect lines indicate distance (in kilometers) alongshore with respect to the $\mathrm{x}$-axis in $A$ and $B$. Abbreviations: DEM, digital elevation model; $\mathrm{km}$, kilometers; lidar, light detection and ranging; $m$, meters; SL, shoreline. 

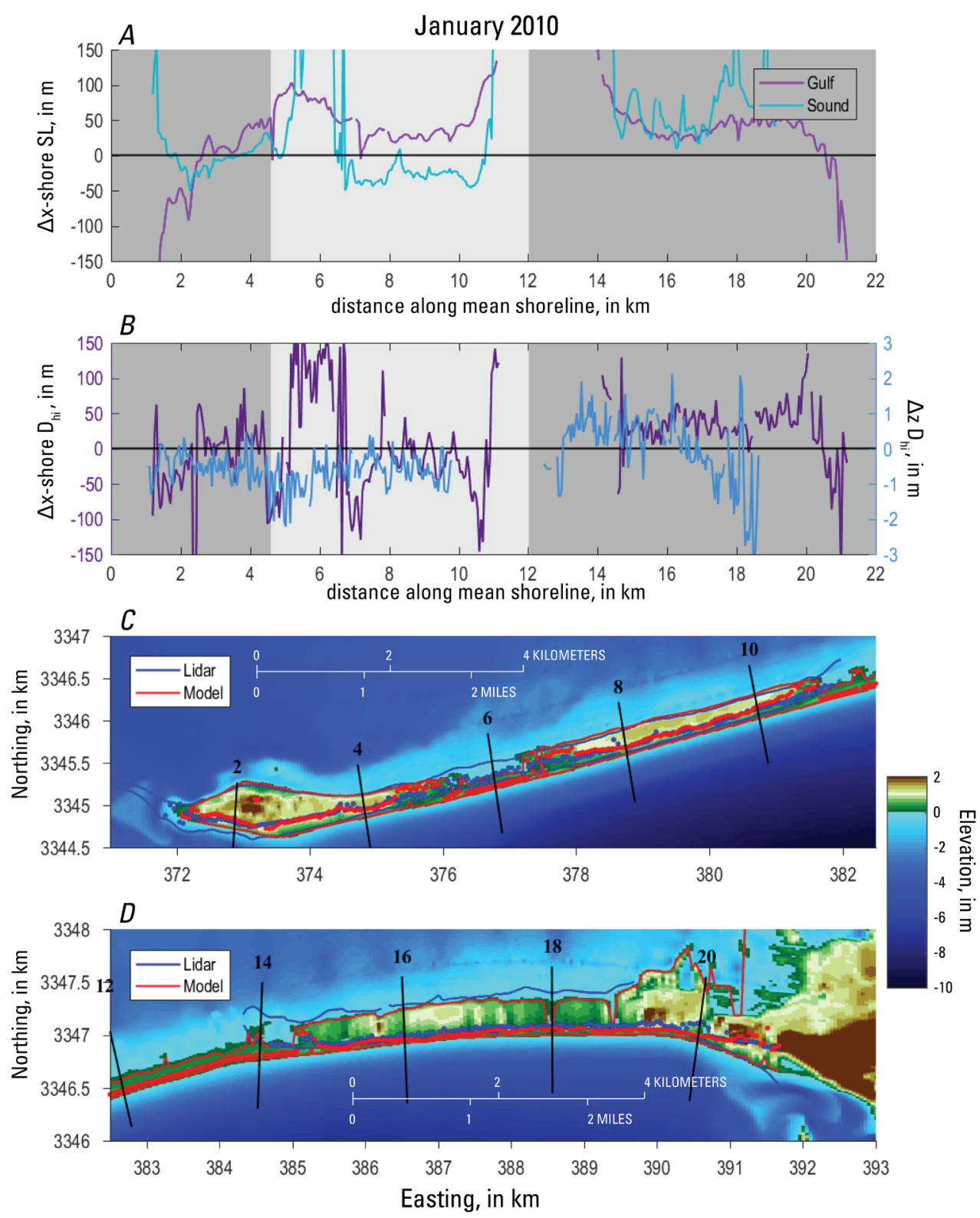

Figure 1-8. Comparison of January 2010 model DEM with January 2010 (post-Hurricane Ida) lidar survey. $A$, Difference between model and lidar shoreline (SL) cross-shore location (Gulf shoreline: purple line; Sound shoreline: blue line). Lightly shaded area indicates alongshore location area where shoreline and dune statistics were calculated. $B$, Difference between model and lidar cross-shore $D_{\mathrm{hi}}$ location $\left(\Delta x\right.$-shore $D_{\text {hi }}$ purple line) and difference between model and lidar cross-shore $D_{h i}$ elevation ( $\Delta z D_{\text {hi }}$ blue line). $C$, Western portion of Dauphin Island with location of model shoreline and $D_{\text {hi }}$ locations (red line and red dot, respectively); and location of lidar shoreline and $D_{\text {hi }}$ locations (blue line and blue dot, respectively); black transect lines indicate distance (in kilometers) alongshore with respect to the $\mathrm{x}$-axis in $A$ and $B$. D. Eastern portion of Dauphin Island with location of model shoreline and $\mathrm{D}_{\mathrm{hi}}$ locations (red line and red dot, respectively); and location of lidar shoreline and $D_{\text {hi }}$ locations (blue line and blue dot, respectively); black transect lines indicate distance (in kilometers) alongshore with respect to the $\mathrm{x}$-axis in $A$ and $B$. Abbreviations: DEM, digital elevation model; $\mathrm{km}$, kilometers; lidar, light detection and ranging; $\mathrm{m}$, meters; SL, shoreline. 

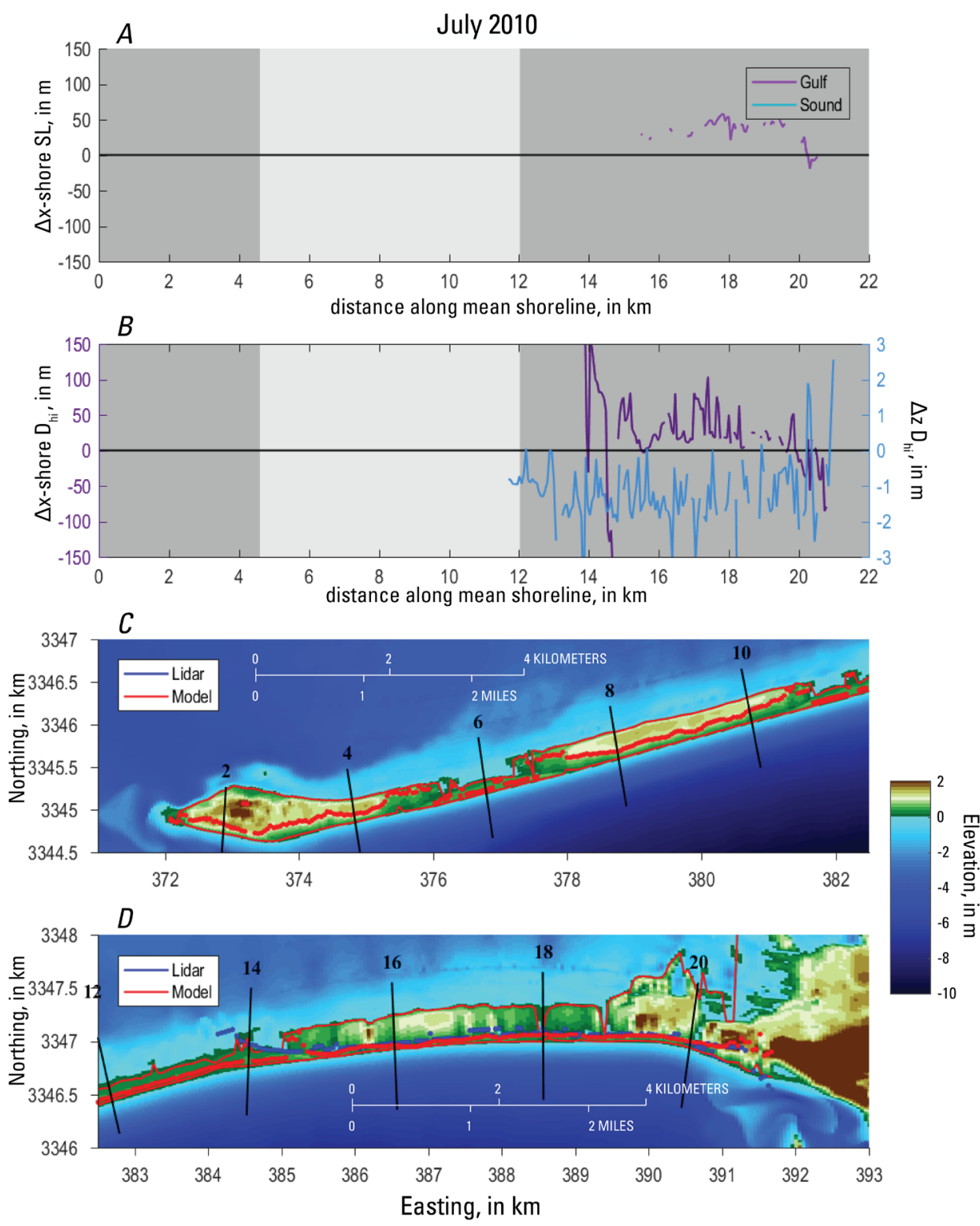

Figure 1-9. Comparison of July 2010 model DEM with July 2010 lidar survey. A, Difference between model and lidar shoreline (SL) cross-shore location (Gulf shoreline: purple line). Lightly shaded area indicates alongshore location area where shoreline and dune statistics were calculated. Note that the "Sound shoreline" data were unavailable for this lidar survey, so a comparison could not be made to the Sound-side shoreline from the hindcast. $B$, Difference between model and lidar cross-shore $D_{\text {hi }}$ location $\left(\Delta x\right.$-shore $D_{h i}$, purple line) and difference between model and lidar cross-shore $D_{h \mathrm{~h}}$ elevation ( $\Delta z \mathrm{D}_{\mathrm{hi}}$, blue line). $C$, Western portion of Dauphin Island with location of model shoreline and $D_{h i}$ locations (red line and red dot, respectively); and location of lidar shoreline and $\mathrm{D}_{\mathrm{hi}}$ locations (blue line and blue dot, respectively); black transect lines indicate distance (in kilometers) alongshore with respect to the x-axis in $A$ and $B$. $D$, Eastern portion of Dauphin Island with location of model shoreline and $\mathrm{D}_{\mathrm{hi}}$ locations (red line and red dot, respectively); and location of lidar shoreline and $D_{\text {hi }}$ locations (blue line and blue dot, respectively); black transect lines indicate distance (in kilometers) alongshore with respect to the $x$-axis in $A$ and $B$. Abbreviations: DEM, digital elevation model; km, kilometers; lidar, light detection and ranging; $m$, meters; SL, shoreline. 

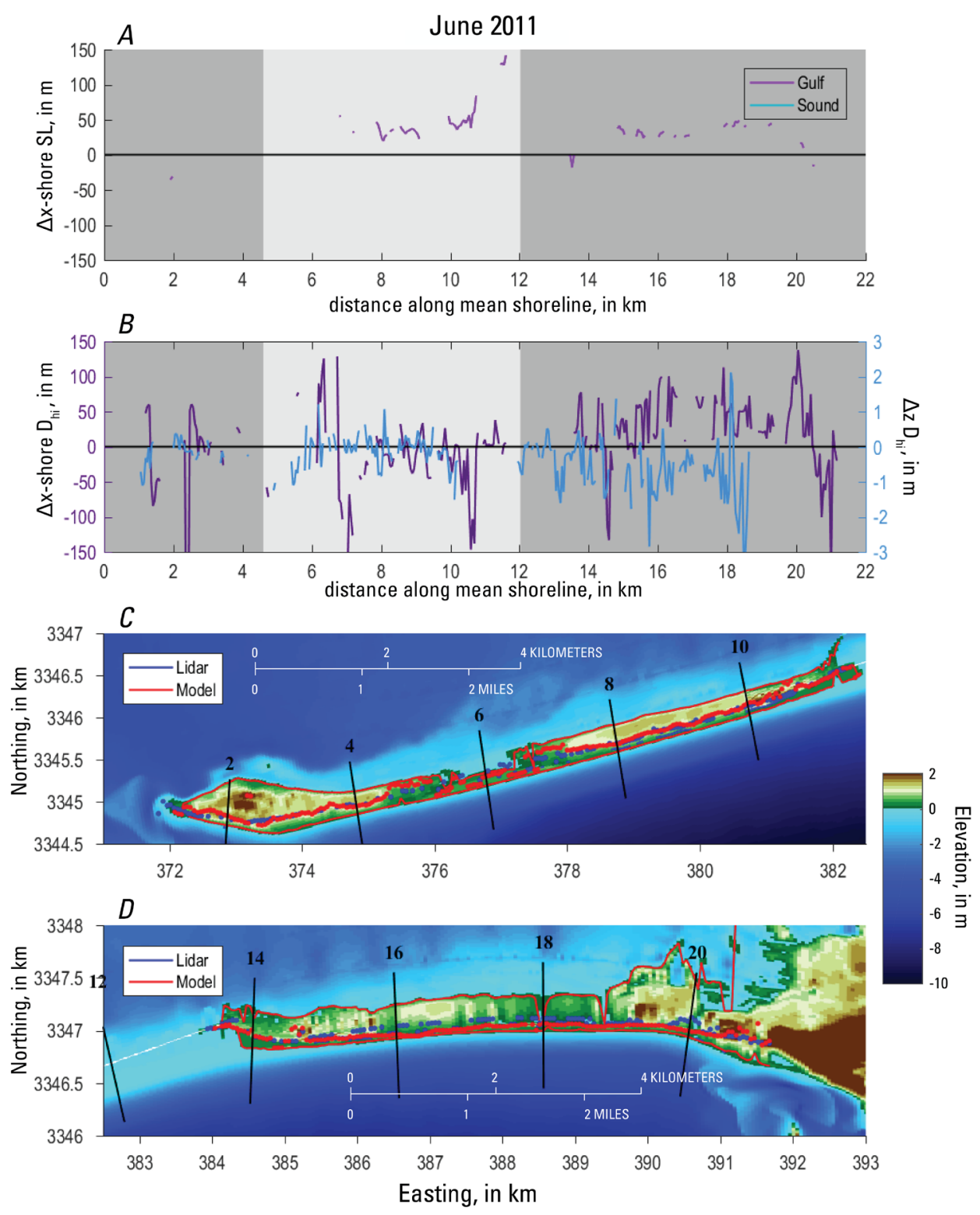

Figure 1-10. Comparison of June 2011 model DEM with June 2011 lidar survey. A, Difference between model and lidar shoreline (SL) cross-shore location (Gulf shoreline: purple line). Lightly shaded area indicates alongshore location area where shoreline and dune statistics were calculated. Note that the "Sound shoreline" data were unavailable for this lidar survey, so a comparison could not be made to the Sound-side shoreline from the hindcast. $B$, Difference between model and lidar cross-shore $D_{\text {hi }}$ location $\left(\Delta x\right.$-shore $D_{h i}$, purple line) and difference between model and lidar cross-shore $D_{h \mathrm{~h}}$ elevation ( $\Delta z \mathrm{D}_{\mathrm{hi}}$, blue line). $C$, Western portion of Dauphin Island with location of model shoreline and $D_{h i}$ locations (red line and red dot, respectively); and location of lidar shoreline and $\mathrm{D}_{\mathrm{hi}}$ locations (blue line and blue dot, respectively); black transect lines indicate distance (in kilometers) alongshore with respect to the x-axis in $A$ and $B$. $D$, Eastern portion of Dauphin Island with location of model shoreline and $\mathrm{D}_{\mathrm{hi}}$ locations (red line and red dot, respectively); and location of lidar shoreline and $D_{\text {hi }}$ locations (blue line and blue dot, respectively); black transect lines indicate distance (in kilometers) alongshore with respect to the $x$-axis in $A$ and $B$. Abbreviations: DEM, digital elevation model; km, kilometers; lidar, light detection and ranging; m, meters; SL, shoreline. 

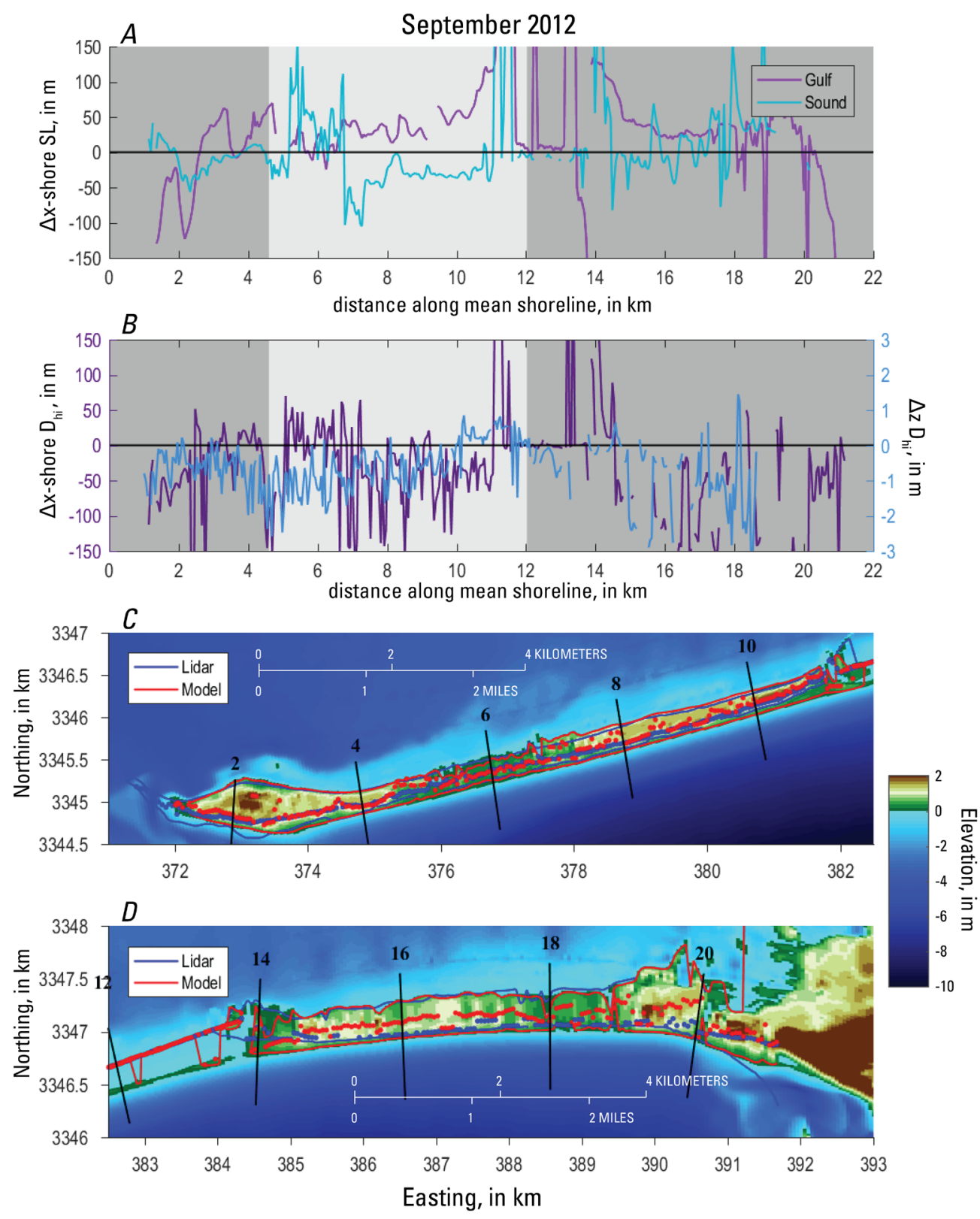

Figure 1-11. Comparison of September 2012 model DEM with September 2012 lidar survey (postHurricane Isaac). A, Difference between model and lidar shoreline (SL) cross-shore location (Gulf shoreline: purple line; Sound shoreline: blue line). Lightly shaded area indicates alongshore location area where shoreline and dune statistics were calculated. $B$, Difference between model and lidar cross-shore $D_{\mathrm{hi}}$ location ( $\Delta x$-shore $D_{h i}$ purple line) and difference between model and lidar cross-shore $D_{h i}$ elevation ( $\Delta z D_{h i}$ blue line). $C$, Western portion of Dauphin Island with location of model shoreline and $D_{h i}$ locations (red line and red dot, respectively); and location of lidar shoreline and $D_{h i}$ locations (blue line and blue dot, respectively); black transect lines indicate distance (in kilometers) alongshore with respect to the $\mathrm{x}$-axis in $A$ and $B$. $D$, Eastern portion of Dauphin Island with location of model shoreline and $D_{h i}$ locations (red line and red dot, respectively); and location of lidar shoreline and $\mathrm{D}_{\mathrm{hi}}$ locations (blue line and blue dot, respectively); black transect lines indicate distance (in kilometers) alongshore with respect to the $x$-axis in $A$ and $B$. Abbreviations: DEM, digital elevation model; km, kilometers; lidar, light detection and ranging; m, meters; SL, shoreline. 

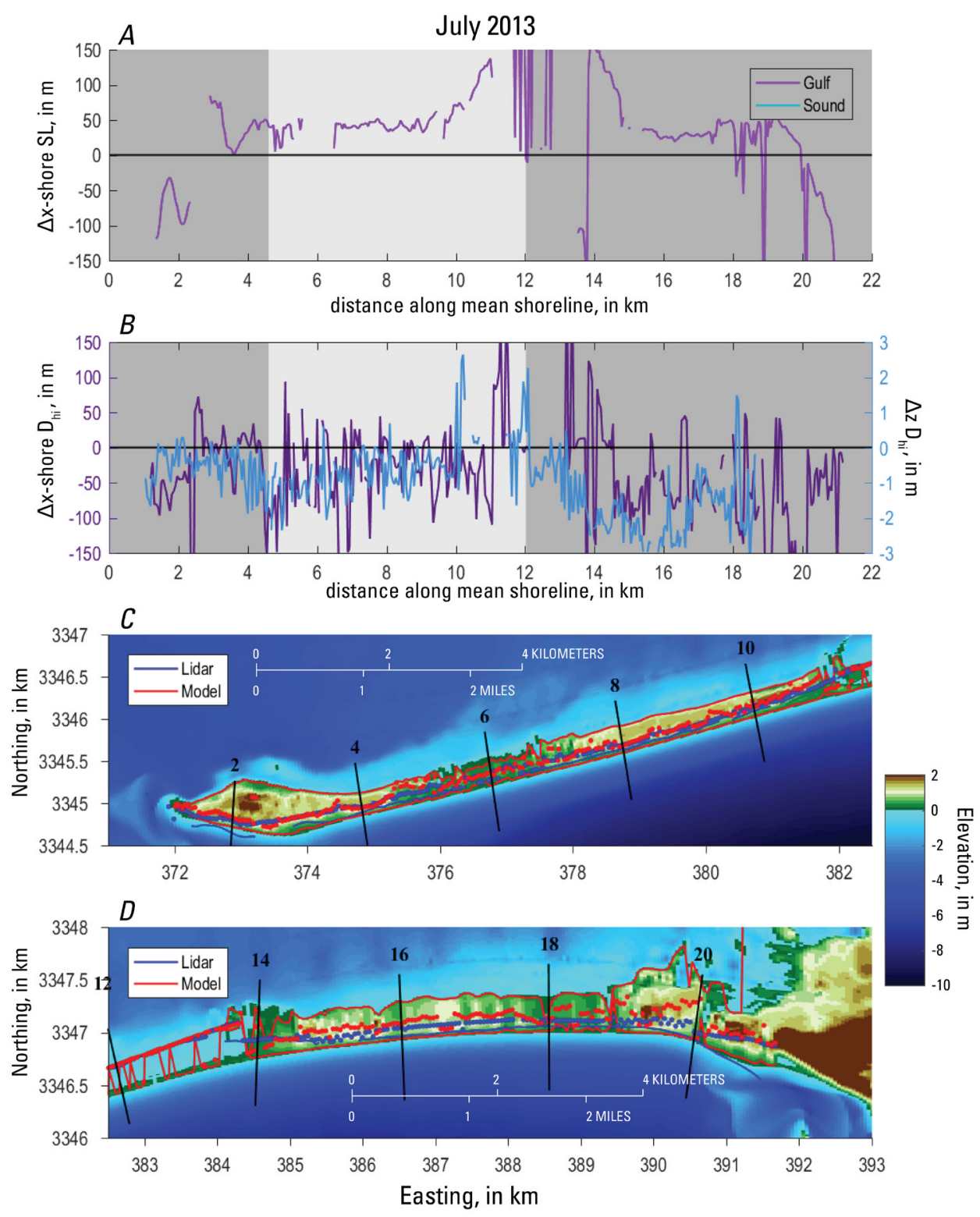

Figure 1-12. Comparison of July 2013 model DEM with July 2013 lidar survey. A, Difference between model and lidar shoreline (SL) cross-shore location (Gulf shoreline: purple line). Lightly shaded area indicates alongshore location area where shoreline and dune statistics were calculated. Note that the "Sound shoreline" data were unavailable for this lidar survey, so a comparison could not be made to the Sound-side shoreline from the hindcast. $B$, Difference between model and lidar cross-shore $D_{\text {hi }}$ location $\left(\Delta x\right.$-shore $D_{h i}$, purple line) and difference between model and lidar cross-shore $D_{h \mathrm{~h}}$ elevation ( $\Delta z \mathrm{D}_{\mathrm{hi}}$, blue line). $C$, Western portion of Dauphin Island with location of model shoreline and $D_{h i}$ locations (red line and red dot, respectively); and location of lidar shoreline and $\mathrm{D}_{\mathrm{hi}}$ locations (blue line and blue dot, respectively); black transect lines indicate distance (in kilometers) alongshore with respect to the $\mathrm{x}$-axis in $A$ and $B$. $D$, Eastern portion of Dauphin Island with location of model shoreline and $\mathrm{D}_{\mathrm{hi}}$ locations (red line and red dot, respectively); and location of lidar shoreline and $D_{\text {hi }}$ locations (blue line and blue dot, respectively); black transect lines indicate distance (in kilometers) alongshore with respect to the $x$-axis in $A$ and $B$. Abbreviations: DEM, digital elevation model; km, kilometers; lidar, light detection and ranging; $m$, meters; SL, shoreline. 

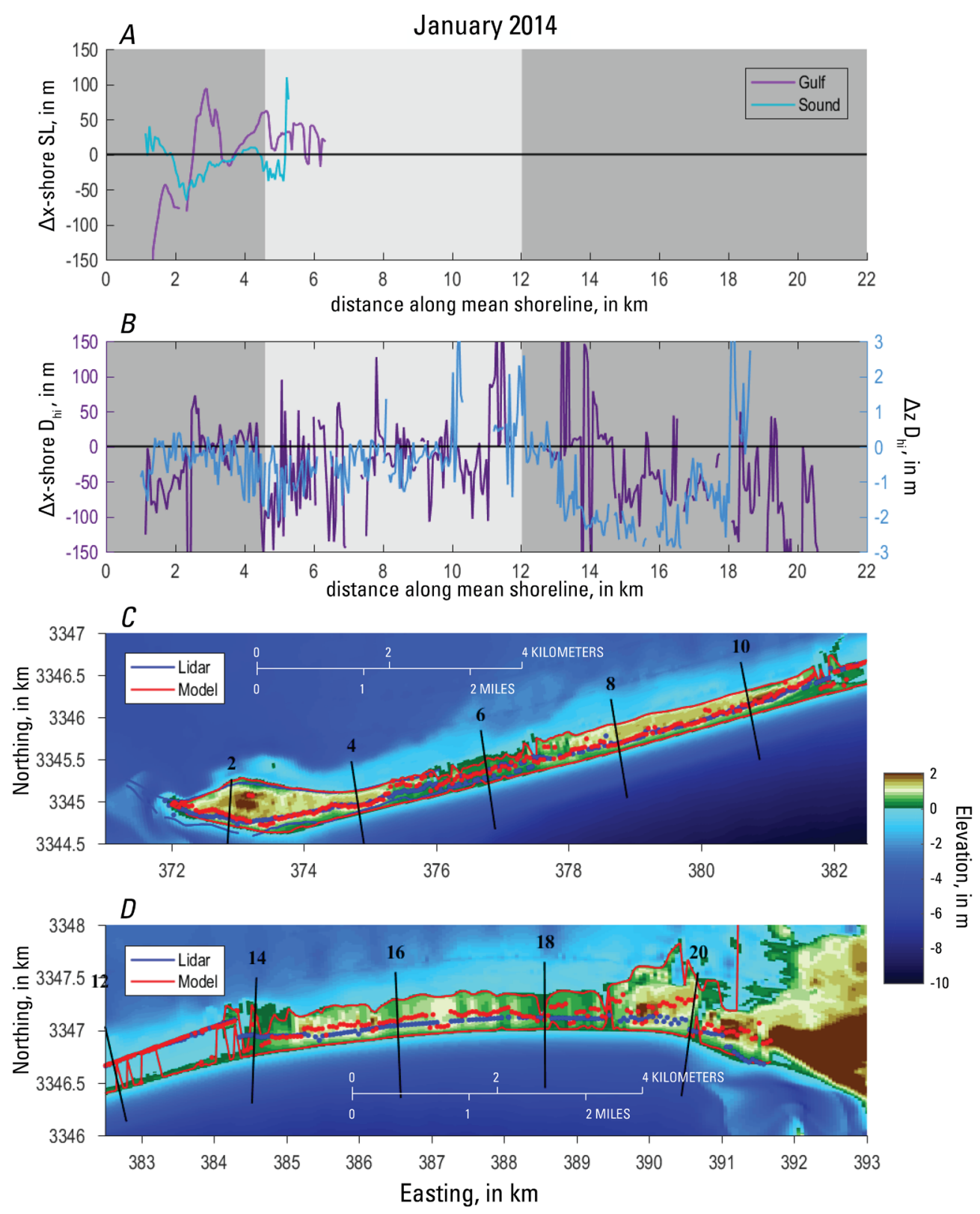

Figure 1-13. Comparison of January 2014 model DEM with January 2014 lidar survey. A, Difference between model and lidar shoreline (SL) cross-shore location (Gulf shoreline: purple line; Sound shoreline: blue line). Lightly shaded area indicates alongshore location area where shoreline and dune statistics were calculated. $B$, Difference between model and lidar cross-shore $D_{h i}$ location ( $\Delta x$-shore $D_{\text {hi }}$ purple line) and difference between model and lidar cross-shore $D_{h i}$ elevation $\left(\Delta z D_{h}\right.$, blue line). $C$, Western portion of Dauphin Island with location of model shoreline and $\mathrm{D}_{\mathrm{hi}}$ locations (red line and red dot, respectively); and location of lidar shoreline and $\mathrm{D}_{\text {hi }}$ locations (blue line and blue dot, respectively); black transect lines indicate distance (in kilometers) alongshore with respect to the x-axis in $A$ and $B$. D, Eastern portion of Dauphin Island with location of model shoreline and $D_{\text {hi }}$ locations (red line and red dot, respectively); and location of lidar shoreline and $\mathrm{D}_{\text {hi }}$ locations (blue line and blue dot, respectively); black transect lines indicate distance (in kilometers) alongshore with respect to the x-axis in $A$ and $B$. Abbreviations: DEM, digital elevation model; $\mathrm{km}$, kilometers; lidar, light detection and ranging; $m$, meters; SL, shoreline. 


\section{Appendix 2. Development and Use of an Empirical Dune Growth Model for Evaluating Barrier Island Recovery from Storms}

\section{Introduction}

A method is required that implements existing knowledge of dune recovery into a predictive model that captures dune formation and growth and can be integrated with storm-response models to comprehensively evaluate dune dynamics and inform management of coastal communities and ecosystems. Houser and others (2015) proposed an empirical approach for estimating coastal dune-crest elevation increase based on a formulation developed for modeling dune building in interior (non-coastal) plains (Hugenholtz and Wolfe, 2005). The underlying assumption to the model is that the change in maximum dune height can be predicted with a sigmoid growth curve, following established growth-rate patterns for dune-building vegetation. Houser and others (2015) found that appropriately parameterized sigmoid dune-growth curves could capture dune growth at Santa Rosa Island, Florida, and Galveston Island, Texas, two barrier islands in the northern Gulf of Mexico (Houser and others, 2015).

In the current study, the sigmoid growth tendency of dunes (Houser and others, 2015) is used as the basis for development of an empirical dune growth model (EDGR) to predict the temporally- and spatially-variable evolution of a barrier island coastal foredune. EDGR was developed by P. Soupy Dalyander, R.C. Mickey, Davina L. Passeri, and Nathaniel G. Plant as part of the Alabama Barrier Island Restoration Assessment, funded by the National Fish and Wildlife Foundation (NFWF). The overall project has been a collaborative effort between the U.S. Geological Survey (USGS), U.S. Army Corps of Engineers (USACE), and the State of Alabama to investigate restoration options that protect and restore the natural resources of Dauphin Island, Alabama. Portions of the research presented here were also funded by the USGS. The model framework is calibrated and evaluated using lidar data from Dauphin Island, Alabama, a barrier island in the northern Gulf of Mexico that has seen significant dune erosion and recovery during multiple storm events in the past two decades. In the next section, the EDGR framework is described along with an overview of Dauphin Island and the underlying datasets used to develop and assess the model. The results section contains assessments of model skill applied to dune growth from 2005 to 2015 .

\section{Methods}

EDGR relies on a novel method to characterize a barrier island cross-shore profile as the sum of shape functions that individually represent the island platform and one or more dunes and (or) berms (if present). This profile decomposition approach allows historical dune features to be rapidly identified, their dimensions quantified in a robust and objective manner, and the resulting features statistically analyzed to characterize spatial and temporal trends and variability. EDGR employs a Gaussian decomposition to characterize the cross-shore features of a barrier island. Gaussian curves represent physically meaningful dune characteristics (height, width, and position). Testing determined that, for over 99 percent of historical cross-shore profiles in the 
Dauphin Island training data set, the nonlinear fitting algorithm robustly converged on a solution with the island and dunes each approximated by individual Gaussians.

Gaussian basis set decomposition is also applied to the initial Digital Elevation Model (DEM) for the time period and site of interest to identify an existing foredune and initialize the model. EDGR then evolves the foredune Gaussian curve using the Houser and others (2015) formulation for dune elevation and newly-derived empirical formulations for dune width and, in the case of incipient dune formation, distance to shore. EDGR can forecast dune change (or hindcast an area with limited historical data) assuming predicted dune evolution is expected to be statistically similar to dune growth in the historical data set used to parameterize the model. The model can run standalone or coupled to an external model predicting dune erosion and (or) the evolution of island characteristics other than the foredune.

\section{Model Initialization and Prediction}

At each longshore location $(x)$ in the initial DEM, EDGR decomposes the observed cross-shore profile $\left(Z_{E}(x, y, t)\right)$ into a basis set of Gaussian curves $\left(Z_{G, n}(x, y, t)\right.$, where " $n$ " enumerates each curve defined by their height $\left(G_{h i g h, n}\left(x, t_{1}\right)\right)$, full width at half maximum $\left(G_{\text {wide, }}\left(x, t_{1}\right)\right)$, and location $\left(G_{Y, n}\left(x, t_{1}\right)\right)$ as:

$$
Z_{E}\left(x, y, t_{1}\right)=Z_{G}\left(x, y, t_{1}\right)+\varepsilon(x, y)=\sum_{n=1}^{n=n_{\max }} Z_{G, n}\left(x, y, t_{1}\right)+\varepsilon(x, y)
$$

where

$$
Z_{G, n}\left(x, y, t_{1}\right)=G_{h i g h, n}\left(x, t_{1}\right) \cdot \exp \left(-\frac{4 \cdot \ln (2) \cdot\left(y-G_{Y}, n\left(x, t_{1}\right)\right)^{2}}{G_{w i d e, n}\left(x, t_{1}\right)^{2}}\right)
$$

and $\varepsilon(x, y)$ describes the fit deviation (error). Each profile is first approximated with a single Gaussian curve through nonlinear regression. The initial values for curve height, width, and location are chosen as the maximum profile elevation, island width, and halfway between the Gulf and Bay shoreline positions, respectively, such that the fit will converge on the island platform $\left(Z_{G, I s}(x, y)\right.$; fig. $\left.2-1\right)$. Dune or berm features are then identified as local maxima $\left(y_{\text {peak }}\right)$ within $\varepsilon(x, y)$. Additional Gaussians representing these features are sequentially added at the local peak with maximum fit deviation until the fit deviation at all peaks is below a prescribed threshold $\left(\varepsilon\left(x, y_{\text {peak }}\right)<\varepsilon_{\text {max }}\right)$ or a user-specified maximum number of additional Gaussians has been applied $\left(n_{\max }\right)$. The value of $n_{\max }$ may be specified to expedite model run-time if site-specific sensitivity testing determines that the foredune can be robustly identified with a fixed number of Gaussians. The Gaussian curve representing the foredune $\left(Z_{G, D}\left(x, y, t_{1}\right)\right)$ is identified as the fitted peak closest to the Gulf shoreline, but may be manually adjusted to a different peak if a berm feature has been incorrectly identified as the foredune. EDGR then calculates the residual island profile $\left(Z_{R}\left(x, y, t_{p}\right)\right)$ by subtracting the identified foredune Gaussian curve from the total elevation profile as:

$$
Z_{R}\left(x, y, t_{1}\right)=Z_{E}\left(x, y, t_{1}\right)-Z_{G, D}\left(x, y, t_{1}\right) .
$$


At subsequent time steps $(t)$, equation 3 is reversed such that the cross-shore profile at each longshore location is generated by adding the EDGR-predicted foredune Gaussian curve to the residual profile as:

$$
Z_{E}(x, y, t)=Z_{G, D}(x, y, t)+Z_{R}\left(x, y, t_{1}\right)
$$

The foredune Gaussian evolves through time via growth of its height and width, while dune position is fixed throughout the model run. The model time-step can be set to resolve observational data or meet forecast requirements, and will be monthly or yearly in most cases given typical dune growth rates.

Dune height in EDGR follows the sigmoid growth curve of Houser and others (2015, hereafter referred to as "Houser2015"), which predicts the total maximum elevation of the foredune $\left(D_{h i g h}\right)$ as a function of the longshore-variable initial dune elevation $\left(D_{\text {high, }}\right)$, terminal dune elevation $\left(D_{\text {high, }}\right)$, growth rate $(r)$, and time of incipient dune formation $\left(t_{0}\right)$ as:

$$
D_{h i g h}(x, t)=\frac{D_{h i g h, F}(x) \cdot D_{h i g h, 0}(x)}{\left(D_{h i g h, F}(x)-D_{h i g h, 0}(x)\right) \cdot \exp \left(-r \cdot\left(t-t_{0}(x)\right)\right)+D_{h i g h, 0}(x)} .
$$

The height of the Gaussian curve at each longshore location and time is calculated from this predicted total dune elevation by subtracting off the residual elevation profile at the location of dune formation $\left(G_{Y}(x)\right)$ as:

$$
G_{\text {high }}(x, t)=D_{h i g h}(x, t)-Z_{R}\left(x, G_{Y}(x), t_{1}\right) .
$$

The width of the foredune Gaussian $\left(G_{\text {wide }}\right)$ is then calculated as a linear function of the height of the foredune Gaussian $\left(G_{h i g h}\right)$ with prescribed values for slope $\left(m_{d W d H}\right)$ and y-intercept $\left(b_{d W d H}\right)$ as:

$$
G_{\text {wide }}(x, t)=m_{d W d H} \cdot G_{\text {high }}(x, t)+b_{d W d H} .
$$

EDGR reconstructs each cross-shore profile after calculating $D_{h i g h}, G_{h i g h}$, and $G_{\text {wide }}$ for the prediction time and adding the dune curve to the residual island profile (equation 4). Because EDGR is formulated as a dune growth model, it is not allowed to reduce the elevation at any location (for example, to predict erosion). Therefore, the last step is to adjust the profile to the initial condition at any location where application of the Gaussian foredune reduced the elevation.

Because EDGR independently operates on each cross-shore profile, there are no constraints on the longshore resolution or scale of the model domain. The cross-shore resolution of the DEM must be sufficient to resolve the dune feature (order of meters), and the entire island must be within the domain to allow for Gaussian curve fitting of the island platform. 

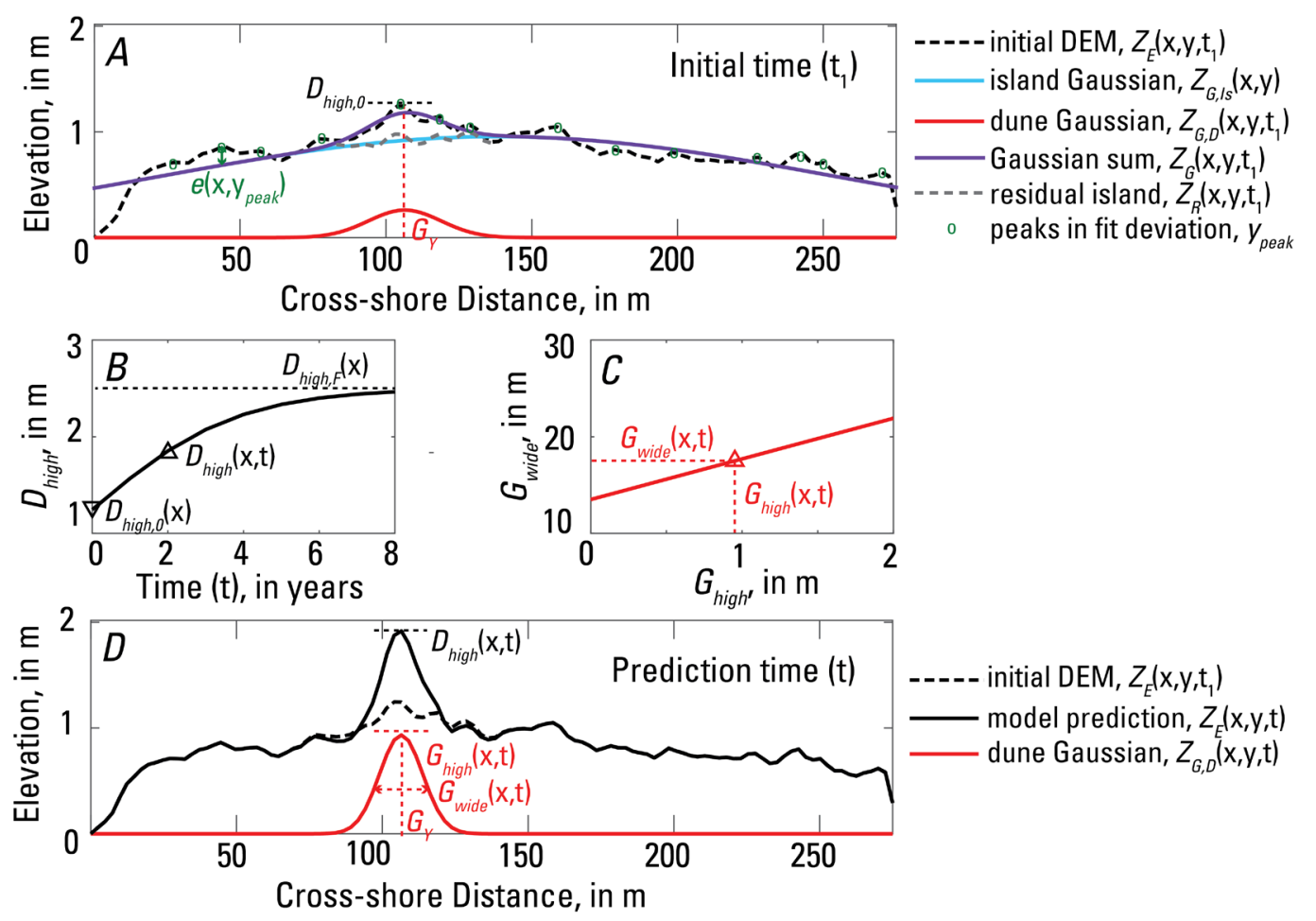

Figure 2-1. Example of EDGR prediction of foredune growth after a storm. $A$, The initial cross-shore elevation profile $\left(Z_{E}\left(x, y, t_{1}\right)\right)$ is approximated as the sum of a basis set of Gaussians $\left(Z_{G}\left(x, y, t_{1}\right)\right.$; equation 1$)$. The profile is first modelled with a single Gaussian representing the island platform $\left(Z_{G, l s}(x, y)\right)$. Gaussians representing the foredune $\left(Z_{G, D}\left(x, y, t_{1}\right)\right)$ and other dune or berm features, if present, are added sequentially at peaks in the maximum fit deviation until a user-defined threshold for goodness-of-fit is achieved $\left(\varepsilon\left(x, y_{\text {peak }}\right)<\varepsilon_{\text {max }}\right)$. The residual island $\left(Z_{R}\left(x, y, t_{1}\right)\right)$ is the elevation profile excluding the existing foredune, if present (equation 3). B. The foredune height $\left(D_{\text {high }}(x, t)\right)$ at time $t$ is calculated following Houser2015 (equation 5) and used to calculate the corresponding Gaussian height $\left(G_{\text {high }}(x, t)\right.$; equation 6$)$ based on the initial $\left(D_{\text {high, }, 0}(\mathrm{x})\right)$ and terminal $\left(D_{\text {high, }, \mathrm{F}}(\mathrm{x})\right)$ dune height. $C$, The foredune Gaussian width $\left(G_{\text {wide }}(\mathrm{x}, \mathrm{t})\right)$ is calculated from $G_{\text {high }}(x, t)$ (equation 7$)$. $D$, The updated cross-shore profile $\left(Z_{E}(x, y, t)\right)$ is created by adding the updated foredune Gaussian $\left(Z_{G, D}(x, y, t)\right)$ to $Z_{R}\left(x, y, t_{1}\right)$ at the cross-shore position of the dune Gaussian $\left(G_{\gamma}\right)$ (equation 4). Abbreviations: DEM, digital elevation model; $m$, meters.

\section{Definition of Model Parameters}

Model parameters $\left(D_{h i g h, P} G_{Y} r, m_{d W d P} b_{d W d H}\right)$ are derived from historical data, where the foredune in each cross-shore profile of a given survey is identified through Gaussian basis set decomposition. Data from the specific site and time period being modelled can be used in cases when EDGR is filling temporal gaps between available surveys. Model parameters may alternately be derived from template (proxy) data under the assumption that growth will be similar for the modelled dunes.

EDGR includes two possible options for imposing $D_{h i g h, F}$. In the first, a known longshore distribution of $D_{\text {high,F}}$ values is prescribed. This mode of operation is applicable to hindcasting island evolution over a period of time when the terminal (recovered) dune state is known. In the second method, data for dune growth associated with recovery from a different storm or 
at another location is used as a template. This method assumes that the forcing mechanisms of dune formation and growth (sediment supply, winds, vegetation types, etc.) for the site and time period of interest are similar to those of the template even as small-scale spatial variation in, for example, vegetation alters the precise longshore distribution of $D_{\text {high, }}$. In this case, the longshore distribution of $D_{\text {high, }}$ for the template is decomposed into its component wavenumber contributions (for example, spatial harmonics) via fast Fourier transform (FFT) (Brigham, 1998). The phases of the wavenumbers are then randomized and an inverse FFT is applied to reconstruct a new longshore distribution of $D_{h i g h, F}$. If there are spatial trends or other patterns in the template $D_{\text {high }, F}$ that are expected to recur in the modeled case, they may be subtracted prior to FFT application and added back to the final distribution. The FFT randomization mode allows multiple realizations of the longshore pattern of dune height to be generated, each of which preserves the mean, standard deviation, and spatial scales of variability of the template data. When operating in a forecast model, these realizations provide realistic spatial variability as well as uncertainty estimates for model predictions.

Similar options are available for imposing cross-shore position of the dune Gaussian $\left(G_{Y}\right)$. Values can be prescribed if dunes have already begun to establish in the initial DEM or in the case of a hindcast where the terminal dune location is known $\left(G_{Y}=D_{Y}\right)$. Dune position may also be estimated from template values using the FFT methodology described for $D_{h i g h, F}$ if, for example, the initial DEM is a post-storm case where dunes have been completely destroyed. Because of the potential for overwash processes to cause island rollover and migration of the barrier island toward the mainland, foredune location in the FFT case is referenced as distance $\left(\Delta_{S L, 0}\right)$ to the post-storm shoreline $\left(S L_{Y}\right)$ as

$$
G_{Y}(x)=S L_{Y}(x)+\Delta_{S L, 0}(x) .
$$

Dune and shoreline position in the template case are smoothed in the longshore with a $100-\mathrm{m}$ Hanning filter to remove high-frequency variation prior to calculating $\Delta_{S L}, 0^{\text {. After }} \Delta_{S L},{ }^{\prime}$ is randomized via the FFT method described above, it is used to calculate $G_{Y}$ from the shoreline location in the initial DEM, also smoothed with a 100-m Hanning filter. Once the dune position is fixed, it remains constant until and unless the dune is subsequently destroyed again at that longshore location.

Growth rates $(r)$ are estimated using nonlinear regression of the Houser 2015 model onto dune growth within the historical data set. $G_{\text {high }}$ and $G_{\text {wide }}$ are extracted via identification of the foredune through Gaussian basis set decomposition (equations 3, 4; fig. 2-1) of available cross-shore profiles. The parameters $m_{d W d H}$ and $b_{d W d H}$ are then derived from a linear model fit to these values. $D_{\text {high, }}$ values are taken as the elevation at $G_{Y}$ at initialization time $t_{0}(x)$. Cross-shore profiles may have different initialization times if, for example, only a portion of the island was overwashed during a storm.

\section{EDGR in a Coupled Model Framework}

EDGR can be coupled to an external model for updating the island's response to storms, longshore sediment transport, or other processes apart from foredune growth. The information from the external model is incorporated into EDGR in two ways. First, the external model can be used to evolve aspects of the profile that EDGR does not alter, such as changes to the oceanfacing and back barrier shorelines. In this case, the residual island profile becomes time-variant 
and is updated (following equations 1-3) whenever output is provided from the coupled model. After EDGR modifies the dune and constructs updated profiles (equation 4), the DEM is passed back to the external model.

If the external model (or data) captures dune erosion, this information is used to identify if dune growth should be reset to $t_{0}$ (fig. 2-2). EDGR is initialized prior to running the external model in order to identify the location of the foredune at each cross-shore profile. EDGR may also be used to update the DEM if, for example, the available lidar for running a storm-impact model such as XBeach (Roelvink and others, 2009) is outdated. After the eroded DEM is passed back to EDGR, elevation loss at the location of the foredune within each profile is evaluated to determine if it exceeds a user-prescribed threshold $\left(\Delta Z\left(x, G_{Y}\right)>\Delta_{\text {Dhigh, max }}\right)$, which should be chosen as a value larger than the vertical uncertainty in the external dune erosion model. If this occurs, dune growth in EDGR is reset back to $t=t_{0}$ and dune location is updated. $G_{Y}$ is set to the location of maximum elevation in the remnant dune if one remains. If the dune was completely destroyed, the dune is repositioned based on distance to the post-storm shoreline $\left(G_{Y}=S L_{Y}+\Delta_{S L, 0}\right)$, if that location is subaerial. Otherwise, $G_{Y}$ is placed at the location of maximum elevation in the subaerial island. The value of $D_{h i g h, 0}$ is set to the elevation of the profile at $G_{Y}$. EDGR stops dune growth at any fully subaqueous longshore location and starts dune growth at new subaerial locations (for example, growth of a terminal spit).
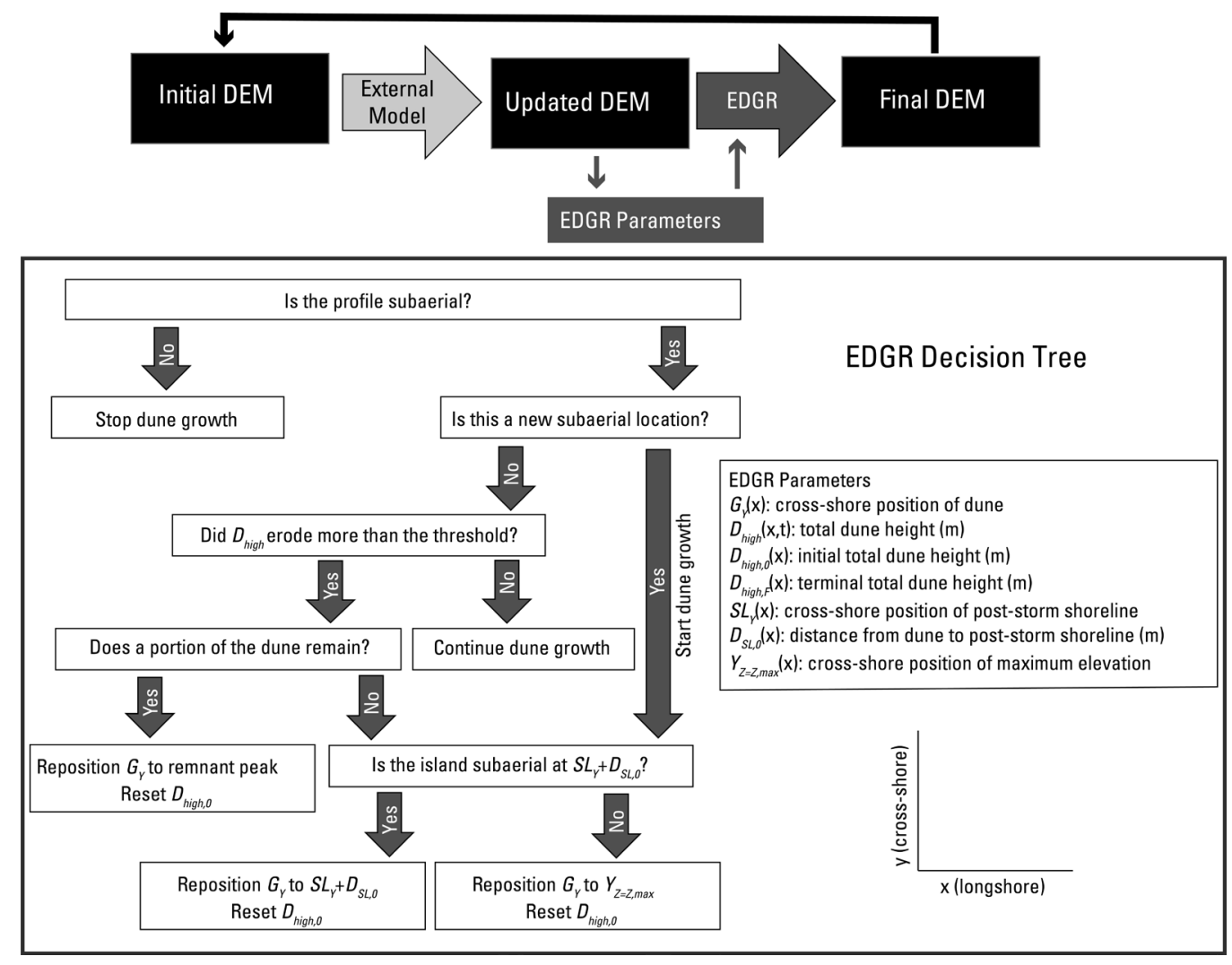

Figure 2-2. EDGR workflow for each time step when coupled with an external model to predict dune erosion. Examples of models that may be coupled with EDGR include those that can capture dune erosion during storms (for example, XBeach (Roelvink and others, 2009)) or models for predicting shoreline change due to longshore transport (for example, Delft3D (Lesser and others, 2004)). 


\section{Study Site and Observational Data}

To test EDGR's predictive skill and evaluate how the model can improve understanding of the processes that control dune growth, a data set was required that contained years (to decades) of dune cross-shore elevation profile recovery following a storm event. One location where such data exist is Dauphin Island, Alabama, a barrier island in the northern Gulf of Mexico (fig. $1 B$ ). The eastern half of the island is inhabited and has been the site of multiple coastal restoration projects (nourishment; seawalls and groins at some locations). The current study focused on the uninhabited western portion of the island, extending from the western terminus to the boundary of what is now Katrina Cut (fig. $1 B$ ). The study site is characterized by dissipative sandy beaches and 2 to 4 meter $(\mathrm{m})$ high foredunes that have historically overwashed or inundated during major storm events (Watkins, 2011). The coast is wave-dominated and microtidal, with a diurnal cycle and tide range of $0.37 \mathrm{~m}$ (Douglass, 1994). The mean annual wind speed in the vicinity of of Dauphin Island is 1.15 meters per second $(\mathrm{m} / \mathrm{s})$ toward the southwest $\left(255^{\circ}\right.$ relative to north). There is noticable seasonable variation in wind climate, which will result in similar variability in Aeolian transport. Offshore winds to the southwest tend to dominate in the fall and winter, with dominant winds to the northwest in spring and weaker, onshore winds during the summer (Gutiérrez de Velasco and Winant, 1996; Dzwonkowski and Park, 2010). The western portion of the island predominantly consists of beach, intertidal flat, meadow, scrub, and dune habitat, with some back barrier marsh areas; dunes are bare or covered in herbaceous vegetation (Enwright and others, 2017).

This study focused on the time period of August, 2005, to January, 2015. During this period, a total of 7 tropical storms and hurricanes passed within 200 kilometers $(\mathrm{km})$ of Dauphin Island (fig. 2-3; https://coast.noaa.gov/hurricanes/). These storms caused dune erosion and, less frequently, overwash and inundation of the island (Douglass, 1994; Sallenger, 2000; Morton, 2008). The largest storm in the study period was Hurricane Katrina, which passed approximately $200 \mathrm{~km}$ to the southwest of Dauphin Island in August, 2005, as a major storm (category 5 weakening to a category 3 just prior to landfall). Katrina resulted in widespread total dune loss, in part due to impacts sustained during Hurricane Ivan in September, 2004 (Passeri and others, 2018). The relatively low central portion of the island breached and a 2-km-wide tidal channel opened (Froede, 2006; Froede, 2008). In 2010, the U.S. Army Corps of Engineers installed a rock wall to close the breach, and dominant longshore transport (east to west) (Douglass, 1994; Morton and others, 2004) has subsequently rebuilt the island in front of the structure. Since Katrina, total dune loss has been confined to isolated areas of the island.

A total of 12 topographic lidar elevation surveys were available for model parameterization and assessment during the study period (fig. 2-3). Initial evaluation of these surveys revealed systematic vertical offsets that were corrected to a common datum. Thompson and others (2017) contains a detailed description of the offset correction method along with descriptions of the datasets and their corrections through 2013. The 2014 lidar data are available on the NOAA Digital Coast web site at https://coast.noaa.gov/htdata/lidar1_z/geoid12b/data/4966 and were corrected for a $-0.23-\mathrm{m}$ offset, and the 2015 lidar data are available at https://nationalmap.gov/ index.html and were corrected for a $-0.01-\mathrm{m}$ offset. Corrected data for each survey were interpolated to shore-normal transects with $2.5-\mathrm{m}$ cross-shore resolution and $5-\mathrm{m}$ longshore resolution. 


\section{Model Application at Dauphin Island}

The study area was split into four analysis regions based on longshore variability in the 2005 and 2015 elevation data. From west to east those regions were R1, the wide western terminus of the island; R2, a somewhat narrower portion of the island associated with overwash fans in 2005 that approached or reached the bay shoreline; R3, a narrow portion of the island that incurred numerous small breaches during Katrina; and R4, the eastern portion of the study domain (fig. 2-4).
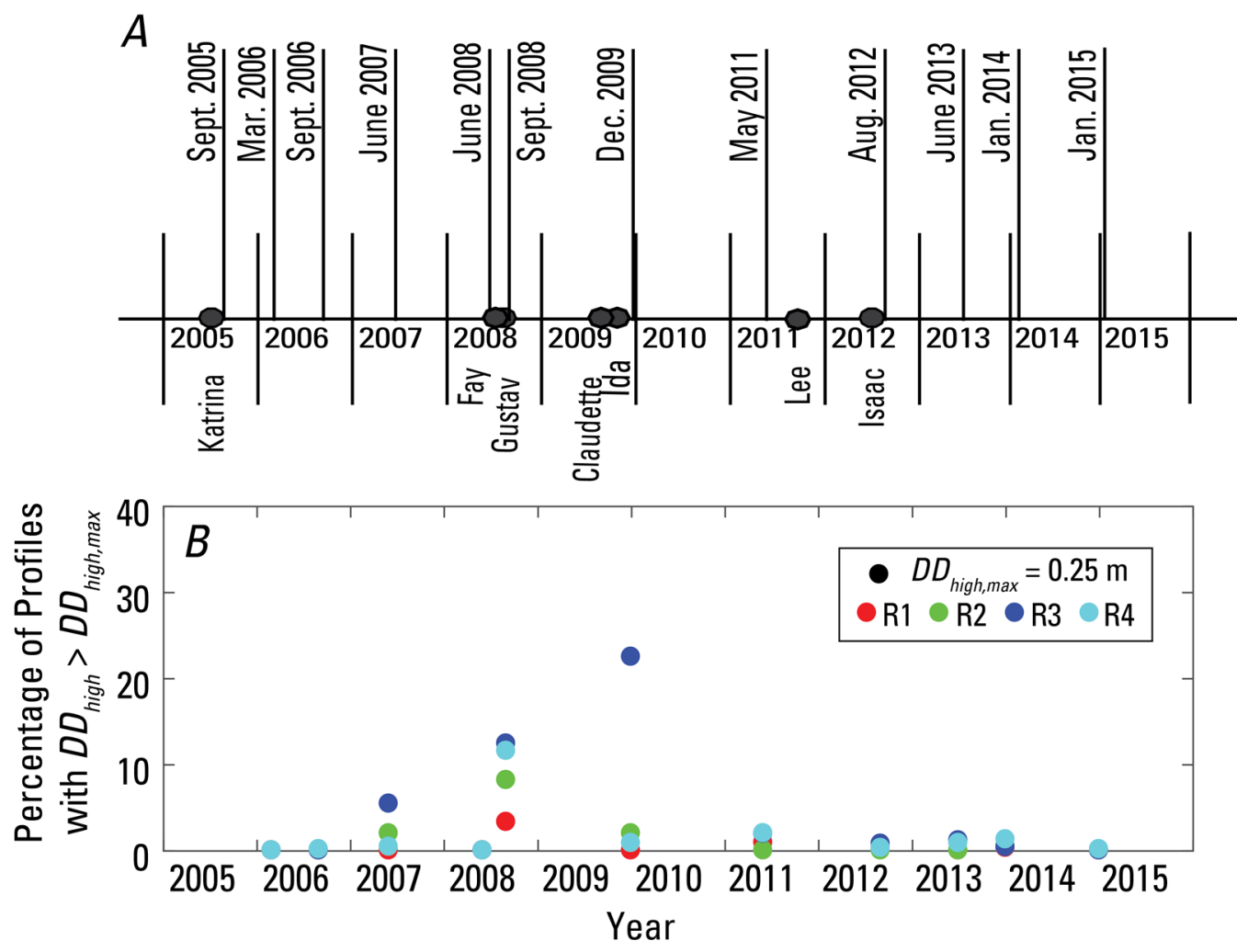

Figure 2-3. A, Dates of lidar surveys used in EDGR model calibration and assessment. The March, 2006, survey does not include complete coverage of R1 and R2. An additional survey of Dauphin Island in July, 2010, was evaluated and excluded from analysis due to sparse coverage. Available first-return lidar surveys from 1998-2004 were excluded since bare earth elevations could not be robustly differentiated from vegetation. Also shown are tropical storms and hurricanes that passed within 200 kilometers of Dauphin Island (black dots). $B$, Percentage of cross-shore profiles within each analysis region (fig. 2-4) with $D_{\text {high }}$ elevation loss $\left(\Delta D_{\text {high }}\right)$ exceeding 0.25 meters $(\mathrm{m})$ compared to the previous survey.

EDGR operated standalone with $D_{h i g h, F}$ and $G_{Y}$ taken as dune height and position in the 2015 lidar survey. This configuration tested the skill of the model at capturing the complete cross-shore dune profile, as well as predicting the dune height between the initial and prescribed terminal value.

Distance to shore was referenced to the $0.5-\mathrm{m}$ contour in the 2005 lidar survey to allow inclusion of profiles with incomplete coverage of the intertidal zone. Dune height and position were extracted from the 2005 lidar survey as the point of maximum island elevation. EDGR time 
steps were chosen such that the model generated output at the times of the observed lidar survey (fig. 2-3, time step of several months to upwards of two years). The longshore and cross-shore resolution of the model matched the gridded lidar $(2.5-\mathrm{m}$ cross-shore resolution and 5-m longshore resolution).
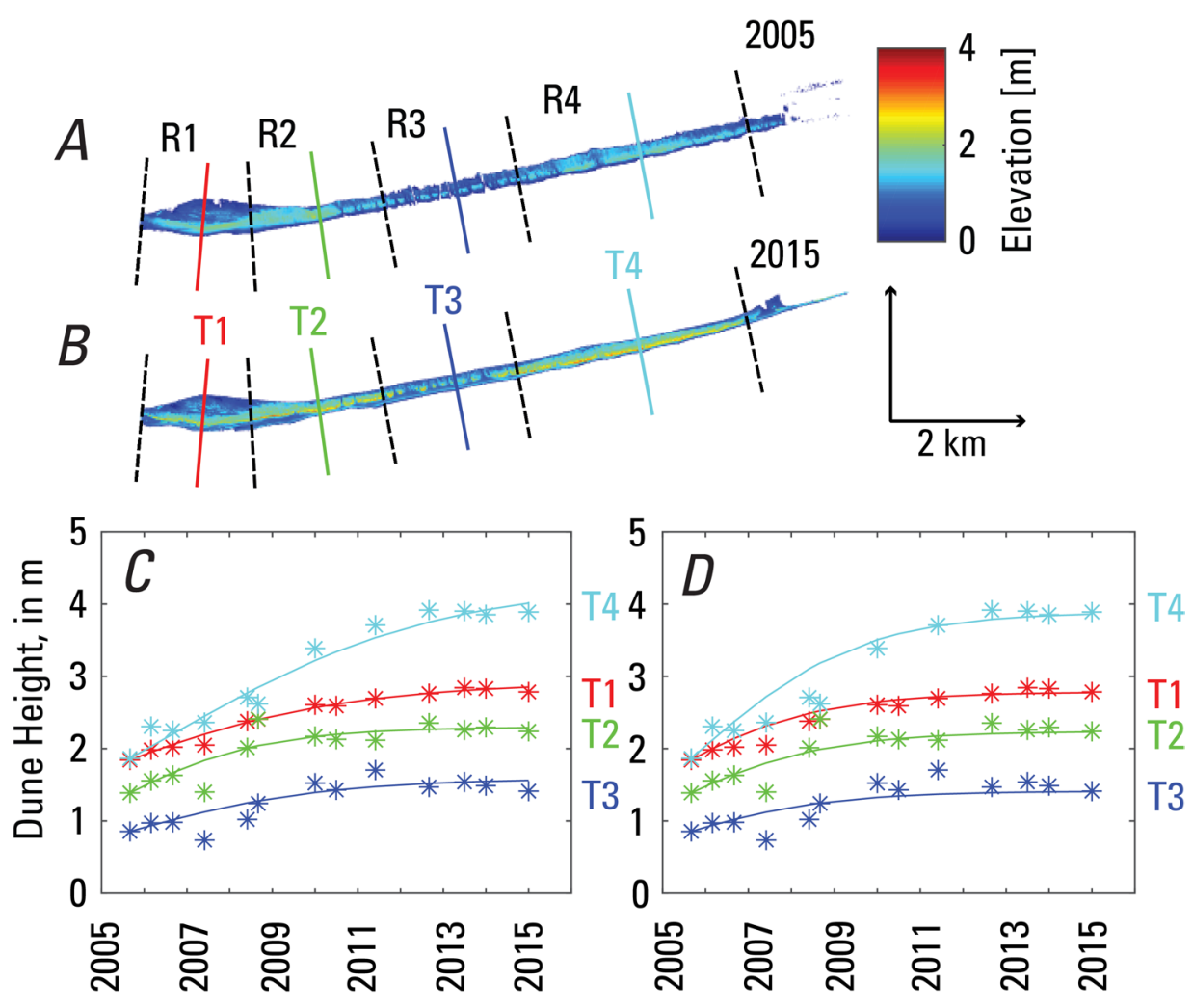

Figure 2-4. A, Dauphin Island topography in September, 2005 (post-Katrina); and B, in January, 2015. Analysis regions (R1-R4) used to delineate longshore variability (vertical dashed black lines) and four representative transects (T1-T4; vertical colored lines) are indicated. Also shown (in $C$ and $D$ ) are post-Katrina lidar observations (stars) of $D_{\text {high }}$ for transects T1-T4 along with results of the Houser2015 model for dune growth using $C$, a fitted growth rate and terminal height $\left(T 1, r=0.33 \mathrm{~m} / \mathrm{yr}, D_{\text {high, } F}=2.92 \mathrm{~m} ; \mathrm{T} 2, r=0.55 \mathrm{~m} / \mathrm{yr}\right.$, $\left.D_{\text {high, } F}=2.30 \mathrm{~m} ; \mathrm{T} 3, \mathrm{r}=0.42 \mathrm{~m} / \mathrm{yr}, D_{\text {high, } F}=1.59 \mathrm{~m} ; \mathrm{T} 4, \mathrm{r}=0.31 \mathrm{~m} / \mathrm{yr}, D_{\text {high, } F}=4.3 \mathrm{~m}\right) ;$ and using $D$, a fixed value of $0.53 \mathrm{~m} / \mathrm{yr}$ and the 2015 elevation as $D_{\text {high,F }}$. Abbreviations: $\mathrm{km}$, kilometers; $\mathrm{m}$, meters; m/yr, meters per year; r, growth rate.

\section{Results}

Island and dune recovery from 2005 to 2015 was broadly similar for analysis regions R1, R2, and R4 (fig. 2-4; table 1). The maximum cross-shore elevation $\left(Z_{\max }\right)$ for each region averaged 1.65 to $1.73 \mathrm{~m}$ in 2005 , increasing to 2.51 to $2.98 \mathrm{~m}$ in 2015 . R1 had lower values of $Z_{\max }$ in 2015 despite having, on average, similar values of $Z_{\max }$ compared to $\mathrm{R} 2$ and higher values compared to R4 in 2005. R3 had the lowest elevations in 2005 (mean $Z_{\text {max }}$ of $1.31 \mathrm{~m}$ ) and remained low compared to the rest of the study region in 2015 (mean $Z_{\max }$ of $1.85 \mathrm{~m}$ ). $Z_{\max }$ in 2005 
for the wide, western portion of the study site (R1, R2) was found inland along overwash fans located on average 115 to $134 \mathrm{~m}$ from the Gulf shoreline. $Z_{\max }$ toward the eastern end of the study site (R3-R4) was also associated with overwash deposits in 2005 , but widespread erosion and a narrower island platform reduced the average distance to shore to 59 to $65 \mathrm{~m}$. By $2015, Z_{\max }$ throughout most of the analysis region was associated with a developed foredune located a relatively consistent distance from the 2005 shoreline (mean $\Delta_{Z \text { max } S L 0}$ of 65 to $85 \mathrm{~m}$ ). At locations where foredune growth was limited or absent (218 profiles, corresponding to 11 percent of the domain), $Z_{\max }$ was associated with either a low (1 to $1.5 \mathrm{~m}$ ) berm near the shoreline or a relic overwash deposit toward the bay side of the island. 75 percent of profiles without a dune in 2015 were located in R3, with the fragmented foredune structure reflected in relatively high longshore variability in both elevation and cross-shore position of $Z_{\max }$ compared to the other analysis regions (table 2-1).

Table 2-1. Longshore mean and standard deviation of maximum elevation $\left(Z_{\max }\right)$ for cross-shore transects within each of the analysis regions (R1-R4; fig. 2-4) for the 2005 and 2015 lidar survey.

$\left[\mathrm{D}_{\text {Zmax }, S L}\right.$ is the distance to the 2005 shoreline, taken as the 0.5 -meter $(\mathrm{m})$ contour to allow inclusion of transects with incomplete lidar coverage of the intertidal zone. Also shown for each of the analysis regions are the mean and standard deviation of model parameters (initial elevation, $D_{\text {high }, 0}$; terminal elevation, $D_{\text {high }, F}$; growth rate, r; distance to the 2005 shoreline, $D_{S L, 0}$; and $m_{d W d H}$ and $b_{d W d H}$, the slope and y-intercept of the linear model used to estimate foredune Gaussian width from height. Abbreviations: EDGR, empirical dune growth model; $\mathrm{m} / \mathrm{yr}$, meters per year]

\begin{tabular}{|c|c|c|c|c|c|c|c|c|c|c|}
\hline & \multicolumn{2}{|c|}{2005 Lidar Survey } & \multicolumn{2}{|c|}{2015 Lidar Survey } & \multicolumn{6}{|c|}{ EDGR Parameters } \\
\hline & $Z_{\max }[\mathrm{m}]$ & $\Delta_{Z \max , S L 0}[\mathrm{~m}]$ & $Z_{\text {max }}[\mathrm{m}]$ & $Z_{\text {max,shore 2005 }}[\mathrm{m}]$ & $D_{\text {high }, 0}[\mathrm{~m}]$ & $D_{\text {high }, F}[\mathrm{~m}]$ & $r[\mathrm{~m} / \mathrm{yr}]$ & $\Delta_{S L, 0}[\mathrm{~m}]$ & $m_{d W d H}$ & $\begin{array}{c}b_{d W d h} \\
{[\mathrm{~m}]}\end{array}$ \\
\hline $\mathrm{R} 1$ & $1.73 \pm 0.31$ & $134 \pm 37$ & $2.51 \pm 0.41$ & $85 \pm 29$ & $1.46 \pm 0.29$ & $2.51 \pm 0.41$ & $0.58 \pm 0.36$ & $83 \pm 25$ & 3.54 & 18.18 \\
\hline $\mathrm{R} 2$ & $1.73 \pm 0.21$ & $115 \pm 55$ & $2.98 \pm 0.48$ & $79 \pm 23$ & $1.50 \pm 0.44$ & $3.05 \pm 0.40$ & $0.45 \pm 0.17$ & $78 \pm 20$ & 2.91 & 18.33 \\
\hline $\mathrm{R} 3$ & $1.31 \pm 0.27$ & $65 \pm 39$ & $1.95 \pm 0.64$ & $75 \pm 42$ & $0.63 \pm 0.59$ & $2.25 \pm 0.61$ & $0.55 \pm 0.40$ & $71 \pm 26$ & 12.66 & 12.23 \\
\hline $\mathrm{R} 4$ & $1.65 \pm 0.21$ & $59 \pm 34$ & $2.86 \pm 0.47$ & $65 \pm 25$ & $1.48 \pm 0.40$ & $2.89 \pm 0.45$ & $0.56 \pm 0.24$ & $62 \pm 19$ & 16.92 & 7.91 \\
\hline $\mathrm{R} 1-\mathrm{R} 4$ & $1.60 \pm 0.29$ & $86 \pm 51$ & $2.63 \pm 0.64$ & $74 \pm 31$ & $1.29 \pm 0.57$ & $2.75 \pm 0.54$ & $0.53 \pm 0.26$ & $71 \pm 23$ & 9.5 & 13.9 \\
\hline
\end{tabular}


Parameters for the EDGR model were derived using dune growth from 2005 to 2015 (table 2-1). $D_{\text {high,o }}, D_{\text {high,F }}$, and $r$ values were extracted for each cross-shore profile by nonlinear regression of the Houser2015 model (equation 5) to the elevation change at the cross-shore position of $D_{\text {high }}$ in the established dunes in 2015. The longshore mean of $D_{\text {high,F }}$ for R1-R4 ranged from 2.25 to $3.05 \mathrm{~m}$, noting that these values are higher than for $Z_{\max }$ due to the exclusion of profiles lacking an identifiable foredune in the 2015 survey. Mean growth rates were similar across R1-R4 (0.45-0.58 m/yr), but varied considerably within each region (standard deviation of $0.17-0.40 \mathrm{~m} / \mathrm{yr})$. In all model configurations, the mean value of $r$ across all regions $(0.53 \mathrm{~m} / \mathrm{yr})$ was prescribed. The slope of the dune width to height relationship was somewhat steeper for the narrower, eastern regions (R3, R4; $m_{d W d H}$ of 12.66 and 16.92 , respectively) compared to areas to the west (R1, R2; $m_{d W d H}$ of 3.54 and 2.91, respectively). A single linear model of $G_{\text {wide }}$ as a function of $G_{h i g h}$ (equation 7) was fit to all regions and surveys, with $m_{d W d H}$ and $b_{d W d H}$ equal to 9.5 and 13.9 (root mean square error [RMSE] of $14.7 \mathrm{~m}$ and coefficient of determination $\left(\mathrm{R}^{2}\right)$ of 0.2 ). 
